\title{
INFLUENCIA DEL REGIMEN HÍDRICO SOBRE PARÁMETROS DE CALIDAD DEL TRIGO DURO (Triticum durum Desf.) EN AMBIENTE MEDITERRÁNEO.
}

\section{VANESSA MARIA MARTOS NÚÑEZ}

Memoria presentada para optar al grado de

Licenciada en Farmacia

El Director del trabajo

. Vanessa Ma Martos Núñez

Fdo. Dr. Luis F. García del Moral Garrido

Profesor Titular

Dpto. Biología Vegetal

Facultad de Ciencias

Universidad de Granada 


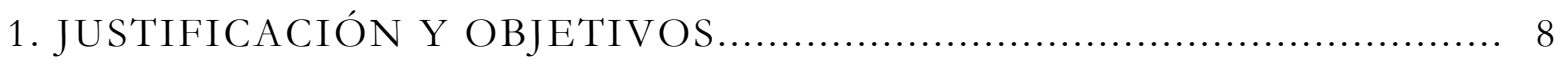

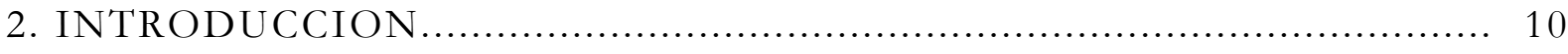

2.1. IMPORTANCIA DEL TRIGO DURO EN EL

CONTEXTO NACIONAL ................................................. 10

2.2. ORIGEN Y CLASIFICACIÓN BOTÁNICA DEL TRIGO................. 10

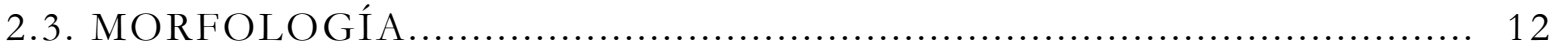

2.3.1. Sistema radical....................................................... 12

2.3.2. Sistema aéreo............................................................ 12

2.3.2.1. Tallos..................................................... 13

2.3.2.2. Hojas................................................... 13

2.3.2.3. Inflorescencia............................................ 13

2.3.2.4. Semilla.................................................... 14

2.4. CICLO DE DESARROLLO DEL TRIGO............................. 14

2.4.1. Período vegetativo...................................................... 14

2.4.2. Período reproductivo................................................ 16

2.4.2.1. Encañado........................................................

2.4.2.2. Espigado............................................ 18

2.4.3. Período de maduración.................................................... 18

2.5. FACTORES QUE REGULAN EL CRECIMIENTO Y DESARROLLO

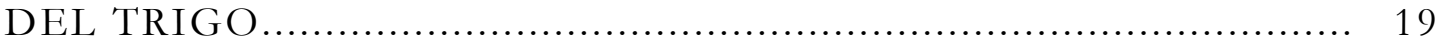

2.6. RENDIMIENTO EN GRANO Y SUS COMPONENTES................. 22

2.7. PARÁMETROS DE CALIDAD ............................................. 23

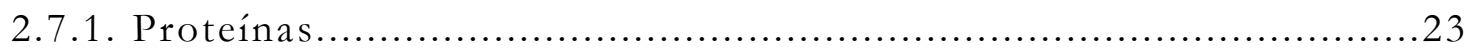

2.7.2. Peso específico.......................................................... 24

2.7.3. Azúcares reductores............................................... 25

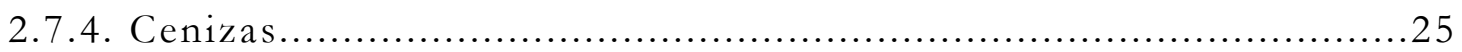

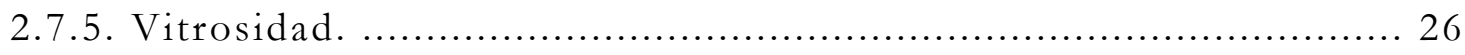

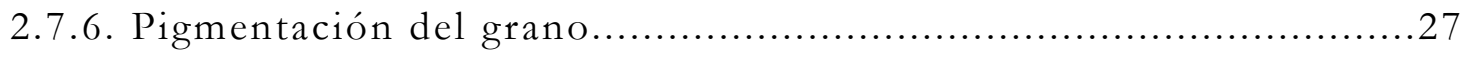

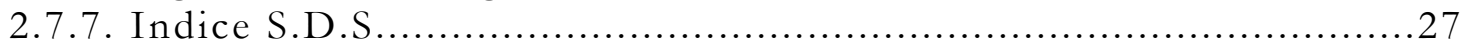

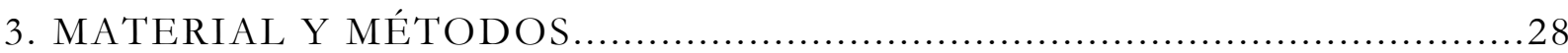

3.1. LOCALIZACIÓN DE LOS ENSAYOS ......................................... 28

3.2. CARACTERIZACIÓN EDAFO-CLIMÁTICA

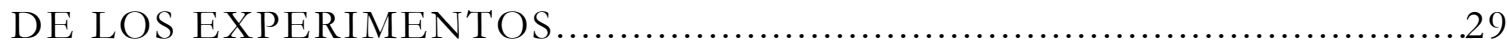

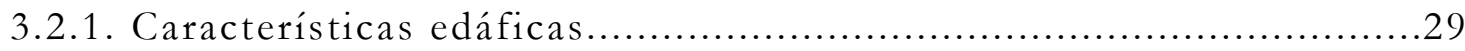

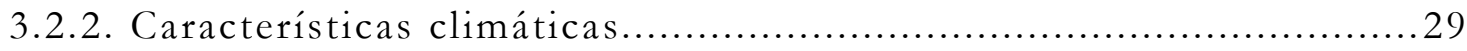

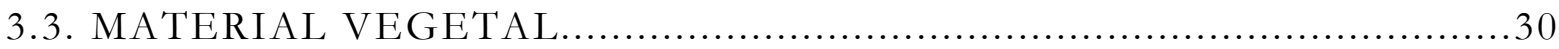

3.4. DISEÑO EXPERIMENTAL ................................................. 30

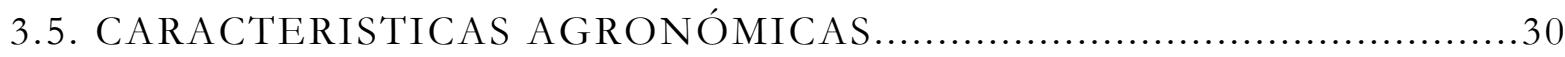

3.6. TOMA DE MUESTRAS EN EL CAMPO........................................ 31

3.7. DETERMINACIÓN DEL RENDIMIENTO Y COMPONENTES........ 31

3.8. DETERMINACIONES ANALÍTICAS ............................................ 31

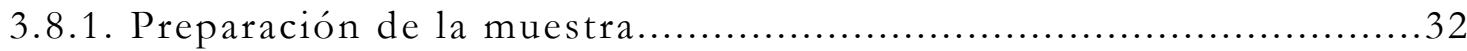

3.8.2. Contenido de humedad .............................................. 32 
3.8.2.1. Material y aparatos........................................... 32

3.8.2.2. Procedimiento...................................................... 32

3.8.2.3. Referencias....................................................... 33

3.8.3. Contenido de cenizas............................................... 33

3.8.3.1. Material y aparatos............................................. 33

3.8.3.2. Procedimiento...................................................... 33

3.8.3.3. Referencias.......................................................... 33

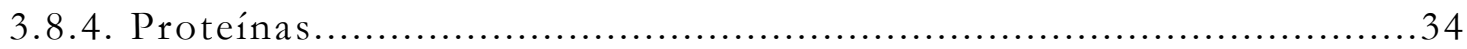

3.8.4.1. Reactivos................................................... 34

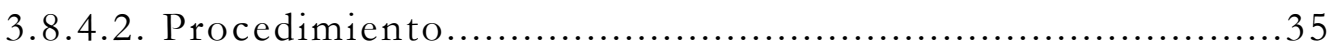

3.8.4.3. Referencias................................................. 35

3.8.5. Azúcares reductores (glucosa, fructosa

y azúcares invertidos) ................................................... 35

3.8.5.1. Material y aparatos............................................ 36

3.8.5.2. Reactivos.................................................... 36

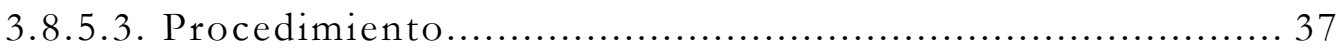

3.9. PARÁMETROS DE CALIDAD DEL GRANO ................................. 38

3.9.1. Peso específico o peso hectolitro..................................... 38

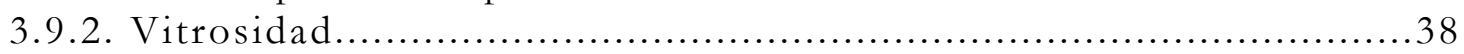

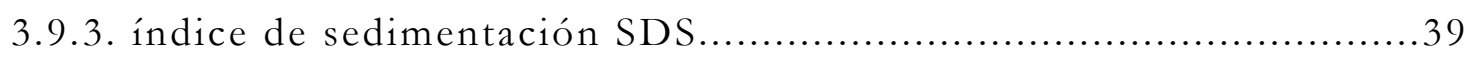

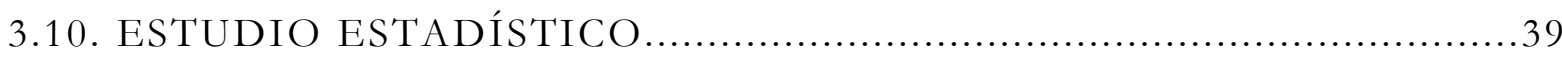

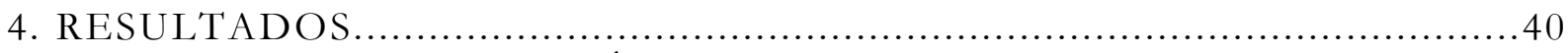

4.1. RENDIMIENTO Y PARÁMETROS RELACIONADOS $\ldots \ldots \ldots \ldots \ldots \ldots \ldots . \ldots . \ldots \ldots$

4.1.1. Rendimiento de grano............................................... 41

4.1.2. Peso medio del grano.......................................................... 41

4.1.3. Duración y tasa de crecimiento del grano..............................44

4.1.4. Altura de la planta.................................................... 47

4.2. CONTENIDO Y COSECHA DE PROTEÍNAS ................................... 50

4.2.1. Contenido de proteínas del grano.......................................50

4.2.2. Cosecha de proteína....................................................... 50

4.3. PESO ESPECÍFICO, CONTENIDO DE AZÚCARES

REDUCTORES Y CONTENIDO DE CENIZAS............................ 52

4.3.1. Peso específico o peso hectolitro..................................... 55

4.3.2. Contenido de azúcares reductores....................................... 55

4.3.3. Contenido de cenizas................................................... 58

4.4 OTROS PARÁMETROS RELACIONADOS CON LA

CALIDAD DEL GRANO....................................................... 58

4.4.1. Vitrosidad....................................................... 58

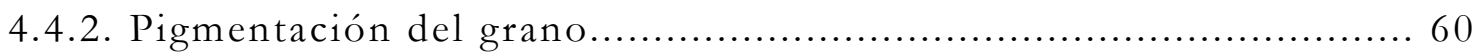

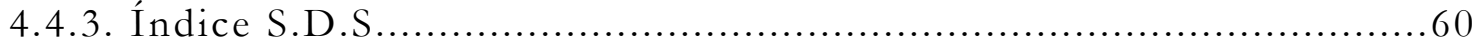

4.5. ANÁLISIS POR COMPONENTES PRINCIPALES .............................. 64

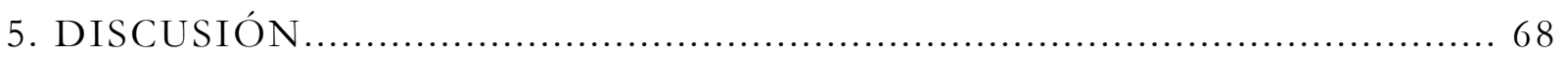

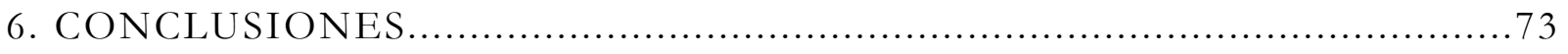




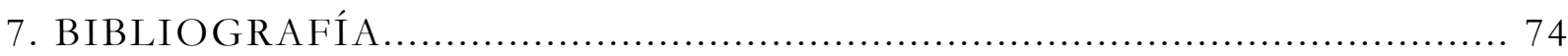

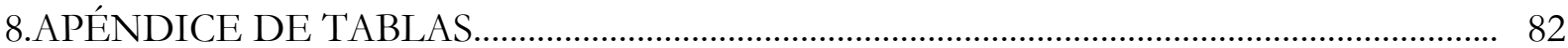


Este trabajo ha sido realizado bajo la dirección del Dr. Luis F. García del Moral Garrido en el Dpto. de Biología Vegetal de la Facultad de Ciencias de la Universidad de Granada y forma parte de las actividades del Proyecto de investigación "Estudio de la adaptación del trigo duro a los estreses abióticos terminales y su relación con la calidad de la cosecha”, financiado por CICYT a través del Programa Sectorial de Investigación y Desarrollo Agrario y Alimentario del MAPA (Proyecto nº SC97-039-C2-02). 
Cuando hagáis la recolección de vuestras tierras, no segaréis hasta la misma orilla del campo, ni recogerás las espigas caídas; déjalas para el pobre y el extranjero.

Levítico, 19, 9-10 
En primer lugar quisiera expresar mi mayor agradecimiento al Dr. Luis F. García del Moral Garrido, director de la tesina. Sus constantes consejos, su colaboración y su gran confianza que desde el principio puso en mí son, sin duda, las principales causas de que este trabajo se haya podido llevar a cabo.

Mi profundo agradecimiento a toda mi familia, por todo lo que han hecho para que yo pueda seguir adelante mi carrera científica.

Agradezco la colaboración de mis compañeros del Departamento, Dr. Sliman El Hani, Yahia Rharrabti, Gustavo Ortiz, y Luis Roca, por la ayuda prestada en los trabajos de campo y de laboratorio. Quisiera expresar mi profundo agradecimiento al Dr. José Marinetto Quiles, del CIFA de Granada por su colaboración en la realización de los ensayos de campo y porque fue la persona que me puso en contacto con el grupo de Investigación de Fisiología de Tecnología de cultivos. También agradezco a la Dra. Concepción Royo i Calpe, del IRTA de Lérida, por la selección del material vegetal y por el suministro de la semilla de las variedades para la siembra.

Quiero expresar mi gratitud a Manuel Pelaez Aguilera, Araceli Cabello García y al Dr. Ignacio Fernández-Figares Ibañez, por su ayuda en la realización de los ensayos de campo.

Quisiera agradecer la colaboración a los profesores del Departamento de Biología Vegetal, en especial a Dr. D. José María Ramos, Dña. Carmen Lluch y Dña. Ana María Negrillo.

Agradezco la colaboración prestada en los ensayos de Jerez a D. Jorge Juan Aracil y D. Carlos Conradi.

Por último agradezco a la Universidad de Granada, por concederme las becas con cargo a proyectos de investigación, que se están desarrollando actualmente en el Departamento de Biologia Vegetal, permitiendo la realización de este trabajo. 


\section{JUSTIFICACIÓN Y OBJETIVOS.}

El clima Mediterráneo se caracteriza por sus veranos secos y calurosos, y sus inviernos cortos y templados. Las precipitaciones suelen ser escasas y muy irregulares de un año a otro. El rápido aumento de las temperaturas en primavera y verano, unido a la falta de lluvias, provoca un intenso déficit hidrico durante el periodo de fructificación de los cereales, lo que limita grandemente no sólo la producción, sino la calidad del grano obtenido. Esta situación tenderá a agravarse en el futuro, debido al cambio climático que, según la opinión de los expertos, afectará de forma especialmente grave a toda la cuenca mediterránea, donde se localiza más de la mitad del cultivo mundial de trigo duro. Resulta, por tanto, de gran interés el estudio y cuantificación de aquellos factores que limitan la producción y la calidad del trigo duro en ambiente mediterráneo, con objeto de mejorar su adaptabilidad y calidad tecnológica.

En este contexto, el objetivo general de este trabajo ha sido la obtención de información, susceptible de ser utilizada en la mejora de la resistencia del trigo duro a la sequia, en el área mediterránea. Este objetivo general puede concretarse en los siguientes objetivos especificos:

1.- Analizar la producción de grano y parámetros asociados, en cuatro genotipos de trigo duro con distinta resistencia a la sequia, cultivados en tres ambientes con diferente régimen hidrico.

2.- Averiguar la influencia que las condiciones ambientales durante la maduración ejercen sobre la acumulación de proteinas en el grano y sobre la cosecha de proteina, asi como sobre otros parámetros que definen la calidad tecnológica del grano de trigo duro. 
3.- Estudiar, mediante análisis por componentes principales, las posibles interrelaciones entre los parámetros de rendimiento y de calidad en el conjunto de ambientes, con objeto de averiguar aquellas caracteristicas que mejor definan el comportamiento de los genotipos en cada ambiente.

Dado que este trabajo se enmarca dentro del proyecto de investigación "Estudio de la adaptación del trigo duro a los estreses abióticos terminales y su relación con la calidad de la cosechan, financiado por el Programa Sectorial de Investigación y Desarrollo Agrario y Alimentario del MAPA (Proyecto $\mathrm{n}^{\circ}$ SC97-039-C2-02), los resultados obtenidos en la presente Memoria serán de gran utilidad para comprender la influencia del régimen hídrico sobre la calidad del grano de trigo duro y para permitir el desarrollo de nuevas variedades, mejor adaptadas a las condiciones de la zona mediterránea. 


\section{INTRODUCCION.}

Las zonas favorables a la maduración del trigo duro son las que reciben una media de más de 250 horas de sol en el curso del mes precedente a la recolección, y menos de $60 \mathrm{~mm}$. de lluvia en menos de diez días durante ese mismo período. E1lo probablemente haya determinado la tradicional implantación de este cultivo en muchos paises de la Cuenca Mediterránea, que desde el Medio Oriente ha sido una primitiva área de expansión, la cual según algunos autores ha jugado un papel determinante en la diferenciación de los trigos, en particular del trigo duro. Dichos países han llegado a ser los productores de más de la mitad del trigo duro mundial. Aunque una parte importante del mercado mundial de trigo es consumida por los animales, en el caso del trigo duro la alimentación humana constituye su única utilización.

\subsection{IMPORTANCIA DEL TRIGO DURO EN EL CONTEXTO NACIONAL}

La superficie dedicada al trigo duro en España ha crecido de forma muy significativa en los últimos años, pasando de 109.400 Has en 1988 a 613.770 en 1998 , lo cual representa el $8,3 \%$ de la superficie cerealícola de nuestro país (AETC, 1998). El origen de este rápido incremento reside en las subvenciones comunitarias para la producción de esta especie en las zonas de cultivo tradicional. Una idea de la importancia de dichas ayudas la da la cifra percibida por nuestros agricultores en las últimas campañas, que ha estado alrededor de los 36.000 millones de pesetas anuales solamente en concepto de subvenciones directas de la CEE. Esta situación ha provocado un aumento de actividad en los sectores implicados. En particular existe en este momento una gran demanda de variedades de trigo duro adaptadas a nuestras condiciones agroclimáticas. Las dos áreas de cultivo del trigo duro en España son, tradicionalmente, el Valle del Ebro y Andalucía Oriental.

\subsection{ORIGEN Y CLASIFICACIÓN BOTÁNICA DEL TRIGO.}

No se conoce con precisión dónde y cuando se originó el trigo, debido a la mezcla de individuos silvestres afines, con características intermedias. De Candolle lo sitúa en Mesopotamia, muy probablemente en el área conocida como el Creciente Fértil entre los ríos Tigris y Eúfrates, mientras que 


\section{Introducción}

Vavilov añadiría las zonas de Turquía, Afganistán, Irán e India. El hecho de que la mayor diversidad genética de trigos silvestres ocurra en las zonas anteriormente mencionadas, particularmente Irán e Israel y países limítrofes, podría ser una de las pruebas a favor de las ideas antes mencionadas. El cultivo del trigo se extendió con éxito en todas direcciones desde el Medio Oriente al resto del mundo (López Bellido, 1991).

Entre las primeras área de expansión del trigo se encuentra la Cuenca Mediterránea, que podría haber jugado, según algunos autores, un papel importante en la diferenciación de los trigos y, en particular, del trigo duro. En la península Ibérica, el cultivo se extendió a partir de los 4000 a.C., destacando las zonas del valle del Duero occidental, regiones lusitánica y bajo Guadalquivir (López Bellido, 1991).

E1 trigo pertenece al orden Graminales, familia Graminae (actualmente denominada Poaceae), subfamilia Festucoidae, tribu Triticaceae, género Triticum, especie T. turgidum, variedad durum.

La característica genética que unifica a todas las especies del género Triticum, es que su número cromosómico es múltiplo de 14. Actualmente (Kimber y Sears, 1987), los trigos se clasifican de acuerdo con su número de cromosomas, agrupándolos de manera general en tres series:

Diploides con 14 cromosomas y genoma AA $(2 n=2 x=14)$.

Tetraploides con 28 cromosomas y genoma AABB $(2 \mathrm{n}=4 \mathrm{x}=28)$

Hexaploides con 42 cromosomas y genoma AABBDD $(2 n=6 x=42)$

Siendo $\mathrm{x}=7$ el número básico de cromosomas.

Entre los trigos tetraploides, el más importante es el trigo duro ( $T$. durum Desf.), cuyo origen se cree que está en un cruzamiento espontáneo de un trigo diploide $(2 \mathrm{n}=14), \quad T$. monococcum var. boeoticum (el llamado "einkorn silvestre"), que ya era cultivado en el Medio Oriente hará unos 10.000 años, con una gramínea, también silvestre, perteneciente al género Aegilops (tal vez A. speltoides, diploide), para dar un híbrido silvestre tetraploide, T. turgidum dicoccoides (conocido como "emmer silvestre") $2 \mathrm{n}=28$. Este parece ser el ancestro común de los trigos duros, siendo el T. turgidum dicoccum de las primeras especies cultivadas (Kimber y Sears, 1987; López Bellido, 1991). 


\subsection{MORFOLOGIA}

La planta de trigo presenta un porte herbáceo que, en la madurez, puede alcanzar incluso hasta $150 \mathrm{~cm}$ de altura. En relación a su morfología, podemos distinguir el sistema radical y el sistema aéreo.

\subsubsection{Sistema radical.}

De tipo fascicular, está compuesto por raíces primarias o seminales, que son las primeras que aparecen cuando tiene lugar la germinación, y por raíces secundarias o adventicias, que sustituyen a las seminales de forma progresiva. Estas nacen del nudo de ahijamiento que es, además, el origen del tallo principal y de los tallos secundarios (López Bellido, 1991).

La capacidad de elongación y ramificación de las raíces está influida por las condiciones del medio, tales como humedad, temperatura, textura y fertilidad del suelo (Lersten, 1987; López Bellido, 1991). Así, mientras un exceso de agua invernal puede ralentizar su crecimiento, un déficit hídrico moderado puede activarlo. Temperaturas del orden de 10 a $15^{\circ} \mathrm{C}$ favorecen la emisión de las raíces en los cereales de invierno, reduciéndose cuando la temperatura es inferior a 6 u $8^{\circ}$ C (Kirby y Appleyard, 1984; Simmons, 1987; López Bellido, 1991).

En suelos arenosos las raíces del trigo adoptan formas más largas y finas que en caso de suelos arcillosos. Igualmente, el déficit de $\mathrm{N}$ o $\mathrm{P}$ provoca un aumento importante en el desarrollo de las mismas, aunque no una carencia de K (López Bellido, 1991). La producción de raíces secundarias cesa al iniciarse el encañado, aunque a veces puede prolongarse durante fases posteriores, coincidiendo con la diferenciación de los órganos florales sobre cada tallo (Lersten, 1987). La formación precoz y abundante de raíces secundarias en los cereales, tiene un efecto positivo sobre el desarrollo de tallos fértiles, existiendo una estrecha relación entre el número de raíces desarrolladas y el de yemas formadoras de tallo en el ahijado (García del Moral y Ramos, 1989; López Bellido, 1991).

\subsubsection{Sistema aéreo.}


El sistema aéreo de los cereales está formado por tallos que parten de una zona situada en la base de la planta, que se denomina nudo de ahijamiento. Cada tallo o vástago porta las hojas, acabando su extremo en la inflorescencia.

\subsubsection{Tallos.}

Están formados por nudos y entrenudos. Los primeros son zonas meristemáticas a partir de las cuales se alargan los entrenudos y se diferencian las hojas. El entrenudo es la parte del tallo entre dos nudos. Los de la base del tallo son más cortos. Su longitud, la cantidad de esclerénquima, y el número de haces vasculares, condiciona la resistencia a la caída fisiológica (encamado), aunque en ello también intervengan otros factores, como los genéticos, ambientales o la propia alimentación nitrogenada. En este sentido, un aporte de nitrógeno en el ahijado, favorece el alargamiento de los entrenudos de la base del tallo en cereales de invierno, mientras que si la aplicación ocurre en el inicio del encañado, elongarán los superiores (Reilly, 1990).

De cualquier forma, la altura de la planta juega un papel importante en la resistencia al encamado, lo que ha estimulado los estudios destinados a disminuirla por parte de los mejoradores.

\subsubsection{Hojas.}

Se disponen alternas en dos filas a lo largo del tallo. Cada hoja consta dos partes, la vaina o zona inferior que envuelve al entrenudo y el limbo o zona superior. En la unión del limbo y la vaina existe una pequeña lámina membranosa no vascular, denominada lígula y cuya misión es impedir que la lluvia o los insectos puedan alcanzar los tejidos meristemáticos de la base de la vaina. A cada lado de ésta, en la base del limbo, se encuentran dos pequeñas estípulas o aurículas, más o menos abrazadoras y vellosas.

\subsubsection{Inflorescencia.}

La inflorescencia, en el caso del trigo, es una espiga que se sitúa en el extremo del tallo. Su unidad morfológica es la espiguilla, cuyo conjunto integra la inflorescencia. La espiguilla está envuelta por dos brácteas o glumas, uniéndose al eje principal de la inflorescencia o raquis. Las flores son 
hermafroditas y están envueltas por dos glumillas, una inferior y otra superior denominadas palea y lema, respectivamente. La prolongación de las lemas forman las aristas, muy largas en algunos genotipos de trigo. El número de flores fértiles por espiguilla suele variar entre 2 y 4.

\subsubsection{Semilla.}

E1 fruto del trigo, denominado cariópside, es un fruto monospermo, seco e indehiscente, donde los tegumentos del ovario están estrechamente soldados al endospermo. En el caso del trigo, el grano maduro aparece desnudo, al desprenderse de las glumillas que lo envuelven.

\subsection{CICLO DE DESARROLLO DEL TRIGO.}

Resulta de especial importancia caracterizar el desarrollo del cultivo, ya que los cambios ontogénicos tienen efectos importantes sobre el crecimiento y explican el efecto de las condiciones ambientales sobre los componentes del rendimiento (Kirby y Appleyard, 1984).

Durante el ciclo biológico del trigo se pueden distinguir tres períodos principales:

- Período vegetativo

- Período reproductivo

- Período de maduración.

\subsubsection{Periodo vegetativo.}

De formación de hojas, transcurre desde la germinación hasta el fin del ahijamiento e inicio de la diferenciación de la espiga.

\section{a) Germinación y emergencia.}

La germinación, que se inicia gracias a una fase previa de imbibición, desencadena un incremento de la actividad fisiológica de la semilla, lo que se traduce en un rápido crecimiento de los meristemos presentes en el embrión, junto con la movilización de las reservas del grano, como consecuencia de una importante activación enzimática. En el interior del grano, los constituyentes insolubles del endospermo (almidón y proteínas) 


\section{Introducción}

desaparecen por la acción de enzimas, liberadas en la capa de aleurona como respuesta a las giberelinas producidas en el escutelo (Simmons, 1987; López Bellido, 1991).

La capacidad de germinación depende del tamaño y composición química de la semilla y del embrión; de las condiciones climáticas durante la germinación; y de la fecha y profundidad de la siembra. El contenido mínimo de agua en el grano para que el proceso tenga lugar está en torno al 35-40\%, mientras que el nivel de temperatura mínima por debajo de la cual la semilla no germina es de $0^{\circ} \mathrm{C}$ (Lersten, 1987; López Bellido, 1991). La germinación finaliza con la elongación de la radícula, y aparición posterior del coleoptilo. Este, que está adaptado a crecer debajo del suelo, cesa su crecimiento cuando llega a la superficie. La primera manifestación visible al exterior es la emergencia. Una primera verdadera hoja emerge por un poro en el ápice del coleoptilo. Las raíces seminales crecen, con lo que la plántula puede alimentarse a partir del suelo. En caso de siembras profundas el entrenudo entre el coleoptilo y la primera hoja (mesocotilo) elonga, de modo que el ápice se sitúa justo debajo de la superficie. La nascencia es lenta cuando el contenido de humedad es excesivo, aumentando el periodo entre la siembra y la emergencia, debido a la falta de oxígeno alrededor de la semilla (Kirby y Appleyard, 1984; Lersten, 1987; López Bellido, 1991).

\section{b) Ahijamiento}

Los cereales se caracterizan por su capacidad de ahijado, que consiste en la formación a nivel del suelo, de un nudo de ahijamiento que dará lugar a varios tallos secundarios. En los cereales existe una secuencia característica de producción y ordenación de los tallos, debido a que éstos se originan a partir de yemas situadas en las axilas de cada hoja. Estas yemas no se forman en aquellas hojas situadas en la base de los entrenudos que elongarán durante el encañado, con la excepción de la hoja del entrenudo más bajo y, ocasionalmente, de la situada por encima de ella. Cada yema porta un meristemo susceptible de formar un tallo y una masa celular capaz de generar una raíz secundaria (Kirby y Appleyard, 1986).

Cuando la planta tiene cuatro hojas comienza el ahijado, apareciendo en la axila de la primera hoja el primer tallo, a partir de la yema lateral o axilar. A medida que progresa el ahijamiento, el crecimiento de las yemas diferenciadas da lugar a la aparición de los tallos de las segunda, tercera y cuarta hojas, sucesivamente. Paralelamente se inicia también la diferenciación 


\section{Introducción}

de las raíces secundarias. Todos estos tallos se llaman primarios, a partir de los cuales, por el mismo proceso, pueden surgir tallos secundarios y terciarios, dependiendo de la capacidad de ahijamiento y condiciones ambientales, especialmente disponibilidad de agua y nitrógeno (Kirby y Appleyard, 1986; Simmons, 1987; Hucl y Baker, 1989; López Bellido, 1991). E1 debilitamiento de la dominancia apical propicia la formación de tallos (Hucl y Baker, 1989; García del Moral y Ramos, 1989).

Los vástagos se independizan de sus tallos parentales cuando han desarrollado tres hojas completamente expandidas y diferenciado las raíces adventicias. Sin embargo, la emergencia de los tallos hijos no asegura su supervivencia, ya que, después de formados, una gran cantidad de ellos mueren frecuentemente en condiciones de campo. Este fenómeno parece depender de que los tallos formados sean capaces de situar sus hojas en las capas superiores mejor iluminadas del dosel foliar, para captar la suficiente cantidad de luz que asegure su crecimiento (Davidson y Chevalier, 1990; García del Moral y García del Moral, 1995).

Esta etapa es de especial importancia para el desarrollo del cultivo, puesto que la capacidad de ahijamiento va a determinar, en los cereales, el número final de espigas (García del Moral et al.., 1991; García del Moral y García del Moral, 1995; ElHani, 1999). El desarrollo de los brotes hijos parece estar regulado por el equilibrio hormonal de la planta y por el suministro de asimilados (Sharif y Dale, 1980).

La magnitud del ahijamiento depende de la variedad y está fuertemente influenciada por las condiciones ambientales durante el crecimiento, así como por el estado hídrico, N, densidad de siembra y temperatura del aire y del suelo (Willey y Holliday, 1971; Hucl y Baker, 1989; García del Moral y García del Moral, 1995).

Durante esta fase también se va determinar otro de los componentes de la cosecha, el número de granos por espiga, al coincidir el final de la misma con el estadio de desarrollo del meristemo apical en el que se alcanza el máximo número de primordios florales (Kirby y Appleyard, 1984, 1986; García del Moral y Ramos, 1989).

\subsubsection{Periodo reproductivo.}

Transcurre desde el inicio del encañado hasta que la espiga se encuentra totalmente fuera de la vaina con grano formado y 
Introducción

acuoso. Tiene lugar a lo largo de dos fases, encañado y espigado.

\subsubsection{Encañado.}

Durante esta etapa se determina el número de tallos hijos que producen espiga, mientras que el resto retrasan su crecimiento o incluso lo detienen. Su primer sintoma visible es un enderezamiento de los tallos, que adquieren cada vez más un porte erecto. El ápice del tallo permanece por debajo de la superficie del suelo hasta que comienza el encañado.

Cuando las condiciones climáticas son favorables, los entrenudos empiezan a crecer en longitud, desarrollándose en cada nudo una hoja. Las vainas foliares se alargan y, por reabsorción del tejido central del entrenudo, aparece la cavidad medular. Posteriormente, el crecimiento del tallo se produce a partir del meristemo intercalar (nudo), y el entrenudo se alarga solamente cuando la hoja que se inserta encima de él ha terminado su crecimiento. Los entrenudos van aumentando su longitud hacia el extremo de tallo, de manera que el último entrenudo puede llegar a representar la mitad de la longitud del tallo, y los inferiores están comprimidos en unos pocos milímetros de tallo.

E1 intervalo de tiempo entre la emergencia de hojas consecutivas varía con la temperatura (Gallagher, 1979a), existiendo una relación lineal entre número de hojas y tiempo térmico, definido como la temperatura acumulada por encima de una temperatura base de 0 C (Baker et al.., 1980; Cao y Moss, 1989). Algunos autores sugieren que la tasa de aparición de hojas en cultivos de trigo depende directamente de la tasa a la cual cambia el fotoperíodo durante la emergencia de la planta (Baker et al.., 1980; Ellis y Russell, 1984; Kirby et al.., 1985; Slafer y Rawson, 1995a; Kirby et al., 1999). Mitchel et al.. (1991), han desarrollado varios modelos para predecir la emergencia de la hoja bandera en cultivos de trigo, concluyendo que existe una compensación entre la formación de primordios foliares en el ápice y la emergencia de la hoja, lo que asegura que el área foliar alcance su máximo desarrollo, en un área determinada, más o menos en la misma fecha.

Durante esta fase existe gran competencia entre los tallos portadores de espiga y el resto, absorbiendo los primeros todos los nutrientes a expensas de los demás, que mueren. Tradicionalmente también se ha sugerido que al aumentar el sombreado de los tallos más jóvenes por el desarrollo del dosel 


\section{Introducción}

foliar, se inicia la prematura senescencia de los tallos (Willey y Holiday, 1971; García del Moral y García del Moral, 1995). Por el contrario, Lauer y Simmons (1989) sugieren que la mortalidad de los tallos no está motivada por falta de luz, sino más bien por una respuesta fotomorfogénica a la calidad de la luz filtrada por el dosel foliar, por lo que el sombreado no sería un factor primordial, sino que juega un papel adicional en la senescencia de los tallos. En esta fase hay un crecimiento muy activo en tamaño y peso, por lo que la planta es muy sensible a la sequía y a la fertilización nitrogenada.

\subsubsection{Espigado.}

La emergencia de la espiga comienza cuando la espiguilla terminal puede verse por encima de la hoja bandera, considerándose que se ha completado, es decir, que la espiga ha aparecido totalmente, cuando la espiguilla basal sobrepasa dicha hoja (Zadoks et al.., 1974). La floración o antesis normalmente tiene lugar tres o cuatro días después de la emergencia de la espiga, aunque pueden reducirse a uno o dos días si el tiempo es cálido. La floración, se manifiesta con la aparición de las anteras amarillas fuera de las espiguillas, primero en la parte central de la espiga y luego en los dos extremos; en este momento se considera que tiene lugar la floración completa del trigo (Zadoks et al.., 1974). La floración comienza en las espiguillas centrales y continúa hacia ambos extremos de la espiga (Simmons, 1987). A nivel del cultivo, el espigado tiene lugar cuando el $50 \%$ de 1 os tallos han superado la situación anterior, concluyendo a los pocos dias.

Durante esta fase el crecimiento del tallo tiende a estabilizarse, aunque el entrenudo superior puede continuar su crecimiento aún después de la antesis, dependiendo del genotipo, riqueza del suelo y condiciones ambientales (Kirby y Appleyard, 1984; Simmons, 1987; García del Moral y Ramos, 1989; López Bellido, 1991). E1 área foliar alcanza su valor máximo antes de la floración, para decrecer posteriormente debido a la senescencia y muerte de los tallos, al avanzar la fase de espigado.

\subsubsection{Periodo de maduración}

Después de la antesis, ocurre la fecundación, seguida de un período de latencia, de gran importancia, ya que cuanto más se 
alarga dicho estado se forman un número mayor de granos por espiga, especialmente si las temperaturas son bajas (López Bellido, 1991).

E1 crecimiento del grano ocurre siguiendo sucesivas etapas (Evans y Wardlaw, 1976; Evans, Wardlaw y Fischer, 1983; García del Moral y Ramos, 1989; López Bellido, 1991):

$1^{\text {a) }}$ De multiplicación celular activa: Durante la cual se forman la mayoría de las células del endospermo y hay un incremento rápido en volumen y en peso fresco. El grano se encuentra en estado lechoso. Esta fase dura de 12-15 días. Paralelamente se produce el crecimiento y desarrollo del embrión.

$2^{\text {a) }}$ Etapa de acumulación de carbohidratos y proteinas: Durante esta fase el peso fresco del grano permanece constante, los tegumentos se solidifican y el grano presenta un aspecto pastoso. Las dos últimas hojas, junto con sus vainas, la espiga y aristas, son las principales fuentes de asimilados para el grano. La hoja bandera tiene un gran papel en la movilización y translocación de sustancias nitrogenadas.

$3^{\text {a) }}$ Etapa de desecación: Tiene lugar una gran pérdida de agua, pasando el grano del estado pastoso a duro. Un 14\% de humedad significa que se ha alcanzado la madurez y el cultivo está en condiciones apropiadas para la recolección. Durante el período de pérdida de agua puede ocurrir una disminución en el contenido de reservas del grano, causando que la semilla presente un aspecto rugoso y sin brillo. Este fenómeno, llamado de asurado, supone un problema importante para la calidad tecnológica del grano, y además crea un medio inadecuado para el desarrollo del embrión, provocando bajas tasas de germinación.

\subsection{FACTORES QUE REGULAN EL CRECIMIENTO Y DESARROLLO DEL TRIGO}

El desarrollo de los cereales se encuentra muy influído por
los factores ambientales, principalmente fotoperiodo,
temperatura y humedad edáfica (Frank y Bauer, 1995; Kirby,
1995; Slafer y Rawson, 1995 a, b; 1996 a, b; Hay y Ellis, 1998;
MacMaster, 1998). 
El estímulo fotoperiódico lo perciben las hojas, las cuales envían una señal al ápice del tallo (Slafer y Rawson, 1995b; Hay y Ellis, 1998; MacMaster, 1998); por tanto, las plantas no responden al fotoperiodo hasta que no emergen de la superficie del suelo (Hay y Kirby, 1991). Sin embargo, la respuesta a la temperatura y a la humedad comienza tan pronto como la semilla es imbibida y continúa hasta la madurez fisiológica (Del Pozzo et al., 1987; Porter et al., 1987; Slafer y Savin, 1991).

El trigo es un cereal con requerimiento cuantitativo de día largo, no formando los primordios de espiguilla hasta que la duración del período de luz diario supera un umbral llamado hemeroperíodo crítico, umbral que suele situarse entre 12-14 horas. Sin embargo, la sensibilidad al fotoperiodo es muy variable entre los diferentes genotipos (Evans y Wardlaw, 1976; Simmons, 1987; López Bellido, 1991; MacMaster, 1998).

Normalmente, los fotoperiodos largos incrementan significativamente el nivel de iniciación de primordios de espiguilla en trigo (Rahman y Wilson, 1977; Slafer y Rawson, 1995a,b), cebada (Kirby y Appleyard, 1980), pero tienden a reducir la longitud de las fases del desarrollo, por lo que el resultado final es una disminución tanto en el número de hojas como de espiguillas sobre el tallo principal (Rawson y Richards, 1993). De igual forma, los fotoperiodos largos generalmente reducen el tiempo desde la siembra a la emergencia de la espiga, siendo el período de formación de dobles arrugas a primordio de aristas el más sensible a este factor (Slafer y Rawson, 1994b, 1995a). En un reciente estudio con 5 genotipos de triticale de diversa precocidad (Yañez, 1987), se encontró que, para que ocurriese el paso de la fase vegetativa a la de doble arruga, fue necesaria una longitud critica del meristemo apical, la cual fue, a su vez, inversamente proporcional a la duración del fotoperíodo.

La temperatura controla la respuesta del desarrollo en los cereales, especialmente en las variedades que requieren vernalización para pasar del período vegetativo al reproductivo (Slafer y Savin, 1991; Slafer y Rawson, 1995b). En triticale, una temperatura por debajo de 5 C bloquea el paso de la fase vegetativa a la de doble arruga, según se deduce de los resultados obtenidos por Yañez (1997) en cámara de crecimiento de plantas.

Temperaturas por debajo de $10^{\circ} \mathrm{C}$ satisfacen las necesidades 
de vernalización en trigo (Flood y Halloran, 1984), aunque los requerimientos de frío no son los mismos para todas las variedades (Slafer y Rawson, 1994a). Así, podemos distinguir variedades de invierno, que precisan hasta un máximo de 50-60 dias con temperaturas bajas (comprendidas entre $0^{\circ}$ y $5^{\circ} \mathrm{C}$ ); trigos de primavera, que no suelen requerir vernalización; y variedades alternativas, que necesitan algo de vernalización, pero menos que las de invierno (López Bellido, 1991; Gardner et al., 1993).

El cumplimiento de la vernalización también es necesario para que ciertos caracteres, algunos de ellos relacionados con el rendimiento, tengan su máxima expresión (Kirby y Appleyard, 1984). Así, cuando la duración del período de frío es menor que la óptima, el peso de mil granos, el número de granos por espiga, la altura de la planta y la longitud de la espiga se ven afectados negativamente (Dalloul, 1980). Además se produce un retraso en la fecha de espigado y en la diferenciación floral.

Las altas temperaturas estimulan el nivel de formación de primordios foliares en el ápice del tallo principal, lo que reduce en gran medida el número de tallos hijos que pueden formarse. Esto puede ser debido a una disminución en el suministro de asimilados a los ahijamientos, a causa del aumento de su demanda por el tallo principal. Las bajas temperaturas, por el contrario, aunque retrasan el desarrollo de los tallos hijos, suelen favorecer el ahijamiento, ya que disminuyen el crecimiento de las hojas y, por tanto, la competencia con los ahijamientos (Thorne, 1974; Kirby et al., 1987; López Bellido, 1991; García del Moral y García del Moral, 1995). Un aumento de la temperatura durante el llenado del grano disminuye el peso del mismo por acelerar la senescencia de las hojas, disminuir la duración del desarrollo del grano y aumentar las pérdidas de carbohidratos por la respiración (Thorne, 1974; Wiegand y Cuellar, 1981). E1 ambiente cálido afecta también a la capacidad de los granos individuales para utilizar los asimilados disponibles, ya que bajo estas condiciones el crecimiento del grano es rápido al inicio, pero al detenerse antes que con condiciones de temperatura más baja, el peso final del grano tiende a decrecer (Thorne, 1981; Wiegand y Cuéllar, 1981).

En ambiente tipo Mediterráneo ocurre con frecuencia que, durante el periodo de llenado de los granos, se presenten periodos de altas temperaturas, casi siempre unidos a sequía. Se sabe que esto causa importantes disminuciones en la cosecha y en la calidad de los granos (Stone y Nicolas, 1995 a,b). En estas 


\section{Introducción}

circunstancias, la mayor parte de los asimilados con destino a los granos provienen de las reservas del periodo vegetativo almacenadas en los tallos (García del Moral y Ramos, 1989; Kameli y Lösell, 1996).

La germinación y la nascencia están fuertemente influidas por el potencial hídrico del suelo. La escasez de agua durante las primeras fases de desarrollo del meristemo apical retrasa el inicio de la floración, pero si el déficit se produce durante la diferenciación de la inflorescencia disminuye el número de espiguillas por espiga, lo que provoca una reducción en el número final de granos por espiga (Evans y Wardlaw, 1976).

La formación de los granos de polen es especialmente sensible a la escasez de agua en el suelo. Así, deficiencias hídricas severas impiden la formación de polen fértil en las espiguillas del ápice y base de la espiga (Evans y Wardlaw, 1976; Evans, Wardlaw y Fischer, 1983). La humedad del suelo incrementa el número de espigas, al favorecer tanto la formación como la supervivencia de los tallos hijos (Kirby y Appleyard, 1984; Krenzer y Nipp, 1991). El número de granos por espiga suele ser el componente del rendimiento más afectado por la sequía (Fischer y Wood, 1979). El peso medio por grano con frecuencia disminuye bajo condiciones de sequía, debido principalmente al acortamiento de la fase de antesis a madurez fisiológica (Wheeler et al., 1996).

\subsection{RENDIMIENTO EN GRANO Y SUS COMPONENTES.}

E1 rendimiento en grano representa el producto final de la interacción de factores relacionados con el genotipo y con el ambiente, cuyos efectos individuales son difíciles de precisar. Sin embargo, se puede expresar en función de sus componentes, siendo los principales: número de espigas por unidad de superficie, número de granos por espiga y peso final de los granos.

E1 peso final de los granos es el último componente del rendimiento que se forma en el trigo. Es función de la duración de la fase de maduración y depende en gran medida del número de células del endospermo, que es fijado en las fases iniciales del desarrollo del grano (García del Moral y Ramos, 1989). La velocidad de formación de células del endospermo está asociada con el suministro de carbohidratos durante este periodo y con el nivel de citoquininas del grano. La mayor parte del peso seco del 


\section{Introducción}

grano proviene, en condiciones climáticas no limitantes, de la fotosintesis después de la emergencia de la espiga (Thorne, 1974). E1 principal órgano fotosintético para el 1lenado del grano en trigo duro parece ser la espiga y más concretamente las glumas, atendiendo a la similitud encontrada en los valores de ${ }^{13} \mathrm{C}$ entre el grano y los asimilados procedentes de diversos órganos (Romagosa y Araus, 1991). No obstante, en condiciones limitantes, la contribución de las reservas de la preantesis aumenta considerablemente, llegando al 45\% o más, muy posiblemente porque la fotosintesis después de la emergencia de la espiga se encuentra muy limitada (Austin et al., 1980; García del Moral y Ramos, 1989; Acevedo et al., 1991).

\subsection{PARÁMETROS DE CALIDAD.}

Las partes constituyentes del grano de trigo (germen, endospermo y tegumentos) están formadas por diferentes tejidos. Las proteínas están localizadas en mayor proporción en el germen y en la capa de aleurona, al igual que los lípidos en el germen. Las sales minerales, en especial el calcio, el fósforo y el potasio, así como numerosas vitaminas, se encuentran, preferentemente, en las zonas externas del endospermo (Finney et al., 1987; López-Bellido, 1991). El almidón es el principal hidrato de carbono de los cereales, constituyendo, aproximadamente, el 64\% del peso seco del grano de trigo y el $70 \%$ de su endospermo. La celulosa y hemicelulosa son los principales constituyentes de la pared celular del grano de trigo, y junto con la lignina, representan la mayor parte de la fibra bruta. También existen azúcares libres (1-3\%), que tienen influencia en la fabricación del pan y en las propiedades de la sémola y pasta obtenida a partir de ella (Finney et al., 1987; Vadillo, 1989; López-Bellido, 1991). Las sustancias minerales del grano de trigo están principalmente compuestas por fosfatos y sulfatos de potasio, magnesio y calcio (Singh et al., 1997).

\subsubsection{Proteinas.}

Las proteínas del grano se pueden dividir en albúminas, globulinas, gliadinas y gluteninas, dependiendo de su solubilidad en agua, solución salina, $70 \%$ de etanol acuoso y dilución de soluciones ácidas o alcalinas respectivamente (Finney et al., 1987; López-Bellido, 1991). Las albúminas y globulinas tienen funciones metabólicas y estructurales y se localizan, principalmente, en el embrión y en la periferia del grano. Las 


\section{Introducción}

prolaminas y las glutelinas son las proteínas insolubles, llamadas proteínas de reserva, que se localizan en las células del endospermo en forma de corpúsculos o cuerpos proteicos. Estas constituyen la fracción más importante, cualitativa y cuantitativamente, de los cereales. Los cuatro tipos de proteínas varian considerablemente en su composición de aminoácidos, las prolaminas son pobres en lisina, mientras que las albúminas y globulinas son más ricas (Booth y Ewart, 1970; Finney et al., 1987; Vadillo, 1989; López-Bellido, 1991). En los cereales existen 18 aminoácidos diferentes, cuya proporción y ordenación en las cadenas peptídicas determinan las propiedades de cada proteína. Hay que destacar el bajo contenido de lisina del grano y la harina de los cereales, la alta concentración de ácido glutámico y de prolina y el mayor contenido de aminoácidos azufrados, metionina y cistina, en comparación con las leguminosas (Booth y Ewart, 1970; López-Bellido, 1991).

E1 contenido de proteínas en el trigo presenta una gran variabilidad intraespecífica, como consecuencia de la interacción genotipo-ambiente, que caracteriza a este componente del grano (Nachit et al., 1995). La calidad de la pasta obtenida del trigo duro depende tanto de la cantidad de proteína como de la proporción de aminoácidos esenciales de la misma (Nachit et al., 1995; Porceddu, 1995). Las variedades de trigo duro difieren en su habilidad para utilizar el nitrógeno. Algunas variedades de trigo duro incrementan el contenido de proteína del grano como consecuencia de aportes de nitrógeno, mientras que en otras el contenido de proteína permanece más o menos constante (Pacucci y Blanco, 1973). Ello está relacionado tanto con la actividad nitrato-reductasa como con la eficiencia en la translocación de los compuestos nitrogenados de las partes vegetativas de la planta a los granos (Kramer, 1979). En general, el contenido de proteína y la vitrosidad suelen presentar una elevada interacción genotipo x ambiente (Porceddu, 1995).

\subsection{2.- Peso específico.}

Expresa el peso del grano por unidad de volumen en $\mathrm{Kg} \mathrm{H} 1^{-}$ 1. Este indice es muy antiguo y se utilizaba para cifrar el valor comercial del grano en la época en que éste era vendido por volumen. El peso específico y el contenido de cenizas del grano son parámetros ligados a la proporción de endospermo y tegumentos. Por tanto, el peso específico es tanto más elevado cuanto mayor es el endospermo, y los tegumentos, sobre todo la capa de aleurona, tienen un contenido más alto de minerales, por ello el porcentaje de cenizas expresa, en cierta manera, la 
proporción entre ambos componentes (López-Bellido, 1991).

E1 peso específico puede ser influenciado por diversos factores, como los espacios vacíos intercalares, el contenido en agua del grano y la naturaleza y cantidad de las impurezas presentes en la muestra. No obstante, el peso específico es todavia importante para definir el rendimiento en harina o sémola del grano, que es más elevado a medida que es mayor. La legislación establece unos mínimos que son diferentes para los trigos harineros y para los duros, más altos en este último tipo (López-Bellido, 1991).

\subsection{3. - Azúcares reductores.}

Los azúcares reductores tienen importancia por ser el sustrato de reacciones enzimáticas que pueden producir $\mathrm{CO}_{2}$ durante el proceso de fabricación de la pasta, influyendo sobre su calidad final (Vadillo, 1989). El porcentaje de azúcares reductores o fermentables (glucosa, fructosa y azúcares invertidos) en el grano de trigo oscila entre el 1 y el 3 \% (LópezBellido, 1991) y está relacionado con la actividad invertasa durante las fases de desarrollo del endospermo (Chevalier y Lingle, 1983).

\subsubsection{Cenizas.}

Representan el porcentaje de sales minerales del grano de trigo o de la harina. Su cuantificación resulta de gran importancia industrial, ya que el rendimiento en harina o sémola suele ser mayor a medida que el porcentaje de cenizas sea más bajo ella (Finney et al., 1987; Vadillo, 1989; López-Bellido, 1991). En efecto, si el endospermo del grano se encuentra muy mineralizado, las sémolas de él obtenidas tendrán también una tasa alta de cenizas, con lo que la fábrica deberá rebajar el grado de extracción para lograr el cumplimiento de la reglamentación vigente, la cual ordena un máximo del 0,90\% en las cenizas de las sémolas destinadas para una calidad superior de pasta alimenticia. Y por otro lado, si el grano tiene mucho salvado en relación al endospermo, también la tasa de cenizas global del grano será elevada, y en este caso tampoco será posible obtener elevadas extracciones de sémola con dicho grano. En cualquiera de las dos situaciones, resulta evidente que va a ser preferible un trigo con baja tasa de cenizas frente a uno con más cenizas (AETC, 1998). 
Las cenizas se obtienen por combustión a $600-900^{\circ} \mathrm{C}$ (López-Bellido, 1991; Singh et al., 1998), y están formadas por los residuos de elementos metálicos y no metálicos y por aquellos residuos minerales incombustibles provenientes de la descomposición de materias orgánicas. No existe una correspondencia estricta entre las materias minerales y las cenizas, pero se consideran similares dado que las diferencias son muy débiles (López-Bellido, 1991). El contenido medio en cenizas del grano de trigo es de alrededor del $1.8 \%$ sobre la materia seca. Las zonas externas del grano y las capas periféricas del endospermo son las que tienen mayor proporción de sales minerales (Singh et al., 1998).

En el contenido en materias minerales del grano y de la harina influyen factores genéticos, edafológicos (naturaleza del suelo, riqueza en humus y disponibilidad de nutrientes), climáticos (insolación y humedad), agronómicos (abonados, densidad de siembra y cultivo anterior), fisiológicos (estado de maduración del grano en la recolección y enfermedades criptogámicas) $y$ los tratamientos tecnológicos (acondicionamiento del grano antes de la molienda y el rendimiento de extracción de harina o sémola). Aunque la composición en cenizas depende de la disponibilidad de nutrientes minerales en el suelo, los diferentes genotipos trigo duro absorben cantidades variables en función del tipo de suelo y condiciones de crecimiento (Dikeman et al., 1982).

\subsubsection{Vitrosidad.}

E1 carácter vitrosidad es un parámetro que tiene importancia en el caso de los trigos duros, principalmente porque a mayor presencia de granos no vitreos (harinosos), se produce en el proceso industrial una menor cantidad de sémolas y una mayor cantidad de harina, que para el trigo duro es un subproducto Si bien una parte de ésta puede ser incorporada a la propia sémola, una excesiva producción de harina implica que ésta deba destinarse a otras utilizaciones de menor rentabilidad. Por tanto, puede admitirse una cierta pérdida de vitrosidad en el trigo, pero deberán desecharse aquellas otras partidas que no alcancen un determinado nivel en la misma (Vadillo, 1989; AETC, 1998).

Aparte de la sensibilidad varietal y de todas aquellas circunstancias que desfavorezcan el depósito de proteínas en el grano o la menor proporción de éstas, la presencia elevada de 
humedad durante la etapa final de maduración del grano, ya sea por precipitaciones o por riegos dados en las semanas previas a la cosecha, es decisiva para la pérdida del carácter vítreo que tiene todo grano inmaduro, transformándose en este caso en grano harinoso (López-Bellido, 1991; Nachit et al., 1995; AETC, 1998).

\subsubsection{Pigmentación del grano.}

Es una medida del grado de color amarillo que presentarán la sémolas y pastas alimenticias, debido principalmente al contenido en -carotenos (Vadillo, 1989; Porceddu, 1995; AETC, 1998). La pigmentación del grano es un parámetro que se demuestra bastante independiente de las condiciones agroclimáticas en las que se ha desarrollado el trigo. Sólo lluvias importantes cuando el cultivo está casi maduro, que mojan el grano y acarrean pérdida de vitrosidad, afectan de una manera significativa al contenido final de este pigmento, ya que en estas circunstancias se produce una pérdida por oxidación del caroteno, debida a la actividad del enzima lipoxigenasa presente en el grano (Porceddu, 1995; AETC, 1998).

\subsubsection{Indice S.D.S.}

El índice S.D.S. es un ensayo de sedimentación que informa de la calidad de la proteína para la pastificación. Sus resultados, a diferencia de lo que ocurre con otras técnicas de sedimentación como el Índice de Zeleny, se muestran independientes de la cantidad de proteína presente en la muestra, y también vienen poco afectados por las condiciones medioambientales en las que se haya desarrollado el cultivo de trigo duro, con lo cual el S.D.S. es una determinación bastante útil en los programas de mejora genética y de selección de variedades por su calidad proteica (Vadillo, 1989; Nachit et al., 1995; ATC, 1998). 


\section{MATERIAL Y MÉTODOS}

\subsection{LOCALIZACIÓN DE LOS ENSAYOS}

Los ensayos se han realizado durante el año 1998 en tres localidades, dos de la provincia de Granada y una de Jerez de la Frontera (Cádiz):

Un regadío ubicado en el Centro de Investigación y Formación Agraria de Granada (C.I.F.A.), situado cerca de Purchil (Fig. 1) a una altitud de $600 \mathrm{~m}$ aproximadamente, con las coordenadas $37^{\circ} 11^{\prime}$ de latitud $\mathrm{N}$ y $3^{\circ} 40^{\prime}$ de longitud $\mathrm{O}$.

Un secano localizado en Ochíchar (Fig. 1), aldea cercana a Ventas de Huelma, a una altitud de $1000 \mathrm{~m}$ aproximadamente, con las coordenadas $37^{\circ} 3^{-}$de latitud $\mathrm{N}$ y $3^{\circ} 52^{\prime}$ de longitud $\mathrm{O}$.

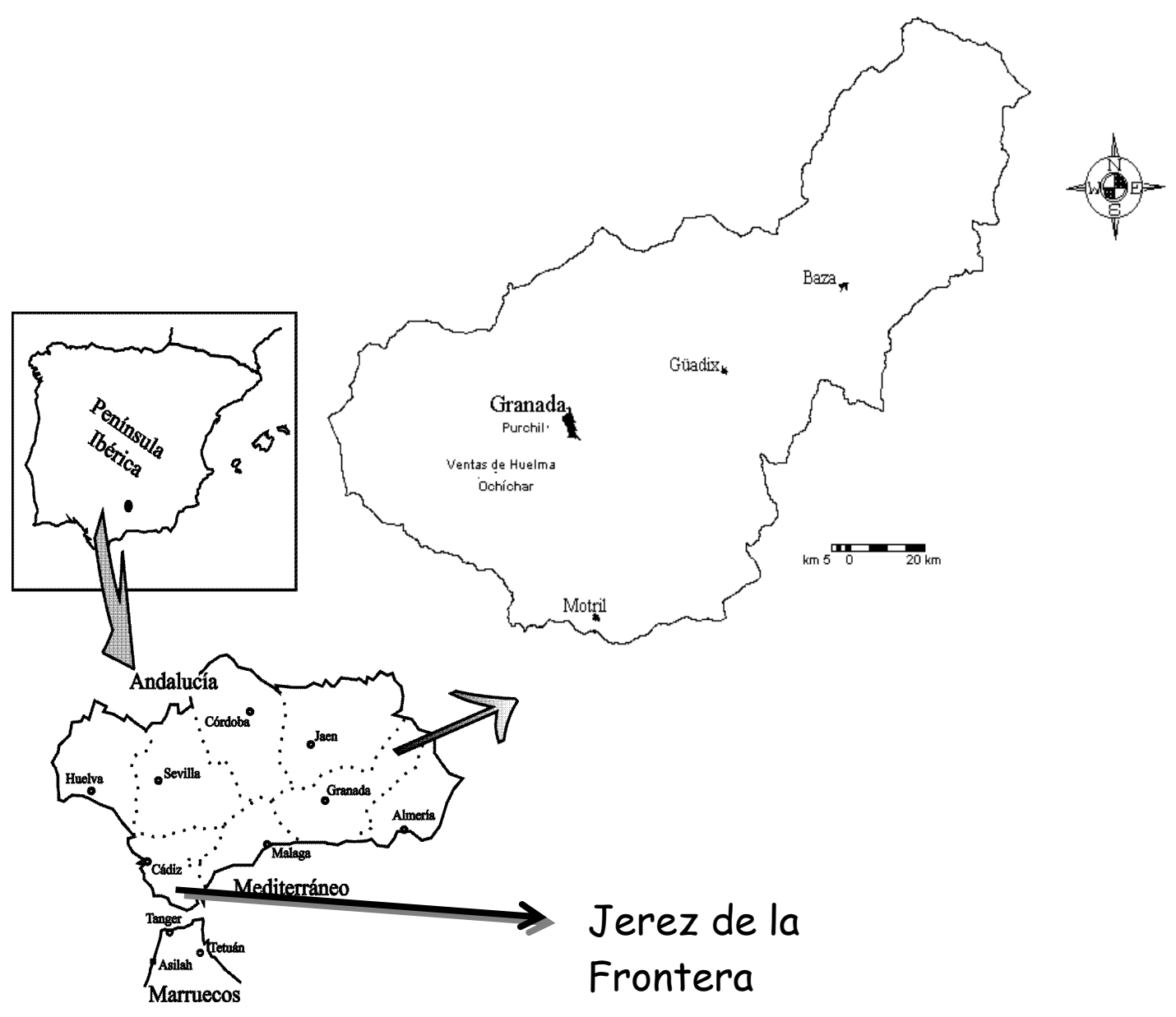

Localización geográfica de los ensayos 
Un secano en Jerez de la Frontera (Cádiz), en la finca del CIFA, a una altitud de $60 \mathrm{~m}$ y con la coordenadas $30^{\circ} 70^{\prime} \mathrm{N}$ y $6^{\circ} 20^{\prime} \mathrm{W}$.

\subsection{CARACTERIZACIÓN EDAFO-CLIMÁTICA DE LOS EXPERIM ENTOS}

\subsubsection{CARACTERISTICAS EDAFICAS}

Según la clasificación de la F.A.O., el suelo de las parcelas experimentales del regadío pertenece al tipo de los fluvisoles calcáreos. El suelo del ambiente del secano, Ochíchar, pertenece al tipo de regosoles calcáreos asociados a cambisoles cálcicos. El suelo de las parcelas experimentales de Jerez corresponde a un tipo de Vertisoles conocidos en la zona genéricamente como Albarizas.

\subsubsection{CARACTERISTICAS CLIMÁTICAS}

Los datos climáticos de los ensayos realizados en Purchil y Jerez se han obtenido a partir de una estación meteorológica instalada en el Centro de Investigación y Formación Agraria (C.I.F.A.), mientras que los datos de la zona del secano, han sido 1 os del aeropuerto de Granada, situado a unos $14 \mathrm{Km}$ de Ochíchar.

La climatología de la campaña agrícola 1997-98 se ha caracterizado por un otoño e invierno muy lluviosos, en especial los meses de noviembre, diciembre y enero; seguido de una primavera bastante seca, con muy escasas precipitaciones durante el mes de febrero y marzo. La pluviometría total recogida ha sido de $549,8 \mathrm{~mm}$ en el regadío, $458,2 \mathrm{~mm}$ en el secano y $609.7 \mathrm{~mm}$ en Jerez. Las temperaturas han sido bastante suaves, no llegando a descender por debajo de cero en ninguno de los tres ambientes a lo largo de todo el ciclo del cultivo. Durante el crecimiento de los granos es de notar que la temperatura máxima fue algo más suave en el secano que en el regadío. En Jerez, sin embargo, tuvo una media de $21.6 \mathrm{C}^{\circ}$ 


\subsection{ATERIAL VEGETAL}

El material vegetal utilizado en esta memoria ha consistido en tres variedades comerciales de trigo duro (Jabato, Mexa y Vitrón) y el genotipo Lagost3, una línea avanzada de la Durum Core Collection del "International Center for Agricultural Research in Dry Areas" (ICARDA), cuyo pedigrí es ICD89-0471ABL-0TR-8AP-0TR-25AP-0TR.

\subsection{DISEÑO EXPERIM ENTAL}

El diseño estadístico utilizado en los tres ambientes fue de bloques al azar con 4 repeticiones y un tamaño de parcela de $12 \mathrm{~m}^{2}$. En todos los experimentos las parcelas fueron de 6 surcos, con una separación entre parcelas de $30 \mathrm{~cm}$.

\subsection{CARACTERISTICAS AGRONÓMICAS}

En la campaña (1997-98) la siembra se realizó en una fecha temprana, el 11 de diciembre de 1997 en el regadío y el 21 de enero de 1998 en el secano, retraso este último debido a las intensas 1luvias registradas a partir del 11 de diciembre.

En Jerez, la fecha de siembra fue el mismo día que en el regadio de Granada, el 11 de Diciembre de 1997.

La siembra se realizó con una sembradora de ensayos y con una densidad ajustada, en función del peso de mil granos, a 350 plantas $\mathrm{m}^{-2}$. Antes de la siembra se aplicaron $300 \mathrm{Kg} / \mathrm{Ha}$ de un fertilizante complejo 15:15:15 (N:P:K) en secano y 400 $\mathrm{Kg} / \mathrm{Ha}$ en los ensayos de Jerez y regadio. En éste último ambiente se aplicó MCPA Sal amina al 40\% para el control de maleza, mientras que en los demás el control fue manual. En esta campaña sólo se aplicó una dosis de riego al principio del encañado simulando una precipitación de $300 \mathrm{~mm}$. En Jerez, se aplicó abono de cobertura el 17 de Marzo de 1998, mediante $350 \mathrm{Kg}$ de Nitrato amónico Cálcico.

Durante la campaña no existió daño provocado por insectos, mientras que el daño de pájaros y enfermedades fue moderado. 


\subsection{TOMA DE MUESTRAS EN EL CAMPO}

Durante la campaña se tomaron los siguientes datos:

$\checkmark$ Número de plantas nacidas por unidad de superficie, contando las plantas en $50 \mathrm{~cm}$ de uno de los surcos centrales de cada parcela.

$\checkmark$ Estadio fenológico según la escala de Zadoks (Zadoks et al., 1974) de 5 plantas representativas de las escogidas del medio metro de cada parcela.

$>$ Incidencia de enfermedades.

\subsection{DETERMINACIÓN DEL RENDIMIENTO Y COMPONENTES.}

Antes de la recolección se tomaron las plantas contenidas en un metro de surco determinado al azar en cada parcela, seleccionándose las 10 plantas más homogéneas para obtener la longitud del tallo principal, sin contar la espiga.

Posteriormente, sobre una muestra de grano procedente de la cosechadora de ensayos, se obtuvieron los siguientes parámetros del rendimiento:

$\checkmark$ Peso medio de 1000 granos, determinado por pesada de 3 grupos de 300 granos seleccionados mediante un contador fotoeléctrico de granos de la casa Pfeuffer,

Peso específico, pesando los granos limpios contenidos en $250 \mathrm{ml}$ y expresándolos en $\mathrm{Kg} / \mathrm{Hl}$.

$\checkmark$ El contenido de humedad en el grano se determinó mediante desecación de cada muestra a $70-75^{\circ} \mathrm{C}$ durante 48 horas.

La producción total de grano se obtuvo mediante la recolección con cosechadora de cada parcela, pesándose posteriormente el grano limpio. El valor de la cosecha se corrigió expresándolo al $12 \%$ de humedad.

\subsection{DETERMINACIONES ANALÍTICAS.}

Para las técnicas analíticas se han utilizado los métodos estándar recomendados para análisis de harinas de cereales (B.O.E. 20-1-1988), que se describen a continuación. 


\subsubsection{PREPARACION DE LA MUESTRA}

Principio: Homogeneización y reducción de la muestra al tamaño adecuado para la correcta realización del análisis. Para estos análisis se ha utilizado un aparato triturador que no provoca calentamiento de la muestra, fácil de limpiar, y que proporciona un tamaño de partícula comprendido entre $800 \mathrm{y}$ $1.200 \mu \mathrm{m}$.

\subsubsection{CONTENIDO DE HUM EDAD}

Principio: Se determina la pérdida de peso de la muestra al someterla a calentamiento en estufa en condiciones determinadas.

\subsubsection{Material y aparatos.}

Balanza analítica con precisión de $0.1 \mathrm{mg}$.

$>$ Pesasustancias de vidrio con tapadera.

$>$ Estufa isoterma de aire reforzado, regulada a $70{ }^{\circ} \mathrm{C}$.

$>$ Desecador provisto de gel de sílice como deshidrantante.

\subsubsection{Procedimiento.}

Pesar con precisión de $1 \mathrm{mg}$, aproximadamente $5 \mathrm{~g}$ de muestra en pesasustancias seco e introducir en la estufa a 70 ${ }^{\circ} \mathrm{C}$ y destapar. Mantener en la estufa hasta peso constante (aprox. $24 \mathrm{~h}$ ). Tapar el pesa sustancias antes de sacar de la estufa, dejar enfriar a temperatura ambiente en el desecador y pesar a continuación.

La humedad de la muestra, expresada en tanto por cien, viene dada por:

$$
\mathrm{H} \%=\frac{\left(\mathrm{P}_{1}-\mathrm{P}_{2}\right) \cdot 100}{\mathrm{P}}
$$

Siendo:

$\mathrm{P}_{1}=$ peso, en g, del pesasustancias con la muestra.

$\mathrm{P}_{2}=$ Peso, en g, del pesasustancia con la muestra desecada.

$\mathrm{P}=$ Peso, en g, de la muestra.

La diferencia resultante entre determinaciones duplicadas de la misma muestra no deberá ser mayor de $0.1 \%$ en valor absoluto. 


\subsubsection{Referencias:}

- Métodos de la Asociación Internacional de Química Cerealista (I.C.C.)

- AOAC, M. 14.0031980

\subsubsection{CONTENIDO DE CENIZAS.}

Definición: Residuo obtenido por incineración a una temperatura de $550 \pm 10^{\circ} \mathrm{C}$ hasta combustión completa de la materia orgánica y obtención de un peso constante.

\subsubsection{Material y aparatos.}

Crisoles de porcelana de $25 \times 35 \mathrm{~mm}$.

$>$ Horno eléctrico (mufla) con dispositivo de control de la temperatura.

$>$ Desecador con gel de sílice.

\subsubsection{Procedimiento.}

Pesar con precisión de $1 \mathrm{mg}$ de 2 a $6 \mathrm{~g}$ de muestra, en un crisol previamente incinerado y tarado. Colocar el crisol y su contenido en el horno mufla a $150{ }^{\circ} \mathrm{C}$ durante 20 min., a 180 ${ }^{\circ} \mathrm{C}$ durante $30 \mathrm{~min}$. y a $200^{\circ} \mathrm{C}$ durante $10 \mathrm{~min}$. Posteriormente aumentar $50^{\circ} \mathrm{C}$ cada $10 \mathrm{~min}$, hasta los $550{ }^{\circ} \mathrm{C}$ durante 8 horas, hasta combustión completa de la sustancia (cenizas blancas o grises). Enfriar a temperatura ambiente en un desecador. Pesar seguidamente.

El contenido en cenizas sobre sustancia natural viene dado por la siguiente fórmula:

$$
\% \text { cenizas }=\frac{\mathrm{P}_{1}-\mathrm{P}_{2}}{\mathrm{P}} \times 100
$$

Siendo:

$\mathrm{P}_{1}=$ Peso, en gramos del crisol con las cenizas.

$\mathrm{P}_{2}=$ Peso, en gramos, del crisol vacío.

$\mathrm{P}=$ Peso, en gramos de la muestra .

\subsubsection{Referencias.}

- AOAC, edición 1980, 14.006. 


\subsubsection{PROTEÍNAS.}

Principio: Se ha utilizado la técnica de Kjeldahl, basada en la determinación del nitrógeno, convirtiendo el nitrógeno orgánico presente en amonio sulfato con ácido sulfúrico. Después de alcalinizar con sodio hidróxido, destilar recogiendo el destilado sobre ácido bórico, titulando el amoniaco recogido con ácido N/10.

\subsubsection{Reactivos:}

172222 Acido Bórico solución 4\% RE

181023 Acido clorhídrico $0.1 \mathrm{~mol} / 1(0.1 \mathrm{~N}) \mathrm{SV}$

131058 Acido Sulfúrico $96 \%$ PA-ISO

181061 Acido Sulfúrico $0.05 \mathrm{~mol} / 1(0.1 \mathrm{~N}) \mathrm{SV}$

131074 Agua PA-ACS

251170 Azul de Metileno (C.I: 52015) DC

121085 Etanol 96\% v/v PA

171327 Fenolftaleína solución $1 \% \mathrm{RE}$

131532 Potasio Sulfato PA-ACS-ISO

171617 Rojo de Metilo (C.I. 13020) RE-ACS

141625 Selenio metal polvo PRS.

131687 Sodio Hidróxido lentejas PA-ACS-ISO

131716 Sodio Sulfato anhidro PA-ACS-ISO

-Ácido Sulfúrico 96\% PA-ISO, libre de Nitrógeno.

-Sodio Hidróxido al 40\%: Diluir Sodio Hidróxido lentejas PAACS-ISO con agua PA-ACS hasta la concentración indicada.

-Catalizador: Mezclar $5 \mathrm{~g}$ de Sodio Sulfato anhidro PA-ACS-ISO con $5 \mathrm{mg}$ de Selenio metal polvo PRS.

-Indicad or de Fenolftaleína: solución 1\% RE.

-Indicador Taschiro: Mezclar $20 \mathrm{mg}$ de Rojo de Metilo (C.I. 13020) RE-ACS y $10 \mathrm{mg}$ de Azul de Metileno (C.I. 52015 DC en $100 \mathrm{ml}$ de Etanol $96 \% \mathrm{v} / \mathrm{v}$ PA.

-Acido Bórico, solución 4\%RE.

-Acido Sulfúrico $0.05 \mathrm{~mol} / 1(0.1 \mathrm{~N}) \mathrm{SV}$ o Chorhídrico $0.1 \mathrm{~mol} / 1$ $(0.1 \mathrm{~N}) \mathrm{SV}$.

- Para la digestión:

-Matraces tipo Kjeldahl o similar.

-Baterías de mantas eléctricas o similar.

- Para la destilación :

-Matraz generador de vapor.

-Refrigerante.

-Matraz receptor. 
- Titulación: Bureta de vídrio o bureta automática.

\subsubsection{Procedimiento.}

Pesar, con la precisión de $1 \mathrm{mg}$, entre 0.5 y $2.5 \mathrm{~g}$ de muestra e introducirla en el matraz kjeldahl. Añadir unos $5 \mathrm{~g}$ de catalizador, $20 \mathrm{ml}$ de Ácido Sulfúrico 96\% PA-ISO. Poner a digerir teniendo cuidado al principio de no elevar demasiado la temperatura hasta que cese el desprendimiento de espuma. Digerir hasta que la solución esté clara. Enfriar, diluir, añadir unas gotas de fenolftaleína solución 1\% RE y conectar el aparato destilador añadiendo Sodio Hidroxido al $40 \%$ hasta viraje. En el matraz receptor poner $100 \mathrm{ml}$ de Ácido Bórico solución 4\% RE con unas gotas de indicador, cuidando que el extremo del refrigerante quede bien cubierto del líquido. Mantener la destilación aproximadamente 15 minutos (o más si es preciso, hasta que no dé reacción básica); lavar el extremo del refrigerante y titular el destilado con Ácido Sulfúrico $0.05 \mathrm{~mol} / 1$ $(0.1 \mathrm{~N}) \mathrm{SV}$. Hacer un blanco.

E1 contenido de proteínas en materia natural viene dado por la siguiente fórmula:

$$
\text { \%proteínas }=\frac{0.14 \times 6,25\left(\mathrm{~V}_{1}-\mathrm{V}_{0}\right)}{\mathrm{P}}
$$

Siendo:

$\mathrm{V}_{1}=$ volumen, en $\mathrm{ml}$, de Ácido Clorhídrico 0.1N o Ácido Sulfúrico $0.1 \mathrm{~N}$ utilizado en la determinación.

$\mathrm{V}_{0}=$ volumen, en $\mathrm{ml}$, de Ácido Clorhídrico $0.1 \mathrm{~N}$ o Ácido Sulfúrico $0.1 \mathrm{~N}$ utilizado en blanco.

$\mathrm{P}=$ peso, en $\mathrm{g}$, de la muestra.

La diferencia entre dos determinaciones sucesivas expresada en $\%$ de proteínas no debe ser superior al $0.25 \%$.

\subsubsection{Referencias:}

- AOAC (1980)2.057.

- Pearson, $5^{a}$ edición (1962).

\subsubsection{AZÚCARES REDUCTORES (glucosa, fructosa y azúcares invertidos).}


Principio: Eliminación de todas las materias reductoras distintas de los azúcares, mediante desburbado a partir de las soluciones de carrez I y II, previa disolución de los azúcares en etanol diluido. Eliminación del etanol y valoración antes $\mathrm{y}$ después de la inversión, según el método de Luff-Schoorl.

\subsubsection{MATERIAL Y APARATOS.}

\section{$>$ AGITADOR MECÁNICO.}

$>$ MATRACES AFORADOS DE 1000, 300, 200, 100 Y 50 ML.

\subsubsection{Reactivos.}

Acido acético glacial PA-ACS--ISO.

Acido cítrico 1-hidrato PA-ACS-ISO.

Acido clorhídrico 35\% PA-ISO.

Acido clorhídrico $0.1 \mathrm{~mol} / 1(0.1 \mathrm{~N}) \mathrm{SV}$

Acido Sulfúrico $96 \%$ PA-ISO

Agua PA-ACS.

Almidón soluble RE

Cobre II sulfato 5-hidrato PA-ACS-ISO.

Etanol 96\% v/v PA

Mercurio II yoduro rojo PA

3-Metil-1 Butanol PA-ACS

Piedra Pómez gránulos QP

Potasio hexacianoferrato II 3-hidrato PA-ACS

Potasio Yoduro PA-ISO

Reactivo de luff-schoorl RE

Rojo de metilo solución $0.1 \% \mathrm{RE}$

Sodio Carbonato anhidro PA-ACS-ISO.

Sodio Hidróxido $0.1 \mathrm{~mol} / 1(0.1 \mathrm{~N})$

Indicador fenolftaleína SV

Sodio tiosulfato $0.1 \mathrm{~mol} / 1(0.1 \mathrm{~N}) \mathrm{SV}$

Zinc Acetato 2-hidrato PA-ACS

- Etanol 40\%(v/v) d=0.948 a $20{ }^{\circ} \mathrm{C}$. Etanol 96\%Diluir etanol 96\% $\mathrm{v} / \mathrm{v}$ PA con Agua PA-ACS hasta la concentración indicada.

- Solución de Carrez I. Disolver en agua PA-ACS 24 g de Zinc Acetato 2-hidrato PA-ACS y $3 \mathrm{ml}$ de Acido Acético glacial PA-ACSISO y añadir Agua PA-ACS hasta $100 \mathrm{ml}$.

- Solución de Carrez II. Disolver en Agua PA-ACS 10.6 g de Potasio hexaciano Ferrato II 3-hidrato PA-ACS K4 (FeCN6).3H2O y añadir Agua PA-ACS hasta $100 \mathrm{ml}$. 
- Rojo de Metilo solución 0.1\% RE.

- Acido Clorhídrico 4N.Diluir Acido clorhídrico 35\% PA-ISO con Agua PA-ACS hasta la concentración indicada.

- Acido Clorhídrico $0.1 \mathrm{~mol} / 1(0.1 \mathrm{~N}) \mathrm{SV}$.

- Sodio Hidróxido $0.1 \mathrm{~mol} / 1(0.1 \mathrm{~N})$ indicador fenolftaleína SV.

- Solución de Cobre Sulfato. Disolver 25 g de Cobre II Sulfato 5hidrato PA-ACS-ISO CuSO $4.5 \mathrm{H} 2 \mathrm{O}$, exento de hierro, en Agua PA ACS y enrasar a $100 \mathrm{ml}$.

- Solución de Acido Cítrico.Disolver 50 g de Acido Citrico 1-hidrato PA-ACS-ISO C6H8O7.H2O en $50 \mathrm{ml}$ de Agua PA-ACS-ISO.

- Solución de Sodio Carbonato. Disolver $143.8 \mathrm{~g}$ de Sodio Carbonato anhidro PA-ACS-ISO en unos $300 \mathrm{ml}$ de agua PA-ACS caliente, dejar enfriar y completar a $300 \mathrm{ml}$.

- Solución de Sodio Tiosulfato $0.1 \mathrm{~mol} / 1$ (0.1 N) SV.

- Solución de Almidón. Añadir una mezcla de 5 g de Almidón soluble RE en $30 \mathrm{ml}$ de $\mathrm{H} 2 \mathrm{O}$ PA-ACS a $1 \mathrm{~L}$ de Agua PA-ACS hirviendo. Dejar hervir durante 3 minutos. Dejar enfriar. Añadir $10 \mathrm{mg}$ de Mercurio II Yoduro rojo PA como agente conservador.

- Acido Sulfúrico 6 N. Diluir Acido Sulfúrico 96\% PA-ISO con agua PA-ACS hasta concentración indicada.

- Solución de Potasio Yoduro 30\% (p/v).Disolver Potasio Yoduro PA-ISO con Agua PA-ACS hasta concentración indicada.

- Piedra Pómez gránulos QP, lavado con Acido clorhídrico 35\% PAISO y aclarada con Agua PA-ACS.

- 3-Metil-1-Butanol PA-ACS.

- Reactivo de Luff-Schoorl RE o bien preparado de la siguiente forma: verter agitando cuidadosamente la solución de Acido Cítrico en la solución de Sodio Carbonato. Agitar hasta la desaparición del desprendimiento gaseoso. A continuación añadir la solución de Cobre Sulfato y completar hasta 1 L con Agua PAACS. Dejar reposar 12 horas y filtrar. Verificar la normalidad del reactivo obtenido $(\mathrm{Cu} 0.1 \mathrm{~N} ; \mathrm{Na} 2 \mathrm{CO} 32 \mathrm{~N})$. E1 PH de la solución no debe ser aproximadamente de 9.4.

\subsubsection{Procedimiento.}

Pesar, con aproximación de $1 \mathrm{mg}, 2.5 \mathrm{~g}$ de muestra e introducirla en un matraz aforado de $250 \mathrm{ml}$. Añadir $200 \mathrm{ml} \mathrm{de}$ Etanol 40\% (v/v) y mezclar durante una hora en el agitador magnético con la ayuda de una palometa de tamaño adecuado. Añadir $5 \mathrm{ml}$ de solución de carrez I y agitar durante un minuto. Adicionar y agitar durante el mismo tiempo con $5 \mathrm{ml}$ de solución de carrez II.

Enrasar a $250 \mathrm{ml}$ con la solución de etanol $40 \%$ (v/v), homogeneizar y filtrar. Tomar $200 \mathrm{ml}$ de filtrado y evaporar. 
aproximadamente hasta la mitad del volumen, a fin de eliminar la mayor parte del etanol. Transvasar en su totalidad el residuo de evaporación, con ayuda de agua PA-ACS caliente, a un matraz aforado de $200 \mathrm{ml}$ y enfriar. A continuación, enrasar con Agua PA- ACS y filtrar si es necesario. Esta solución será utilizada para la determinación de azúcares reductores y después de la inversión para la determinación de azúcares totales. Tomar como máximo $25 \mathrm{ml}$ de la solución preparada y que contenga menos de $60 \mathrm{mg}$ de azúcares reductores, expresado en glucosa. Si es necesario, completar el volumen hasta $25 \mathrm{ml}$ con Agua PA-ACS y determinar la cantidad de Azúcares reductores según Luff-Schoorl. El resultado se expresa en tanto por ciento de glucosa.

Cálculos: Establecer, mediante los valores de la tabla de referencia, la cantidad de glucosa en $\mathrm{mg}$. correspondiente a la diferencia entre las dos valoraciones, según los $\mathrm{ml}$ de Sodio Tiosulfato $0.1 \mathrm{~N}$ gastados en cada una de las valoraciones. E1 resultado se expresa en \% de azúcares en la muestra.

Observaciones: Es recomendable añadir aproximadamente $1 \mathrm{ml}$ de alcohol iso-amílico (sin tener en cuenta el volumen) antes de la ebullición, con el reactivo Luff-Schoorl para evitar la formación de espuma.

\subsection{PARÁM ETROS DE CALIDAD DEL GRANO}

\subsubsection{PESO ESPECÍFICO O PESO HECTOLITRO.}

Mide el peso de los granos por unidad de volumen. El peso específico es directamente proporcional al rendimiento en la sémola. Para determinar este parámetro se pesan los granos limpios contenidos en $250 \mathrm{ml}$, expresándolos en $\mathrm{Kg} / \mathrm{H1}$.

\subsubsection{VITROSIDA D.}

Indice que determina el porcentaje de granos que presentan fractura vitrea, en contraposición a los granos con "berrendeo", blancos y harinosos. La vitrosidad se evalúa visualmente sobre la fractura del grano realizada mediante un farinotomo de Pohl. Para este análisis se tomaron muestras de 50 granos, realizándose dos repeticiones. 


\subsubsection{INDICE DE SEDIM ENTACIÓN SDS}

Se utiliza para medir la fuerza del gluten, factor importante de la calidad final de la pasta, estando directamente relacionado con la cantidad y el tipo de proteínas insolubles del grano. Este índice oscila desde 50 en los trigos débiles hasta 80 en los muy fuertes.

La técnica mide el volumen del sedimento en $\mathrm{ml}$, tras haber disgregado e hidratado las proteínas con ácido láctico y el detergente SDS (dodecil sulfato de sodio). En este trabajo, se tomaron muestras de $1 \mathrm{~g}$ de harina integral, a las que se adicionó $4 \mathrm{ml}$ de agua destilada y $12 \mathrm{ml}$ de ácido láctico en la proporción $1: 48$. Se agitaron varias veces y se realizó la lectura 14 minutos después de realizarse la última agitación.

\subsection{ESTUDIO ESTADÍSTICO}

El análisis estadístico de los datos se ha basado en la realización de análisis de la varianza (ANOVA) y test de mínimas diferencias significativas (MDS), para el estudio del efecto del genotipo y ambiente. La interdependencia de unos parámetros con otros y con la cosecha, se ha analizado mediante técnicas de regresión y correlación simple (Steel y Torrie, 1985) y análisis por componentes principales (Johnson, 2000). Para el análisis estadístico de los datos se ha utilizado el programa "Statgraphics Plus" Versión 3.1 para Windows. 


\section{RESULTADOS}

En primer lugar se presentarán los resultados de la producción de grano, parámetros relacionados y factores de calidad del grano, obtenidos mediante análisis de la varianza usando el procedimiento "general linear model" de statgraphics, de acuerdo al modelo:

$$
y i j=\quad+g i+e j+g i e j+b(e j)
$$

Este análisis permite subordinar el efecto del bloque al del ambiente, incrementando así la sensibilidad de las comparaciones en el análisis de la varianza. los análisis se han realizado para el conjunto de genotipos y ambientes, y sus resultados, para cada una de las variables estudiadas, se presentan ordenados en el apéndice de tablas incluido al final de esta memoria.

Las relaciones más relevantes entre las distintas variables se han establecido mediante técnicas de correlación y regresión simple. finalmente, se ha realizado un análisis por componentes principales para considerar simultáneamente las variables más importantes y establecer sus interrelaciones en un único modelo multivariante. 


\subsection{Rendimiento y parámetros relacionados.}

En la tabla 1 se presentan los valores medios de la producción de grano y parámetros relacionados por genotipo y ambiente. en las tablas 1 a a 5 a del apéndice se encuentran los correspondientes resultados del análisis de la varianza. para permitir la comparación entre genotipos, y debido a que en algunos casos la interacción genotipo ambiente ha sido significativa, en las figuras 1 a 5 se presentan los valores medios de estas variables por genotipo y ambiente.

\subsubsection{Rendimiento de grano.}

Los resultados indican (tabla 1) que, para el conjunto de ensayos, el genotipo más productivo ha sido jabato, con más de $4066 \mathrm{~kg}$ ha-1 de media, seguido de vitrón. los genotipos menos productivos han sido lagost3 y mexa, no alcanzando este último los $3000 \mathrm{~kg}$ ha- 1 .

Entre ambientes, el más productivo ha sido el regadío (tabla $1 \mathrm{y}$ figura 1), que con $4390 \mathrm{~kg}$ ha-1 ha superado en un $22 \%$ la producción media del ambiente de jerez (3591 kg ha-1) y en un $95 \%$ la del secano, el ambiente que con $2254 \mathrm{~kg}$ ha-1 ha sido el menos productivo de los estudiados.

\subsubsection{Peso medio del grano.}

E1 genotipo que, en valores medios, ha presentado los granos de mayor tamaño ha sido lagost3 (tabla 1), con diferencias significativas frente a los demás, entre los cuales no se han detectado diferencias estadísticas (tabla 1). entre ambientes, ha sido el regadío el que ha posibilitado, en general, la formación de granos de mayor tamaño, seguido de jerez y, finalmente, del secano, cuyos granos han sido los de menor peso (tabla 1). en el promedio de genotipos, el rango de variación en el peso de los granos ha sido tan sólo del $11 \%$ desde jabato (el genotipo de granos más pequeños) hasta lagost3, el de granos más pesados. entre ambientes, esta variación ha sido ligeramente mayor, del orden de1 $12,6 \%$. en ambos casos, este rango ha sido notablemente inferior al que ha presentado el rendimiento, como se ha comentado. no obstante, la variación entre genotipos individuales ha sido algo mayor (fig. 2). 
Tabla 1. comparación de los valores medios por genotipo y ambiente del rendimiento en grano, peso medio por grano, duración del llenado del grano, tasa de llenado del grano y altura de la planta.

\begin{tabular}{|c|c|c|c|c|c|}
\hline genotipo & $\begin{array}{l}\text { rendimiento } \\
(\mathrm{kg} h \mathrm{~h}-1)\end{array}$ & $\begin{array}{l}\text { peso del } \\
\text { grano } \\
\text { (mg) }\end{array}$ & $\begin{array}{l}\text { duración } \\
\text { llenado } \\
\text { (días) }\end{array}$ & $\begin{array}{c}\text { tasa de } \\
\text { llenado } \\
(\text { mg día- } 1)\end{array}$ & $\begin{array}{l}\text { altura } \\
(\mathrm{cm})\end{array}$ \\
\hline jabato & $4066 a$ & $43,8 b$ & $28,1 \mathrm{c}$ & $1,65 \mathrm{a}$ & $73,9 b$ \\
\hline lagost3 & $3137 c$ & $48,6^{a}$ & $30,2 \mathrm{~b}$ & $1,64^{\mathrm{a}}$ & $72,9 b$ \\
\hline mexa & $2975 c$ & $44,9 b$ & $30,9 b$ & $1,32 \mathrm{c}$ & $78,8^{\mathrm{a}}$ \\
\hline vitrón & $3469 \mathrm{~b}$ & $43,9 \mathrm{~b}$ & $34,9^{a}$ & $1,43 b$ & $73,0 \mathrm{~b}$ \\
\hline \multicolumn{6}{|l|}{ ambiente } \\
\hline regadío & $4390 a$ & $48,3 a$ & $34,8 a$ & $1,39 b$ & $82,5 b$ \\
\hline secano & $2254 c$ & $42,9 c$ & $24,8 c$ & $1,77 \mathrm{a}$ & $55,6 c$ \\
\hline jerez & $3591 \mathrm{~b}$ & $44,7 b$ & $33,3 b$ & $1,36 \mathrm{~b}$ & $85,9 a$ \\
\hline
\end{tabular}

a-c: medias seguidas por idéntica letra dentro de cada columna y apartado no difieren a nivel de probabilidad del 0,05 según un test de minimas diferencias significativas.

Tabla 2. comparación de los valores medios por genotipo y ambiente del contenido y cosecha de proteína, peso específico, contenido de azúcares reductores y de cenizas y otros parámetros asociados con la calidad del grano.

\begin{tabular}{|c|c|c|c|c|c|c|c|c|}
\hline genotipo & $\begin{array}{l}\text { proteinas } \\
\text { del grano } \\
(\%)\end{array}$ & $\begin{array}{l}\text { cosecha } \\
\text { proteína } \\
(\mathrm{kg} \text { ha-1) }\end{array}$ & $\begin{array}{l}\text { peso } \\
\text { específico } \\
\text { (kg hl-1) }\end{array}$ & $\begin{array}{l}\text { azúcares } \\
\text { reductor } \\
\text { es }(\%)\end{array}$ & $\begin{array}{l}\text { contenido } \\
\text { cenizas } \\
(\%)\end{array}$ & $\begin{array}{l}\text { vitrosi } \\
\text { dad } \\
(\%)\end{array}$ & $\begin{array}{l}\text { pigmen } \\
\text { tos } \\
(-)\end{array}$ & $\begin{array}{l}\text { indice } \\
\mathrm{sds} \\
(\mathrm{m} 1)\end{array}$ \\
\hline jabato & $14,07 b$ & $551 \mathrm{a}$ & $83.1^{a}$ & $2,01^{\mathrm{a}}$ & $1,82^{a}$ & $6,50^{a}$ & \multirow{2}{*}{$15,03^{a}$} & \multirow{2}{*}{$50,8 \mathrm{c}$} \\
\hline lagost3 & $14,74 a$ & $458 b$ & $81,6 b$ & $1,97^{\mathrm{a}}$ & $1,91 \mathrm{bc}$ & $7,29^{a}$ & & \\
\hline mexa & $14,10 \mathrm{~b}$ & $451 \mathrm{~b}$ & $80,2 c$ & $2,00^{\mathrm{a}}$ & $1,86 \mathrm{~cd}$ & $8,29^{a}$ & \multirow{2}{*}{$\begin{array}{l}15,07^{\mathrm{a}} \\
14,76 \mathrm{~b}\end{array}$} & \multirow{2}{*}{$\begin{array}{l}57,9 \mathrm{~b} \\
63,8^{\mathrm{a}} \\
\end{array}$} \\
\hline vitrón & $13,37 \mathrm{c}$ & $413 b$ & $82,6^{a}$ & $2,04^{a}$ & $1,78 \mathrm{~d}$ & $7,83^{\mathrm{a}}$ & & \\
\hline ambiente & & & & & & & & \\
\hline regadío & $12,47 \mathrm{c}$ & $543 a$ & $80,5 c$ & $2,01 \mathrm{~b}$ & $1,87 \mathrm{a}$ & $8,15 b$ & \multirow{2}{*}{$\begin{array}{l}14,53 b \\
14,53 b\end{array}$} & $58,4 \mathrm{a}$ \\
\hline secano & $15,47 \mathrm{a}$ & $349 b$ & $81,7 \mathrm{~b}$ & $1,88 \mathrm{c}$ & $1,82 \mathrm{a}$ & $\begin{array}{l}9,63 a \\
4,66 c\end{array}$ & & $49,7 b$ \\
\hline $\begin{array}{l}\text { a-c: me } \\
\text { no difie } \\
\text { diferenc }\end{array}$ & s segu & nor & , & $\begin{array}{l}\text { ntro } \\
0,05\end{array}$ & n & t & $\begin{array}{l}15,54 a \\
\text { partado } \\
\text { minimas }\end{array}$ & $57,2 \mathrm{a}$ \\
\hline
\end{tabular}




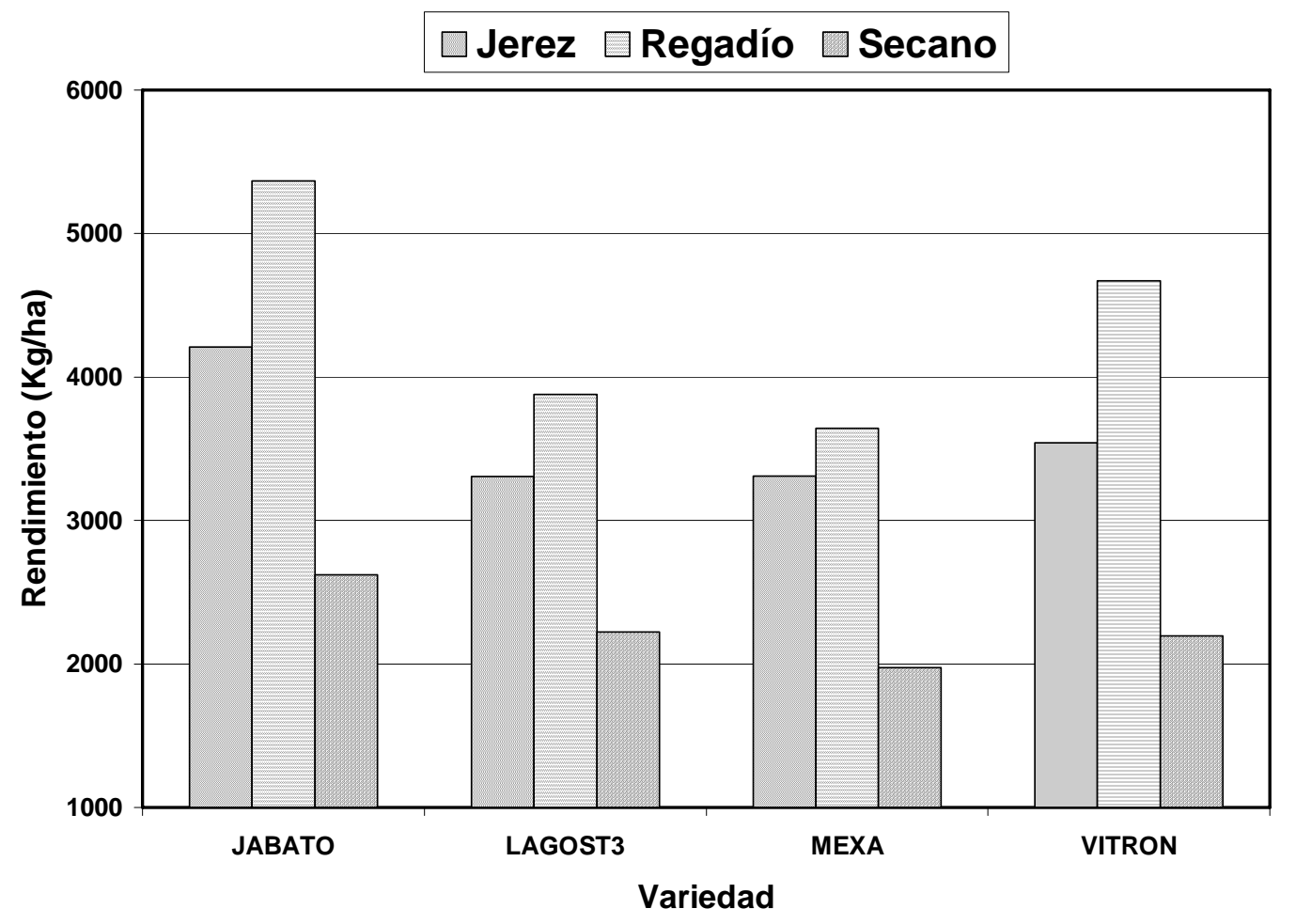

fig. 1.- valores medios de producción de grano por variedad y ambiente. 


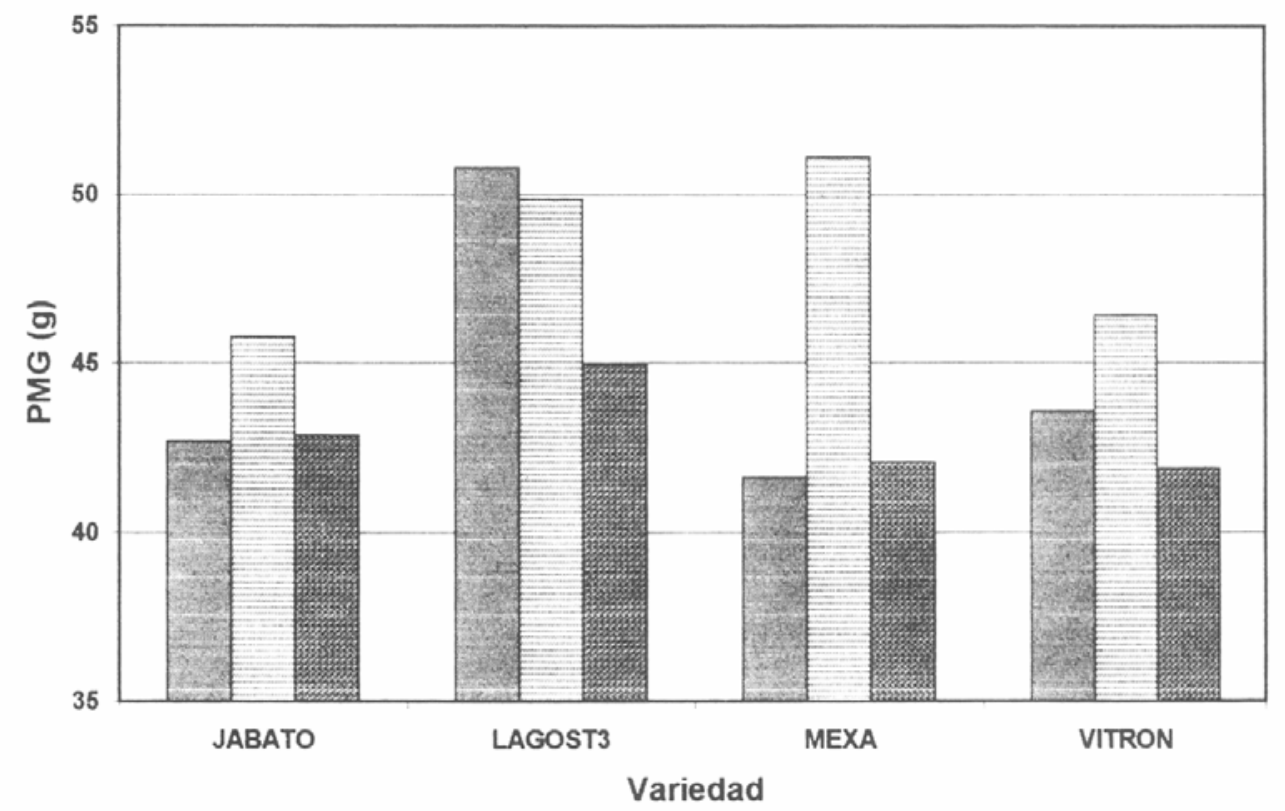
ambiente.

Fig. 2.- Valores del peso medio del grano por variedad y

\subsubsection{Duración y tasa de crecimiento del grano.}

E1 peso medio del grano en los cereales depende tanto de la duración del período de crecimiento o de llenado de los granos, fijada por las condiciones ambientales (principalmente humedad y temperatura) durante el periodo de maduración, como de la tasa de crecimiento del grano, determinada por el aporte de asimilados desde los órganos fotosintéticos y por la movilización de reservas desde los órganos de almacenamiento (las vainas foliares y la base de los tallos, principalmente).

En este estudio se han encontrado diferencias significativas entre genotipos y ambientes para ambos determinantes del crecimiento del grano (tablas $3 a$ y $4 a$, apéndice). en efecto, la duración del crecimiento del grano ha oscilado, en promedio, desde 28.1 días en jabato hasta 34.9 en vitrón (tabla 1), lo que representa un rango de variación del $24.2 \%$. entre ambientes esta variación ha sido aún mayor, del orden del $34.3 \%$, presentando el secano de granada la menor duración del llenado de los granos (tabla 1 y figura 3), debido a las mayores temperaturas y menor humedad edáfica que ha presentado en ese período, en relación con los demás.

En cuanto a la tasa de llenado de los granos, las variaciones han sido del $25 \%$ entre el promedio de genotipos, estratificándose en forma inversa a la duración del crecimiento, 
de tal manera que aquellos genotipos con mayor tasa de llenado (jabato y lagost3) han presentado la menor duración del crecimiento de sus granos (tabla 1 y figura 4). ello se comprueba por la estrecha relación negativa encontrada entre tasa de crecimiento y duración del llenado de los granos (regresión 1). esto indica que los genotipos presentan diferentes estrategias para llenar sus granos, de tal forma que una baja tasa de llenado de los granos tiende a compensarse con una mayor duración de su crecimiento. entre ambientes, el rango de variación en la tasa de llenado ha sido del $30 \%$, correspondiendo al secano de granada el máximo valor (tabla 1 y figura 4).

De los resultados encontrados en este trabajo, por tanto, se deduce que, los genotipos más adecuados para obtener un elevado peso medio por grano en ambiente mediterráneo, parecen ser aquellos que presenten una elevada duración de la tasa de llenado de sus granos junto a una duración intermedia lagost3.

del periodo de crecimiento, como ocurre en el genotipo 
REGRESIÓN 1.- DURACIÓN Y TASA DE LLENADO DEL GRANO.

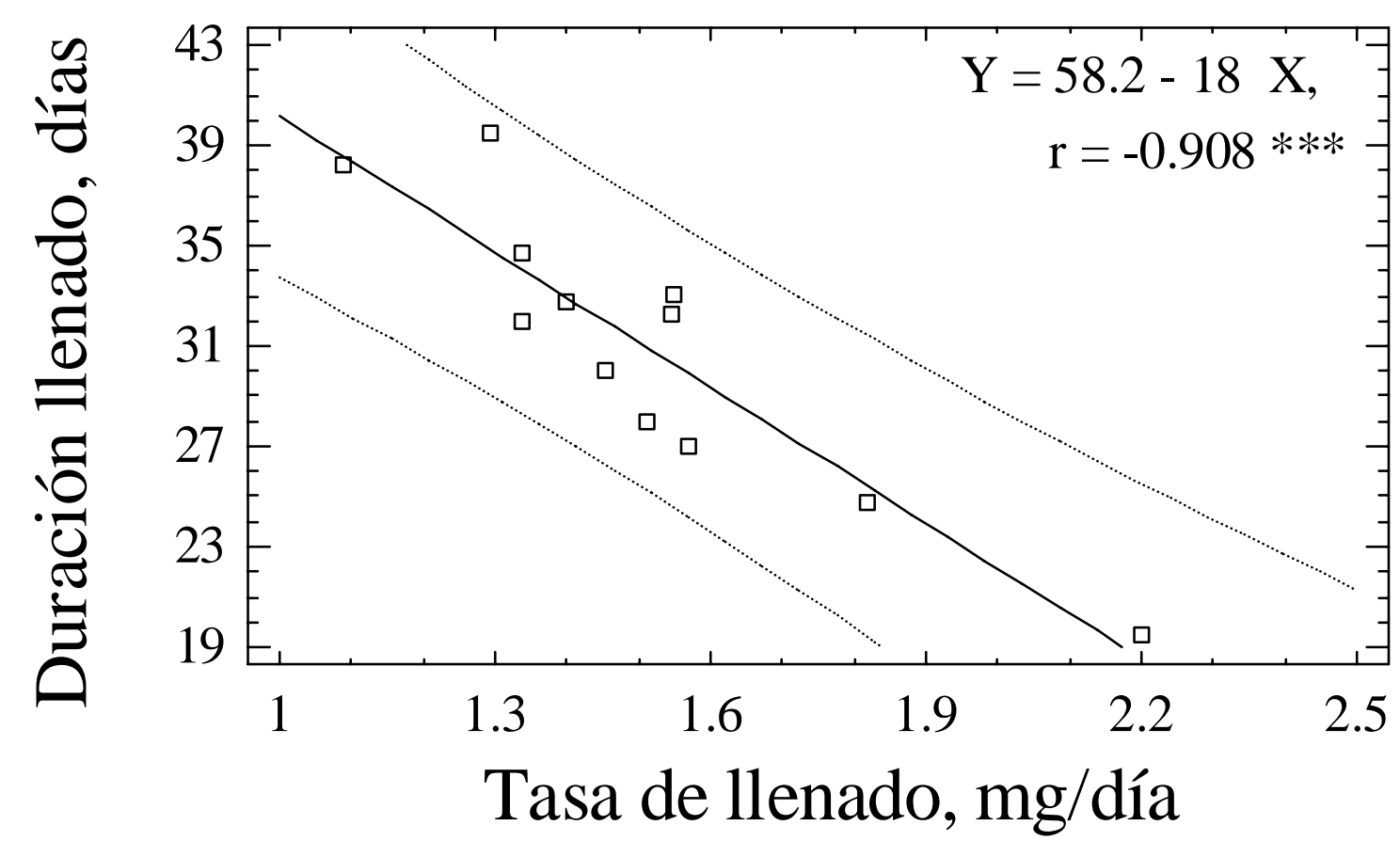

REGRESIÓN 2.- ALTURA DE LA PLANTA Y RENDIMIENTO DE GRANO.

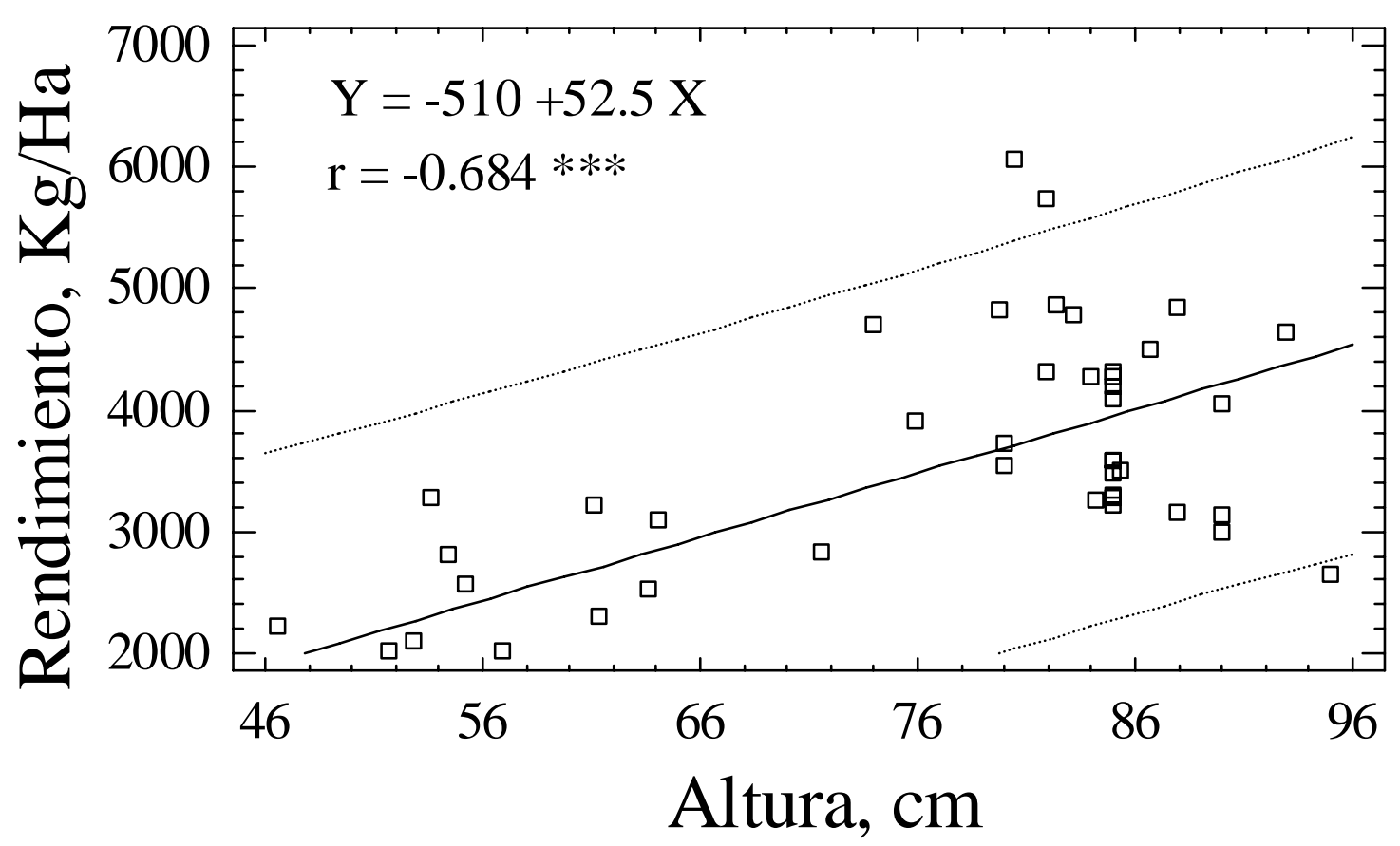


E1 de mayor tamaño del grano. dado que el rendimiento por ha sin embargo, no sólo depende del tamaño medio de los granos, sino del número de granos por m-2 (condicionado a su vez por la densidad de espigas por m-2 y por el número de granos por espiga), no siempre aquellos genotipos de mayor peso medio del grano son, necesariamente, los de mayor rendimiento por ha. ello se comprueba por la moderada regresión existente entre el peso medio por grano y el rendimiento por ha para el conjunto de genotipos y ambientes $(r=0,495$ n.s., $n=12)$.

\subsubsection{Altura de la planta.}

La altura de la planta constituye un factor de rendimiento en el trigo, ya que tallos excesivamente largos predisponen a la planta al encamado fisiológico, limitando la cantidad de abonado nitrogenado que pueden recibir y, por tanto, su capacidad productiva. además, la altura de la caña resulta un indicador de la incidencia de estreses ambientales (sequia y deficiencias nutritivas, principalmente) durante el desarrollo de los cereales.

En este estudio han aparecido diferencias significativas entre genotipos (tabla $5 \mathrm{a}$, apéndice), siendo mexa el de mayor longitud de sus tallos (tabla 1 y fig. 5), mientras que el resto de los genotipos no han diferido significativamente (tabla 1). entre los tres ambientes estudiados han existido diferencias significativas, presentando el secano las plantas de menor longitud, seguidas del regadío y de jerez (tabla 1 y fig. 5), ambiente que ha posibilitado el mayor crecimiento en longitud de las plantas, aunque sus diferencias frente al regadio han sido menores que frente al secano. para el conjunto de ambientes y genotipos la altura de la planta ha presentado una relación estadísticamente significativa con el rendimiento por ha (regresión 2) y con el peso medio por grano, aunque ésta última de menor magnitud (regresión 3). 


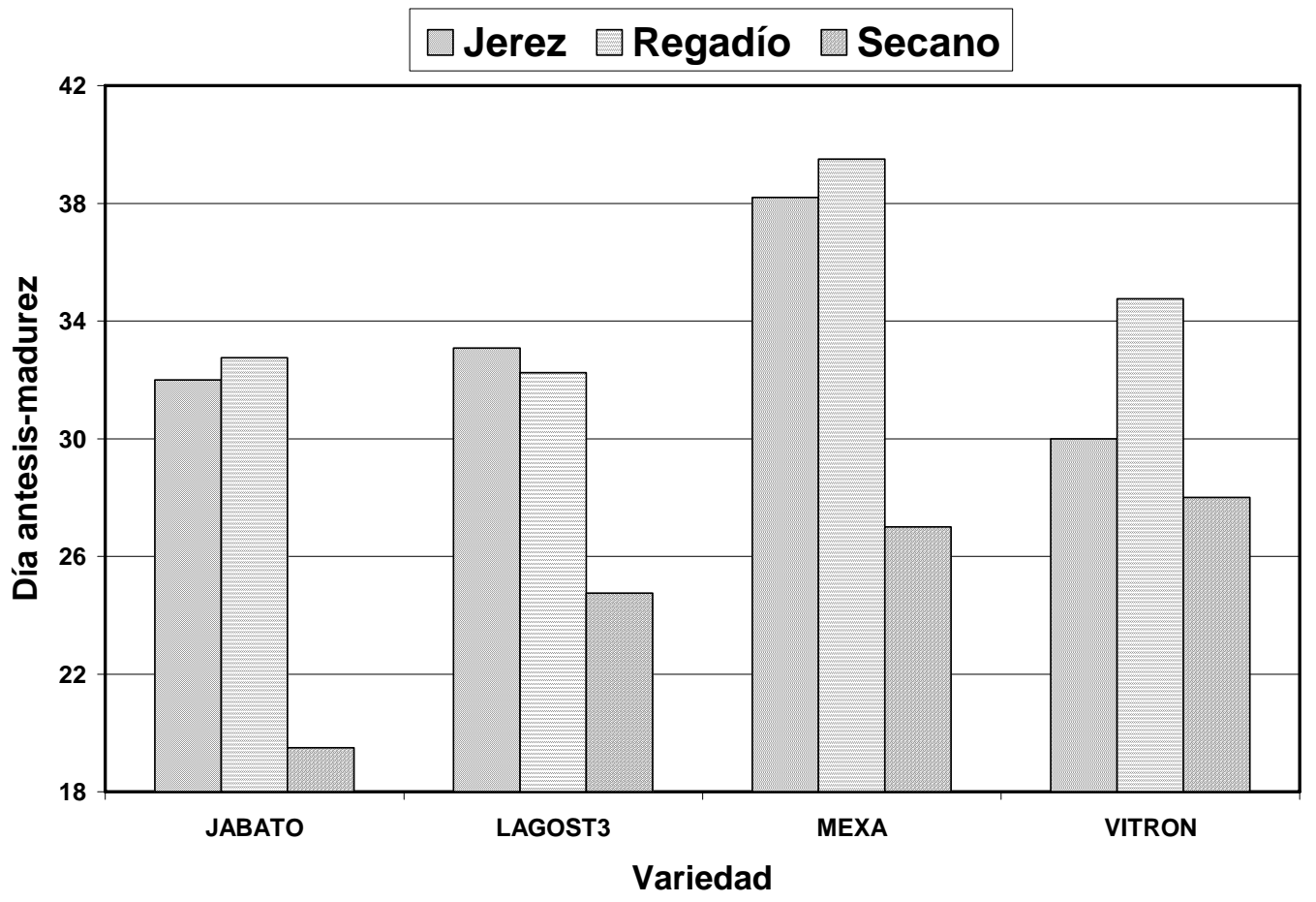

Fig. 3. - Valores medios de la duración del llenado (días antesis a madurez) por variedad y ambiente

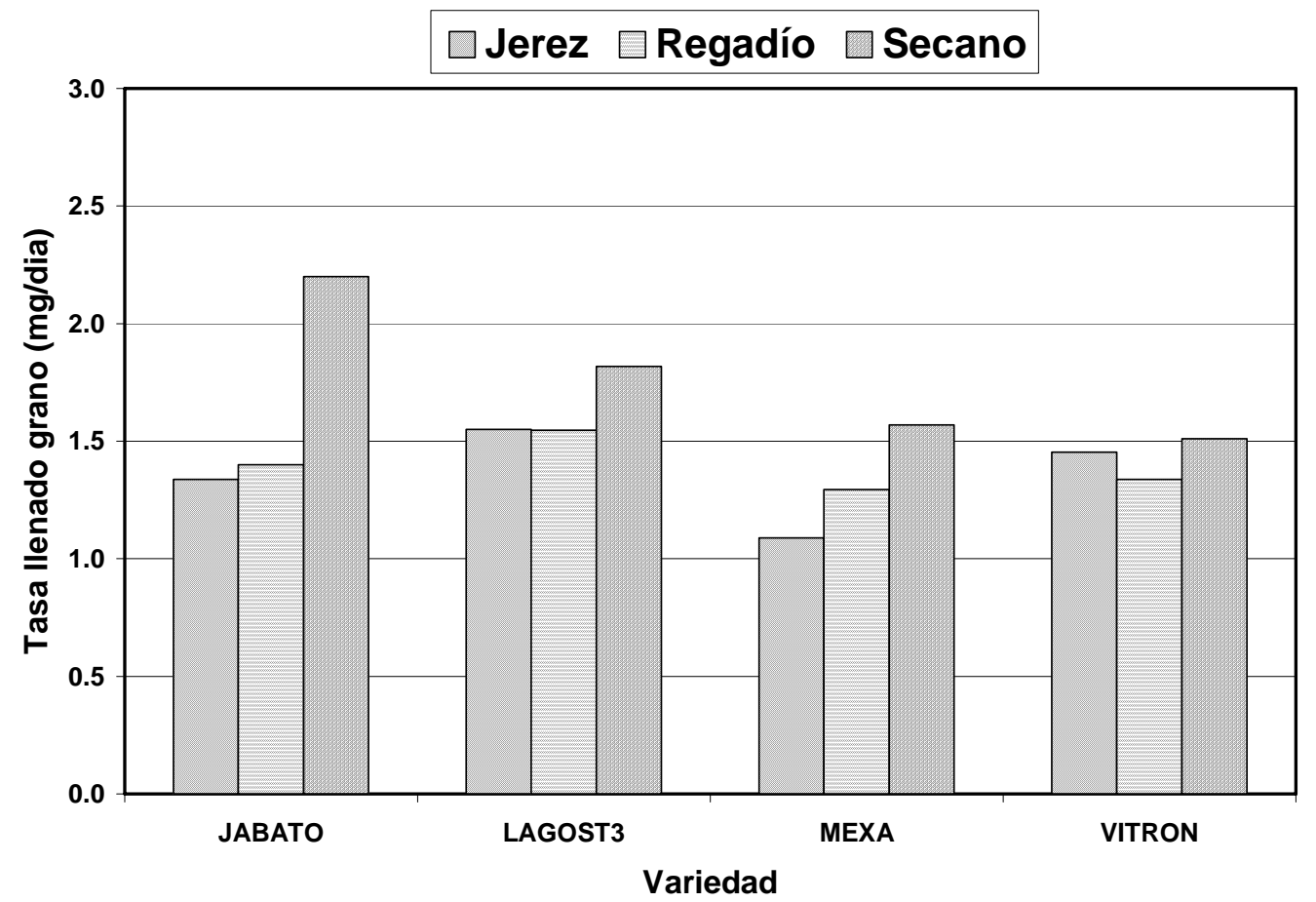

Fig. 4. - Valores medios de la tasa de llenado del grano por variedad y ambiente. 
Regresión 3.Rendimiento y peso medio del grano.

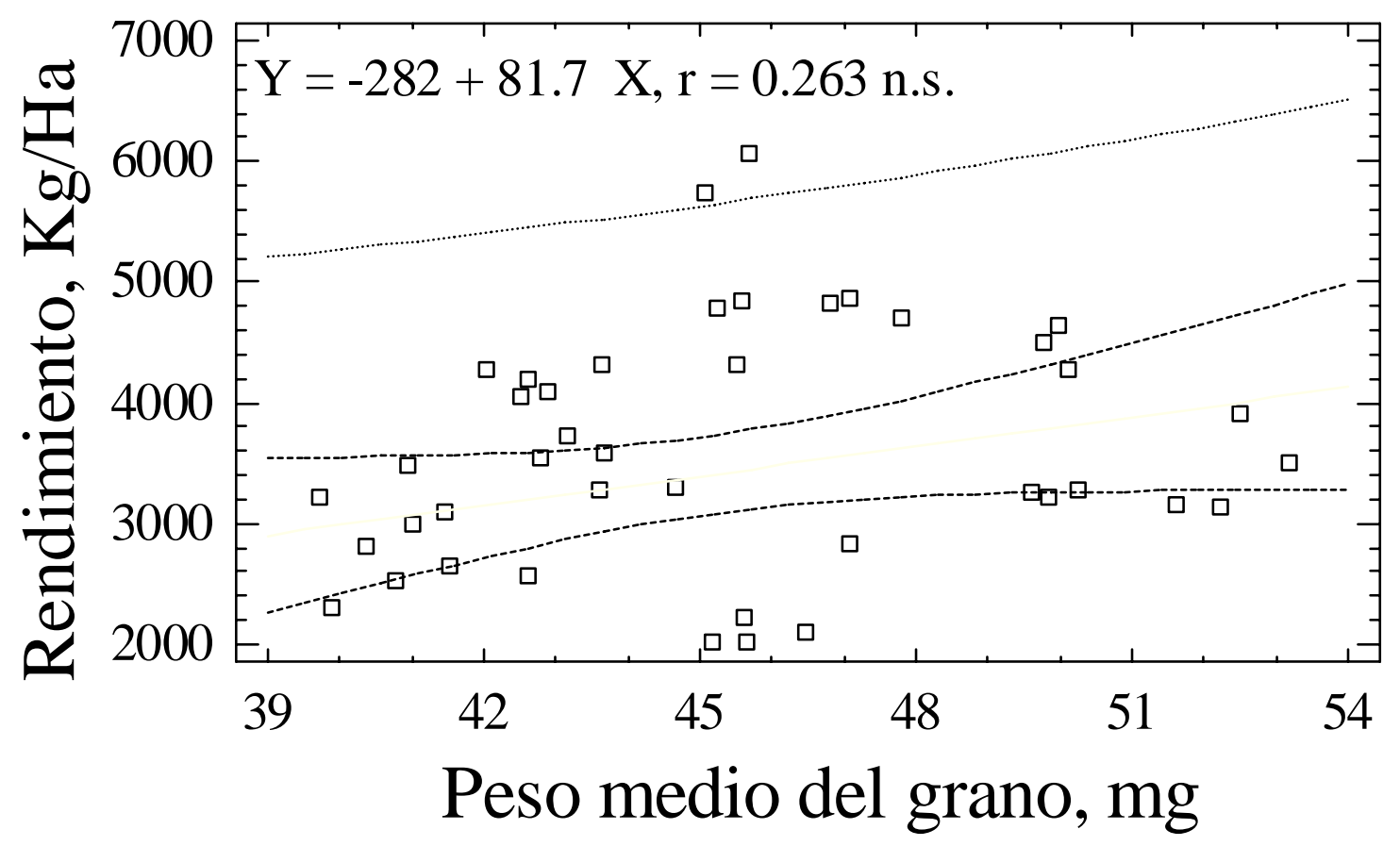

Regresión 4. Rendimiento y contenido en proteína del grano.

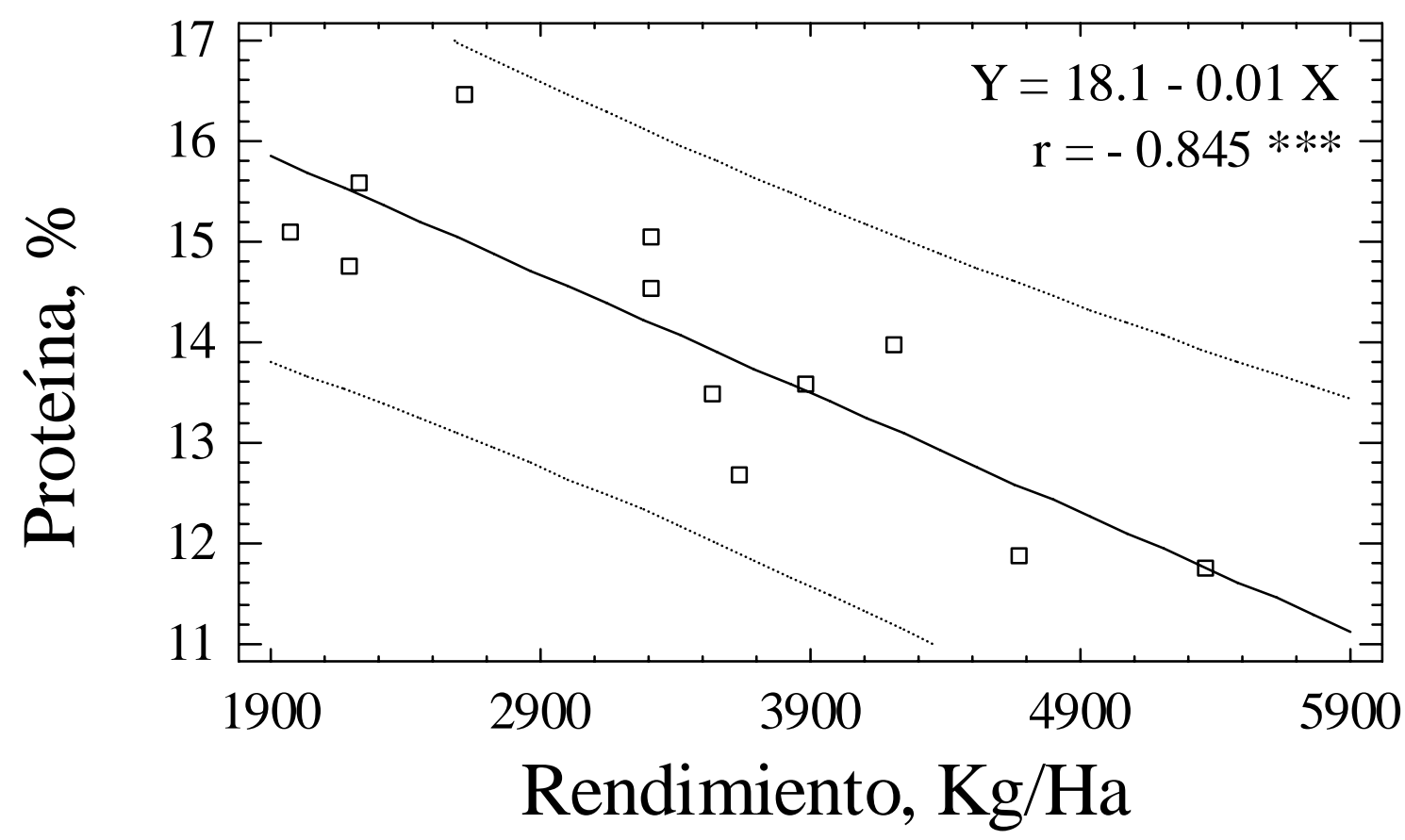




\subsection{Contenido y cosecha de proteinas.}

En la tabla 2 se presentan los porcentajes de proteínas encontrados en el grano de los diferentes genotipos y ambientes, así como la producción de proteína por ha. en las tablas 6a y 7 a (apéndice) se encuentran los correspondientes análisis de varianza, y en las figuras 6 y 7 sus valores medios.

\subsubsection{Contenido de proteinas del grano.}

El porcentaje de proteínas ha variado significativamente entre genotipos y ambientes, correspondiendo, en promedio, a lagost3 el mayor valor $(14,74 \%)$, con diferencias significativas frente a todos los demás (tabla 1). el genotipo con menor concentración proteica, en promedio, ha sido vitrón, con tan sólo $13,37 \%$, a su vez también significativamente diferente del resto. entre genotipos individuales, jabato en secano ha sido el de mayor contenido de proteínas (fig. 6).

Entre ambientes (tabla 1 y fg. 6), la menor concentración de proteínas la han presentado los granos cosechados en el regadio, el ambiente de mayor rendimiento, seguidos del secano de jerez $y$, por último, del secano de granada, el ambiente menos productivo y con mayor concentración de proteínas.

En nuestro estudio ha aparecido la conocida relación inversa entre rendimiento de grano y contenido de proteinas (regresión 4), descrita con frecuencia en la bibliografía, y que parece obedecer a un efecto de dilución de los compuestos nitrogenados a medida que incrementa la acumulación de compuestos amiláceos en el endospermo del grano, como se discutirá con detalle más adelante. además, el contenido de proteínas ha mostrado una correlación significativa con la tasa de llenado de los granos (regresión 5) y negativa con la duración del período de crecimiento del grano (regresión 6), indicando que las condiciones secas y calurosas favorecen el enriquecimiento en proteínas del grano de trigo, cuyas causas se discutirán posteriormente.

\subsubsection{Cosecha de proteina.}

A los efectos del valor alimenticio de los cultivos de cereales, es importante considerar no sólo el contenido o la calidad de las proteínas contenidas en el grano, sino también la cantidad de proteína producida por ha, lo que se conoce como 
REGRESIÓN 5. CONTENIDO DE PROTEÍNAS Y TASA DE

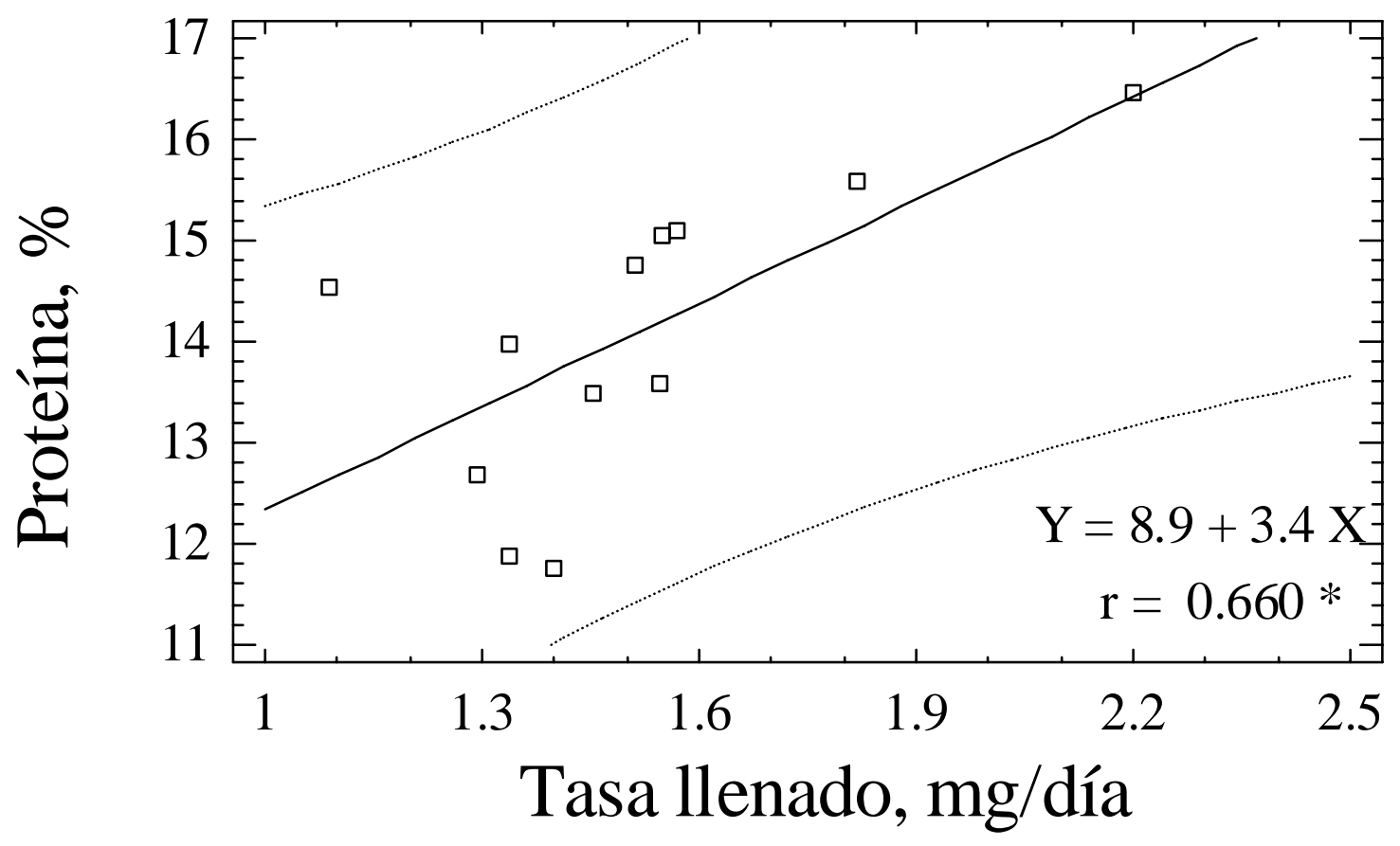

REGRESIÓN 6. CONTENIDO EN PROTEÍNAS Y DURACIÓN DE LLENADO DEL GRANO.

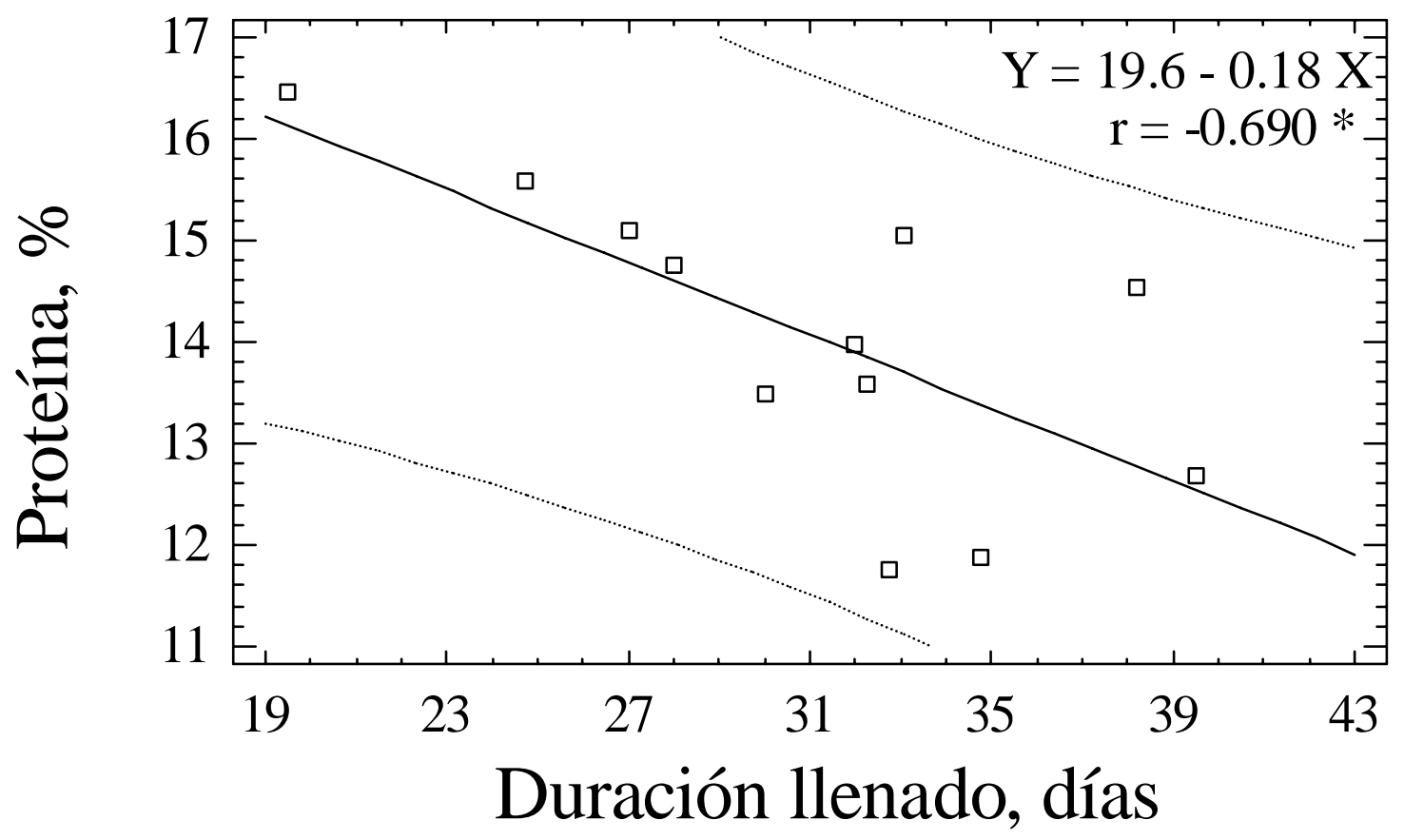


cosecha de proteína, y que depende tanto de la concentración de proteínas como del rendimiento de grano.

De la comparación entre genotipos (tabla 2) se comprueba que ha sido jabato, debido a su superior rendimiento de grano, el genotipo que mayor cantidad de proteína ha suministrado por ha, con diferencias significativas frente a los demás. entre el resto de genotipos, en promedio, no han aparecido diferencias significativas, ya que el elevado rendimiento de grano de vitrón ha compensado su menor concentración proteica, llevando su cosecha de proteína hasta valores estadisticamente similares a lagost3 y mexa (tabla 2). entre ambientes ha ocurrido algo similar (tabla 2 y fig. 7), de forma que el regadio ha compensado un menor contenido proteico con una mayor cosecha de grano, no presentando diferencias significativas en producción total de proteína con el ambiente de jerez, a pesar de que éste ha producido granos de mayor concentración proteica. en el secano, por el contrario, la superioridad en el contenido de proteínas no ha sido suficiente para compensar su bajo rendimiento de grano, por lo que ha obtenido la menor cosecha de proteína por ha.

De este estudio puede deducirse que bajo clima mediterráneo, la producción de proteína por ha depende en mayor medida del rendimiento de grano que de su contenido en proteínas. en efecto, mientras que la relación entre rendimiento de grano y de proteínas aparece altamente significativa (regresión 7), la regresión entre porcentaje de proteínas y cosecha de proteína ha sido menor e, incluso, de signo negativo (regresión $8)$.

\subsection{Peso especifico, contenido de azúcares reductores y contenido de cenizas.}

Al igual que para los parámetros anteriores, los análisis de varianza para estas características se encuentran en las tablas $8 \mathrm{a}, 9 \mathrm{a}$ y $10 \mathrm{a}$ del apéndice y la representación gráfica por genotipo y ambiente, en las figuras 8 a 10. la comparación por minimas diferencias significativas de sus valores promedio se encuentra en la tabla 2 . 
REGRESIÓN 7. RENDIMIENTO Y COSECHA DE PROTEÍNAS.

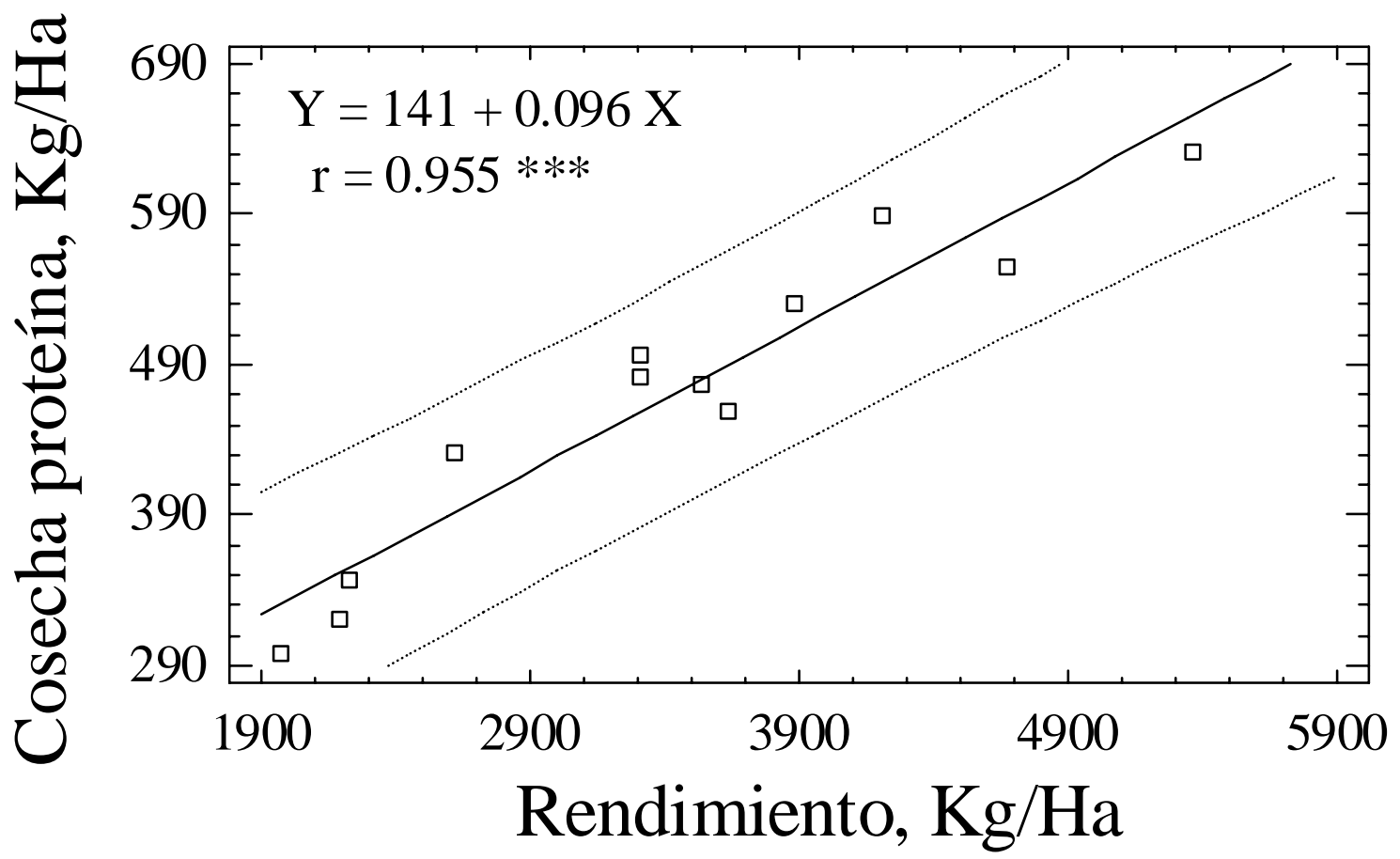

REGRESIÓN 8. CONTENIDO EN PROTEÍNAS Y COSECHA DE nחNTrítice

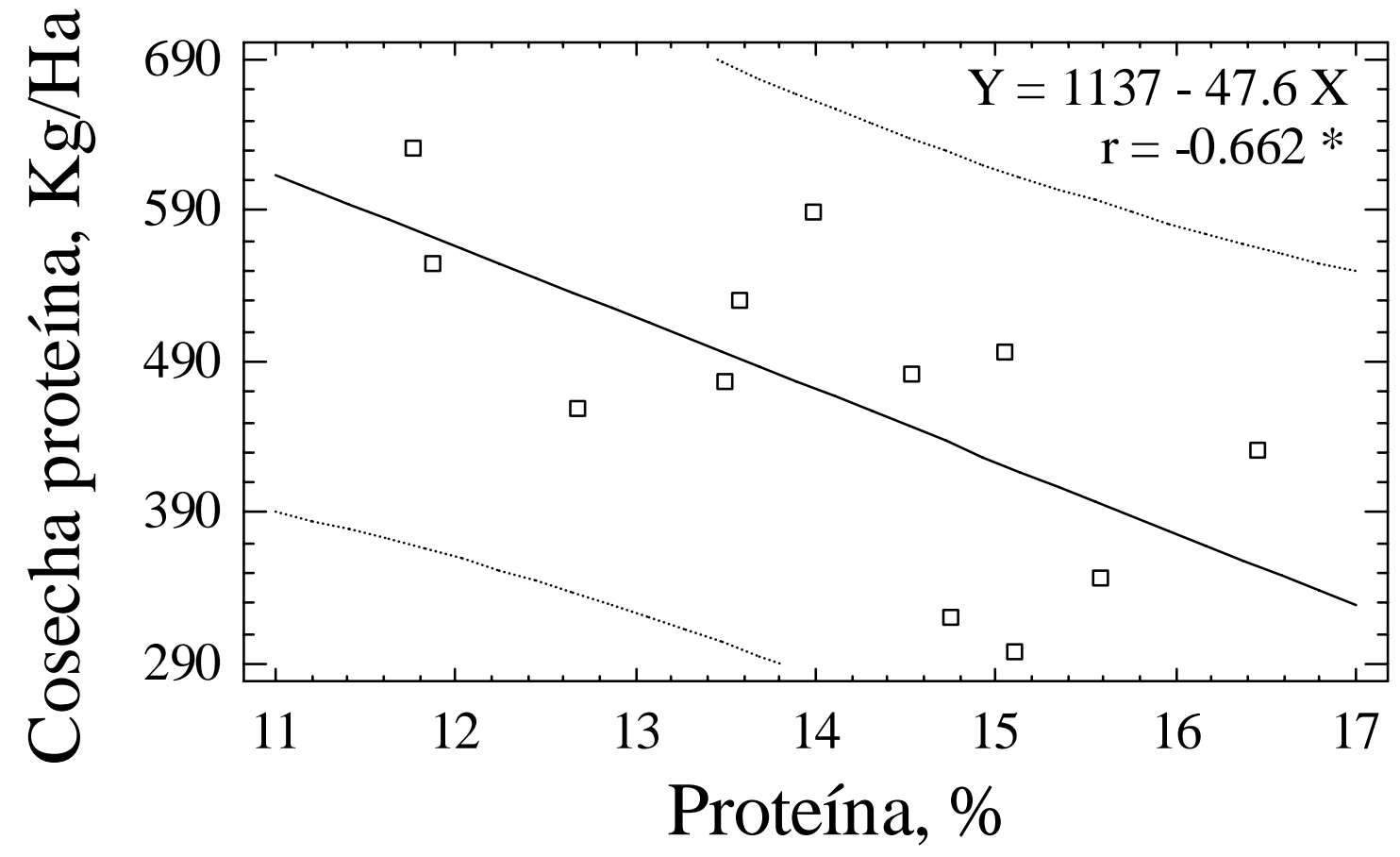




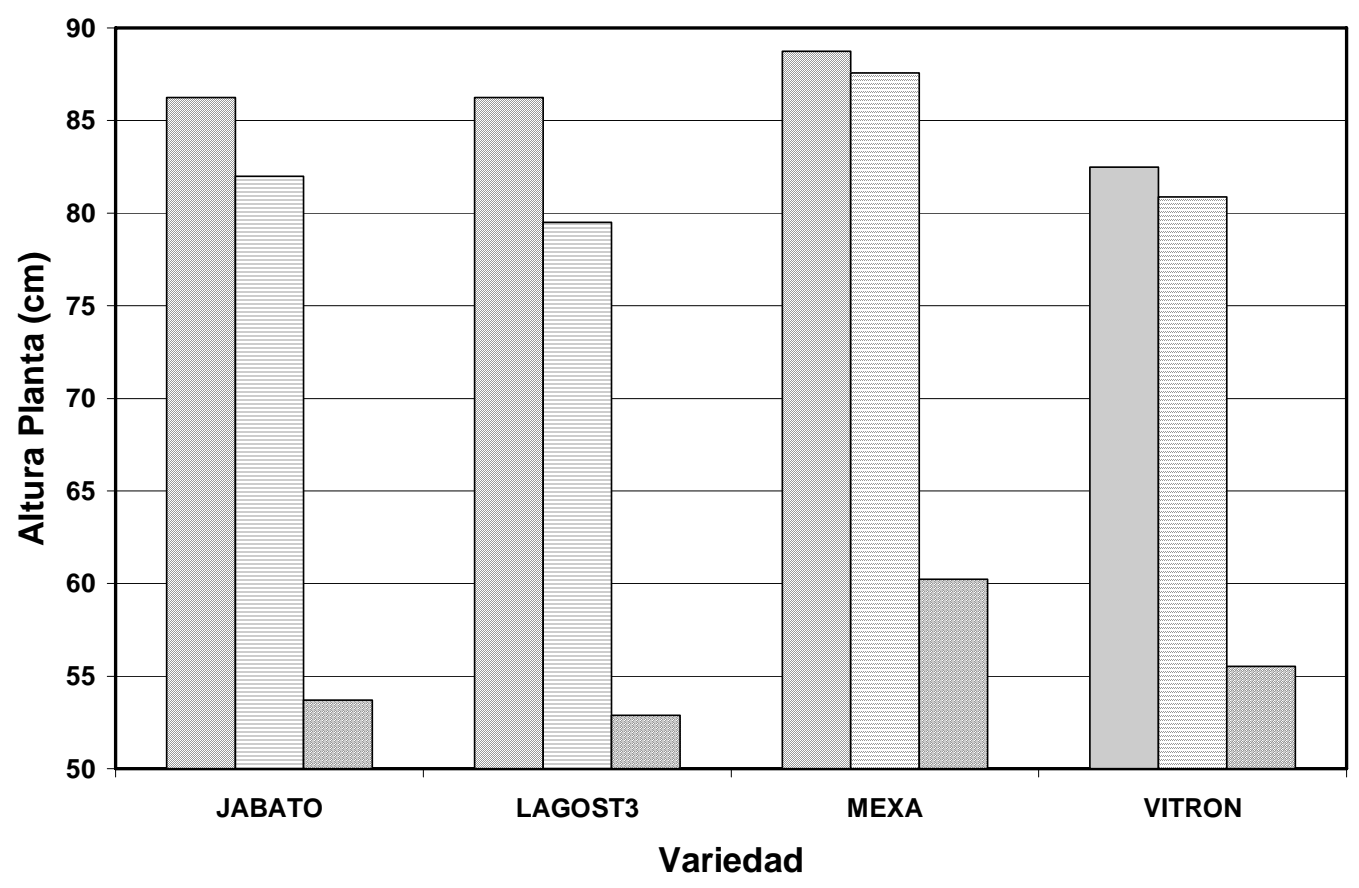

FIG. 5.- VALORES MEDIOS DE LA ALTURA DE LA PLANTA POR VARIEDAD Y AMBIENTE.

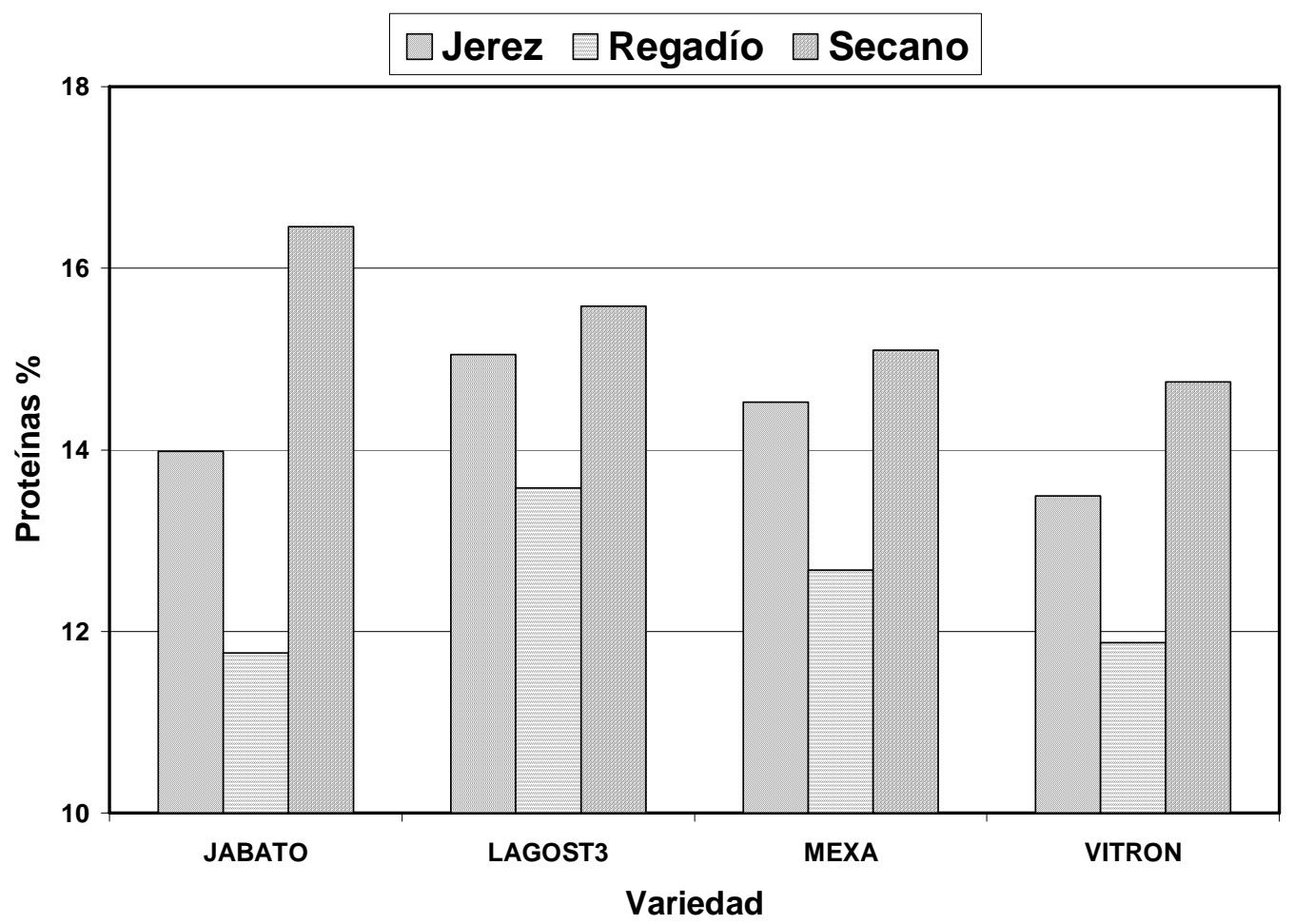

FIG. 6.- VALORES MEDIOS DEL CONTENIDO EN PROTEÍNAS DEL GRANO POR VARIEDAD Y AMBIENTE. 


\subsubsection{Peso específico o peso hectolitro.}

Representa la densidad aparente del grano o peso del grano por unidad de volumen en $\mathrm{kg} / \mathrm{hl}$. en nuestro ensayo (tabla 2) han existido diferencias significativas entre genotipos,

presentando jabato y vitrón, los genotipos de mayor rendimiento de grano, también los mayores valores de peso hectolitro. análogamente, ha sido mexa, el genotipo de menor rendimiento, el que ha presentado el valor mínimo de peso específico (tabla 2 y fig. 8). respecto a los ambientes, se comprueba (tabla 2 y fig. 8), que han sido los secanos, y especialmente jerez, los de mayor peso específico de los granos, mientras que el regadio ha presentado el valor mínimo. ello probablemente se ha debido a que el grano de los secanos, por su menor tamaño, deja menos vacíos intercalares y posee mayor densidad. en efecto, en nuestro estudio la relación entre el peso medio por grano y el peso hectolitro ha sido negativa, aunque no significativa $(\mathrm{r}=-0.357, \mathrm{n} . \mathrm{s} ., \mathrm{n}=12)$. entre el rendimiento y el peso específico no ha existido relación significativa en este estudio $(\mathrm{r}=0.090 \mathrm{n} . \mathrm{s} ., \mathrm{n}=12)$.

Dado que el valor mínimo exigido por la legislación española para la intervención es de $78 \mathrm{~kg} \mathrm{hl-1}$ para el trigo duro, puede concluirse que tanto los genotipos como los ambientes han producido un grano de valor tecnológico adecuado.

\subsubsection{Contenido de azúcares reductores.}

Entre genotipos no han aparecido diferencias significativas para este parámetro (tabla 9a) mientras que sí se han producido entre los ambientes. en efecto, el secano de jerez ha presentado los mayores contenidos de azúcares reductores, seguido del regadío y. finalmente, del secano de granada (tabla 2 y figura 9).

En nuestro estudio el contenido de azúcares reductores ha presentado una relación estadísticamente significativa con el rendimiento (regresión 9), de forma que la cantidad de azúcares en el grano ha aumentado paralelamente con el rendimiento, relación particularmente acusada a bajos niveles de producción de grano. con el peso medio por grano, sin embargo, no ha existido relación significativa $(\mathrm{r}=0,172$ n.s., $\mathrm{n}=12)$. 

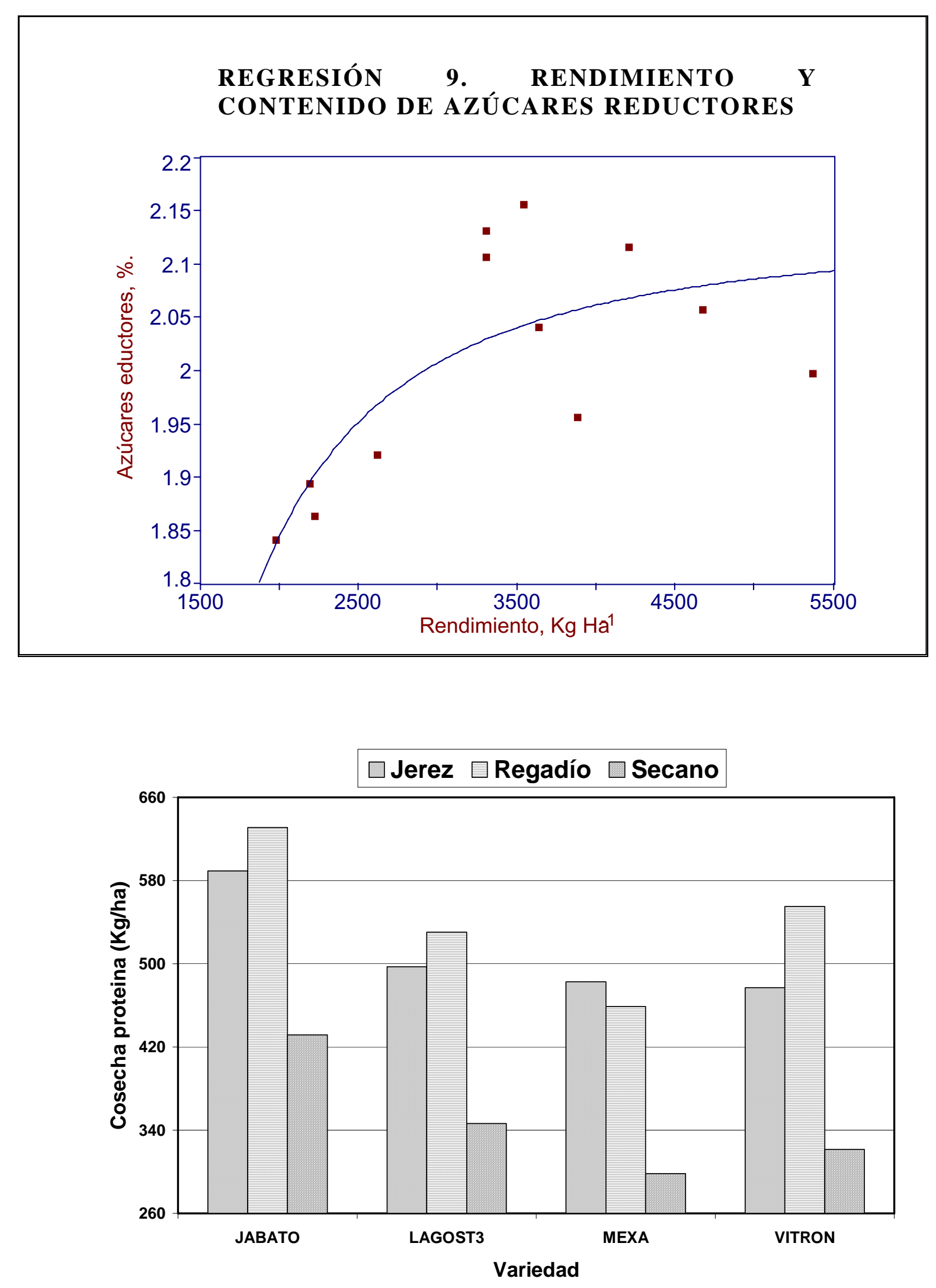

FIG. 7. VALORES MEDIOS DE LA COSECHA DE PROTEÍNAS POR VARIEDAD Y AMBIENTE 


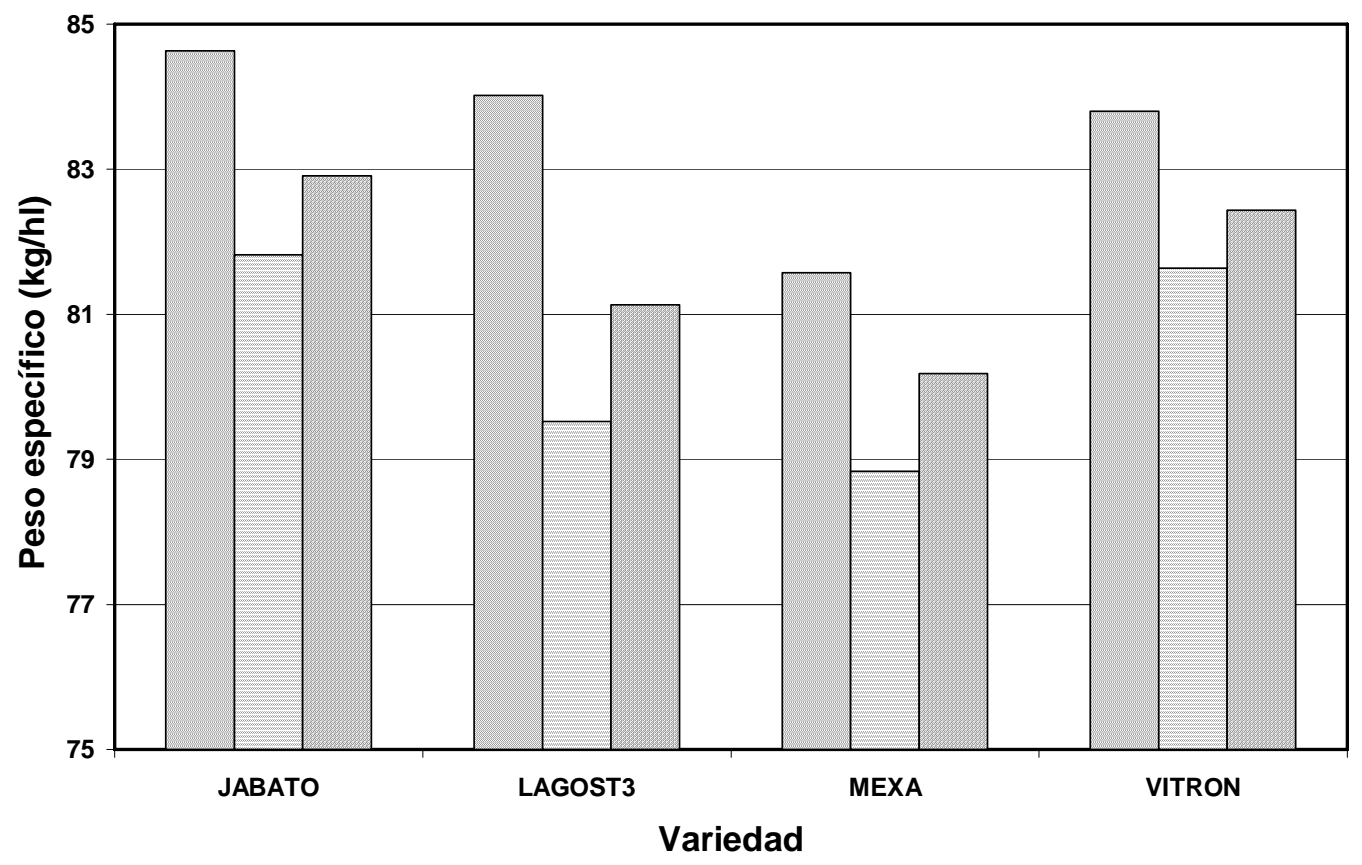

fig. 8.- valores medios del peso especifico del grano por variedad y ambiente.

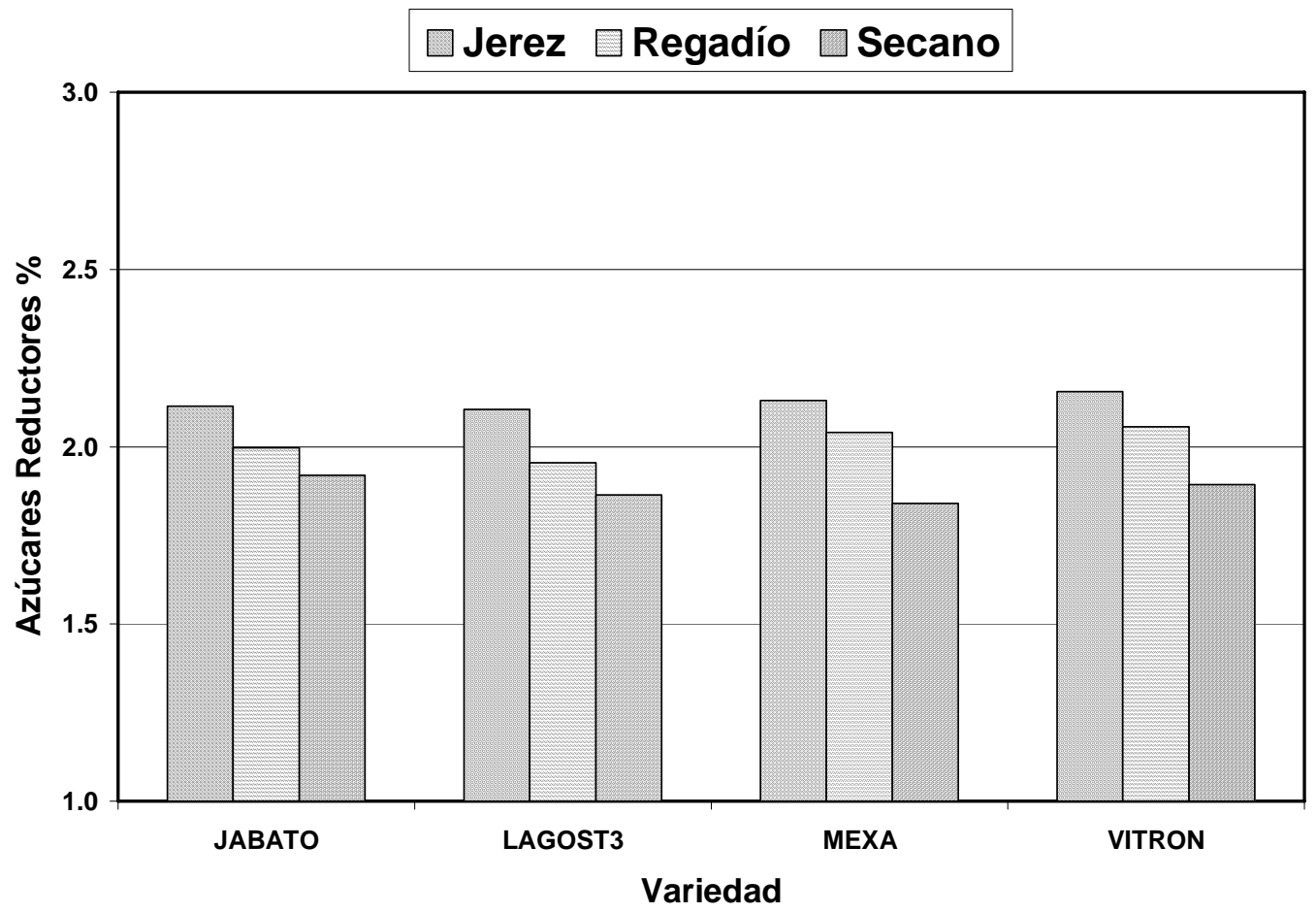

fig. 9.- valores medios de los azúcares reductores del grano por variedad y ambiente. 


\subsubsection{Contenido de cenizas}

Representa el contenido en sales minerales del trigo o de la harina, expresado en tanto por ciento. en nuestro estudio han aparecido diferencias significativas entre genotipos (tabla 2), correspondiendo a lagost3, en promedio, el contenido mayor de sustancias minerales, mientras el contenido de cenizas ha sido mínimo en el genotipo vitrón (tabla 2 y fig. 10). entre ambientes, al contrario que para el contenido de azúcares reductores, no se han presentado diferencias significativas en la cantidad de cenizas (tabla 10a), lo que indica que este carácter está intimamente ligado a la constitución génica, siendo menos influenciable por las condiciones de crecimiento. dado que son las zonas externas del grano y las capas periféricas del endospermo las que contienen mayor proporción de sales minerales, en nuestro estudio ha aparecido una estrecha relación significativa entre el peso medio por grano y su contenido en cenizas (regresión 10), mientras que la relación con el rendimiento o con el resto de parámetros de calidad no ha sido significativa en ningún caso.

\subsection{Otros parámetros relacionados con la calidad del grano.}

Como características físicas de la calidad del grano se han estudiado su vitrosidad, pigmentación e índice de sedimentación s.d.s. el análisis de la varianza para estas características se presenta en las tablas $11 \mathrm{a}$ a $13 \mathrm{a}$ del apéndice y su representación gráfica por genotipo y ambiente en las figuras 11 a 13 .

\subsubsection{Vitrosidad.}

La vitrosidad o porcentaje de granos córneos y de sección translúcida indica la dureza y compacidad del grano, estando directamente relacionada con el rendimiento en sémola. a efectos prácticos, la vitrosidad se suele expresar como porcentaje de granos no vítreos o harinosos en la muestra (en realidad el valor complementario de la vitrosidad), notación que se seguirá en esta memoria.

Los resultados del análisis de la varianza indican (tabla $11 \mathrm{a}$, apéndice) que el porcentaje de granos harinosos no ha diferido significativamente entre genotipos, pero sí entre 


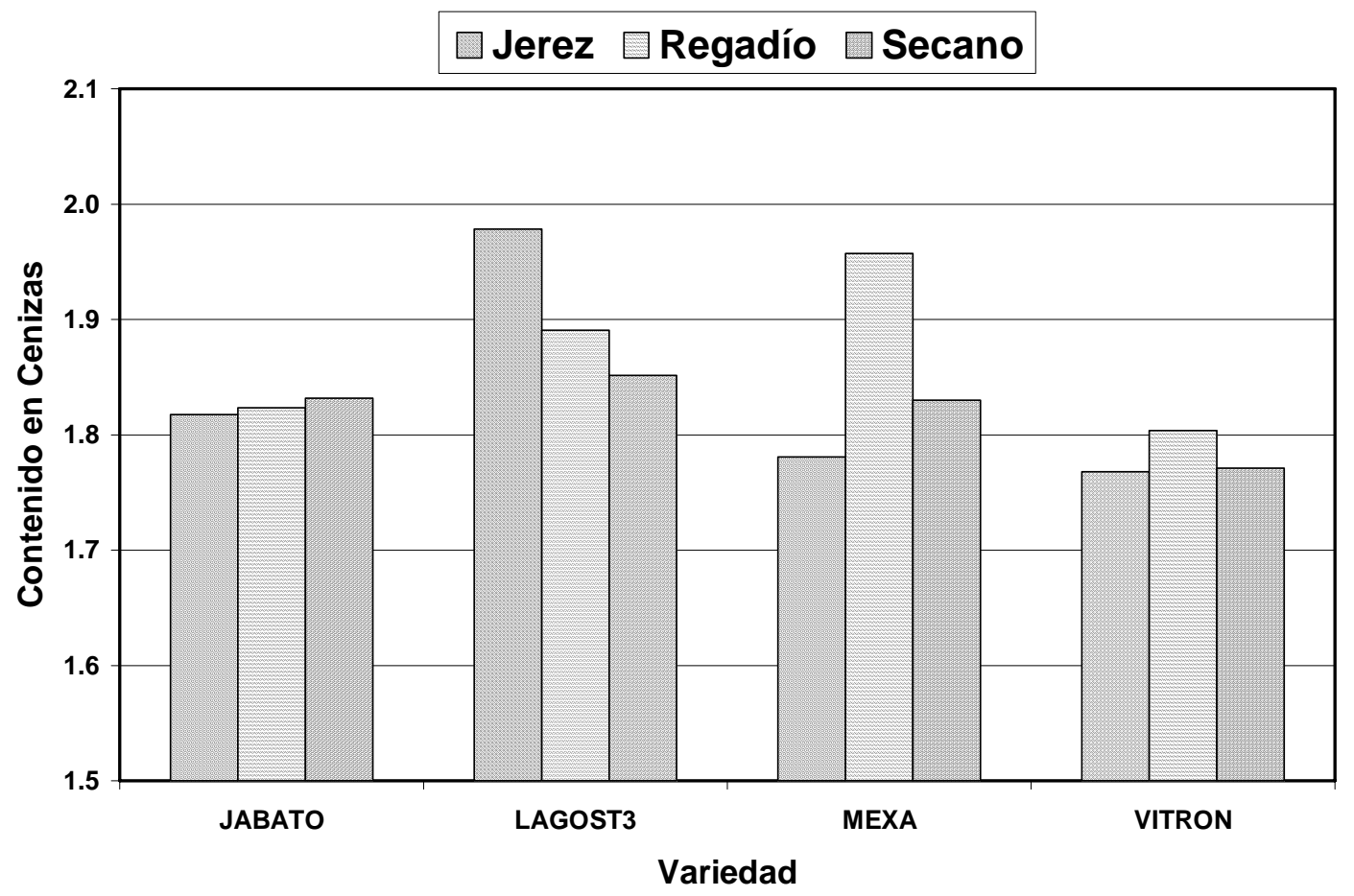

fig. 10.- valores medios del contenido de cenizas en el grano por variedad y ambiente.

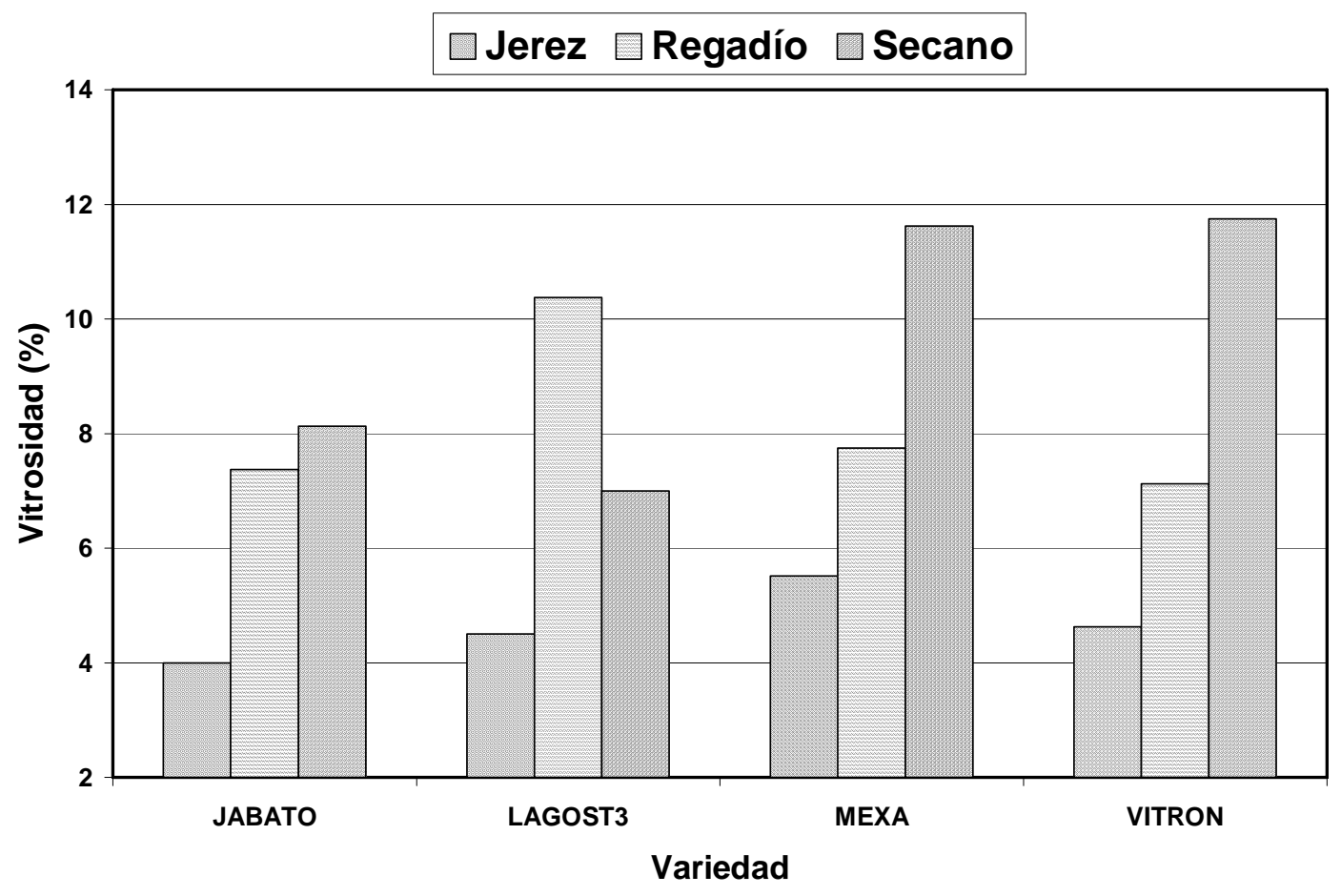

fig. 11.- valores medios de la vitrosidad (granos harinosos) en el grano de trigo por variedad y ambiente. 
ambientes. en efecto, el ambiente con menor índice de granos no vítreos ha sido jerez, seguido del regadio $y$, finalmente, del secano de granada (tabla 2 y fig. 11 ).

En este trabajo se ha encontrado una correlación inversa y altamente significativa entre el contenido de azúcares reductores en el endospermo del grano y el porcentaje de granos no vítreos (regresión 11), indicando que la textura cristalina del endospermo bajo condiciones mediterráneas aumenta cuando el grano acumula mayor cantidad de azúcares reductores en relación a las proteínas y carbohidratos totales.

\subsubsection{Pigmentación del grano.}

Otro factor de calidad de los trigos duros es la coloración del grano. es preferible el color amarillo ámbar que se debe a un elevado contenido de -caroteno, ya que confiere un color agradable a las pastas. la medida utilizada en este trabajo es relativa y, por tanto, adimensional.

En este trabajo se ha encontrado variabilidad estadística para la coloración del grano inducida tanto por el genotipo, como por el ambiente (tabla 12a, apéndice). así, los genotipos jabato y mexa (tabla 2 y fig. 11) han presentado granos de mayor coloración que lagost3 y vitrón, excepto en el ambiente de secano de granada. respecto a los ambientes, jerez ha producido los granos más pigmentados, con diferencias significativas frente a los dos ambientes de granada, entre los cuales no han aparecido diferencias estadísticas (tabla 2).

E1 análisis por regresión ha puesto de manifiesto la existencia de una relación inversa y significativa entre la pigmentación y el porcentaje de granos harinosos (regresión 12), indicando un mayor contenido de -caroteno en los granos de textura vítrea. como era de esperar, la pigmentación del grano ha presentado una relación positiva con el contenido de azúcares reductores (regresión 13), dada la relación negativa entre azúcares reductores y vitrosidad descrita en el apartado anterior.

\subsubsection{Indice s.d.s.}

Este indice mide la fuerza del gluten tanto de los trigos harineros como de los trigos duros, es decir las características de tenacidad de la masa y su aptitud panadera o para la fabricación de pastas. 
REGRESIÓN 10.- CENIZAS Y PESO MEDIO DEL GRANO.

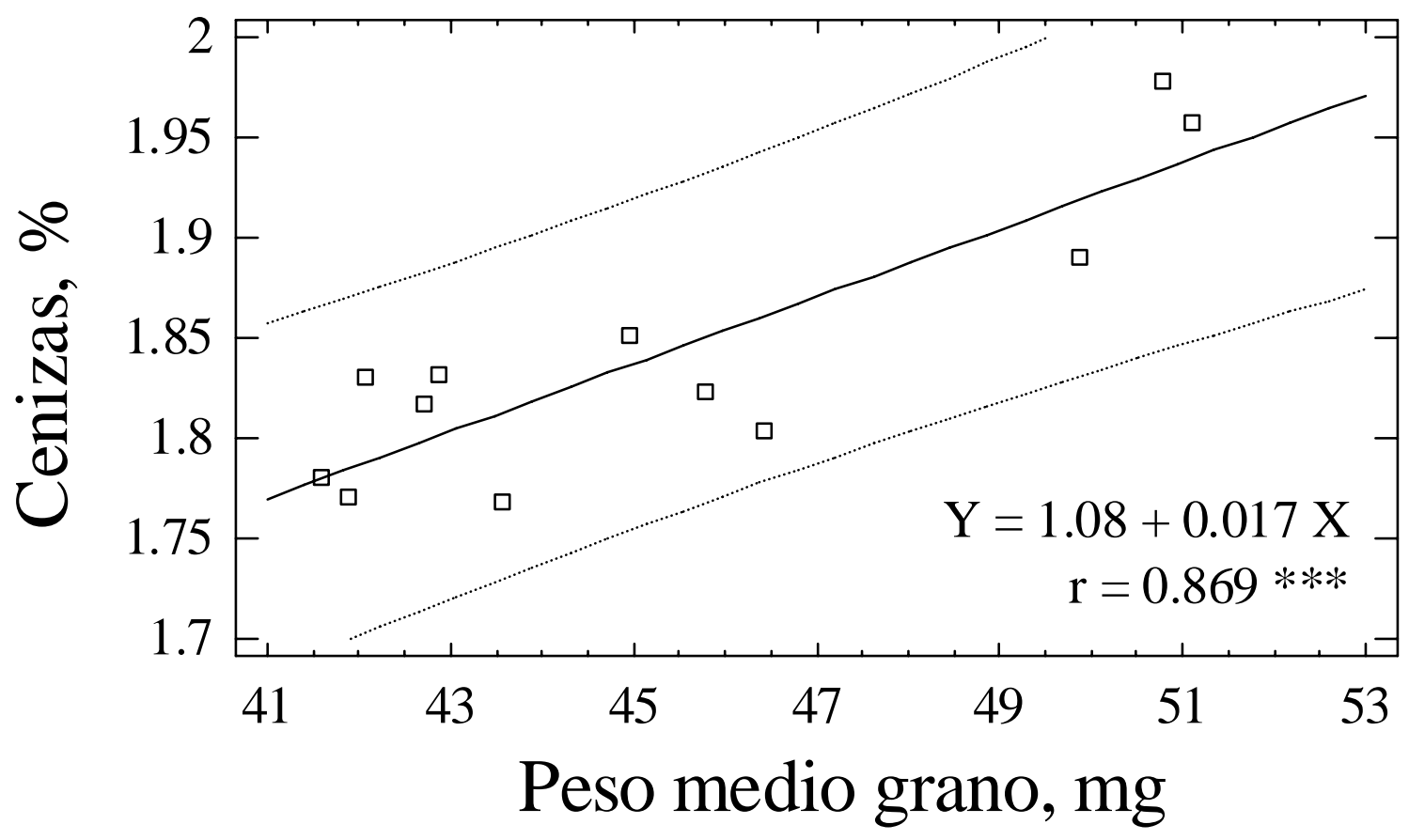

Regresión 11. - Azúcares reductores y vitrosidad del grano

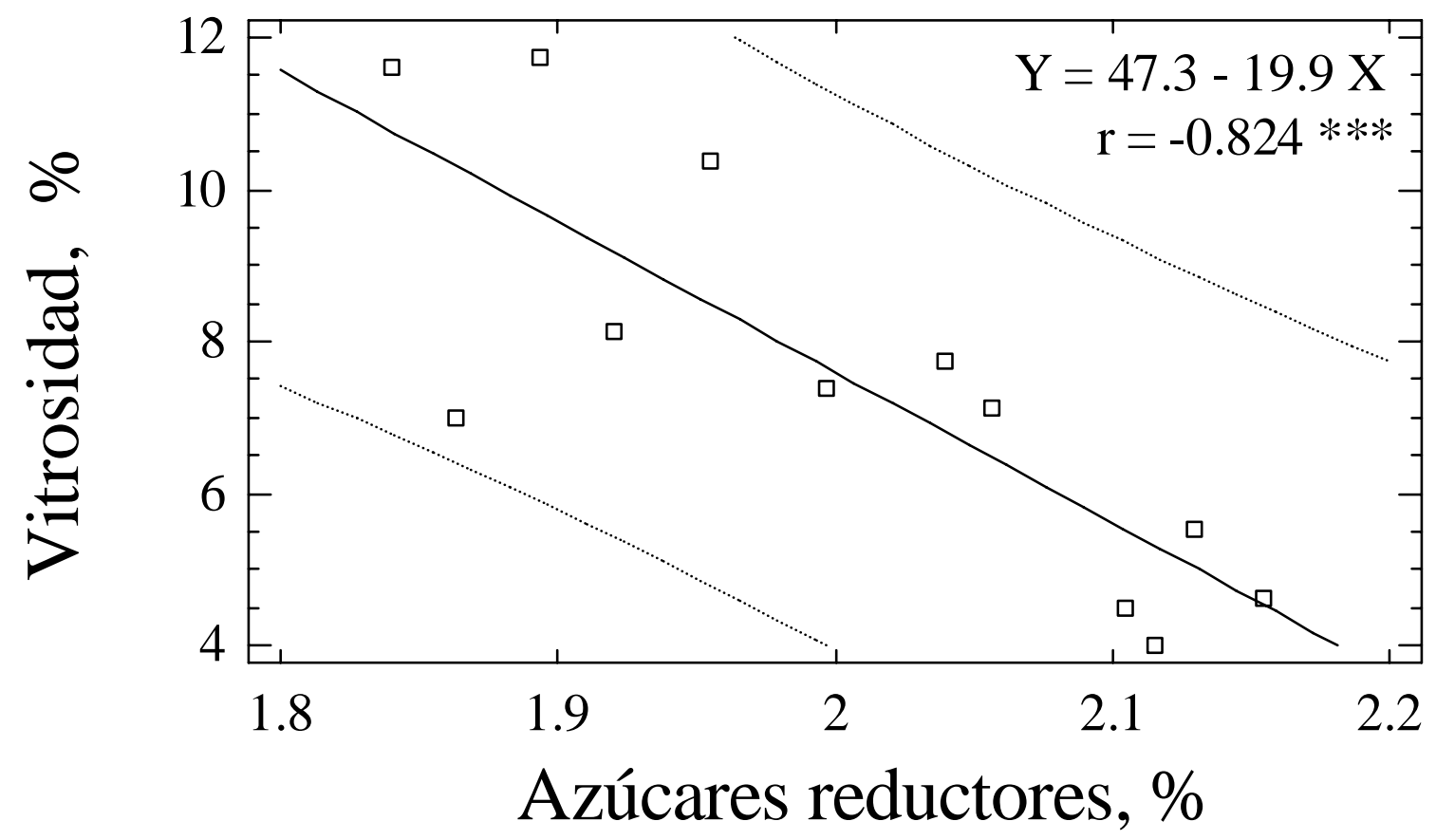


Regresión 12. - Pigmentación del grano y vitrosidad.

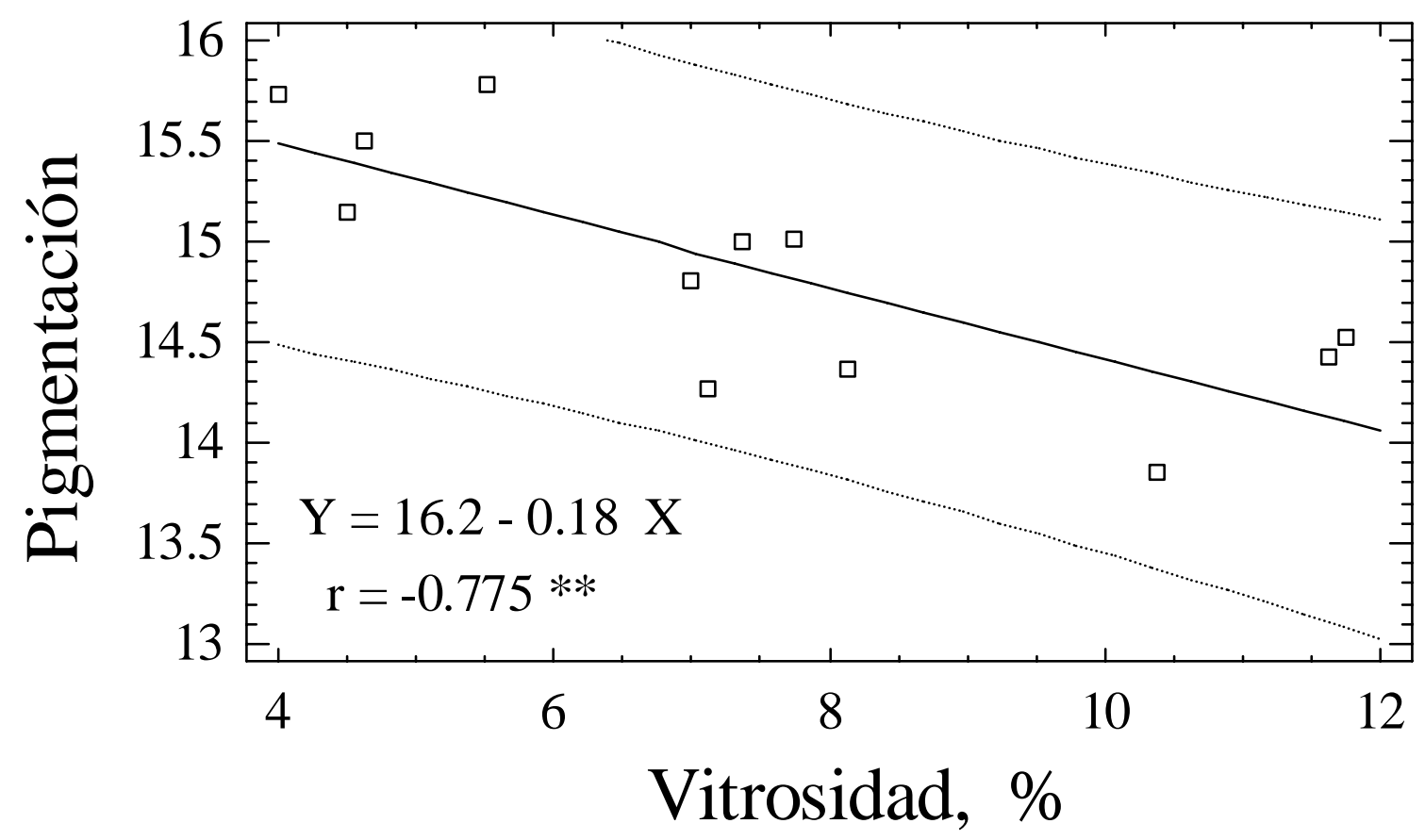

REGRESIÓN 13.- AZÚCARES REDUCTORES Y PIGMENTACIÓN DEL GRANO.

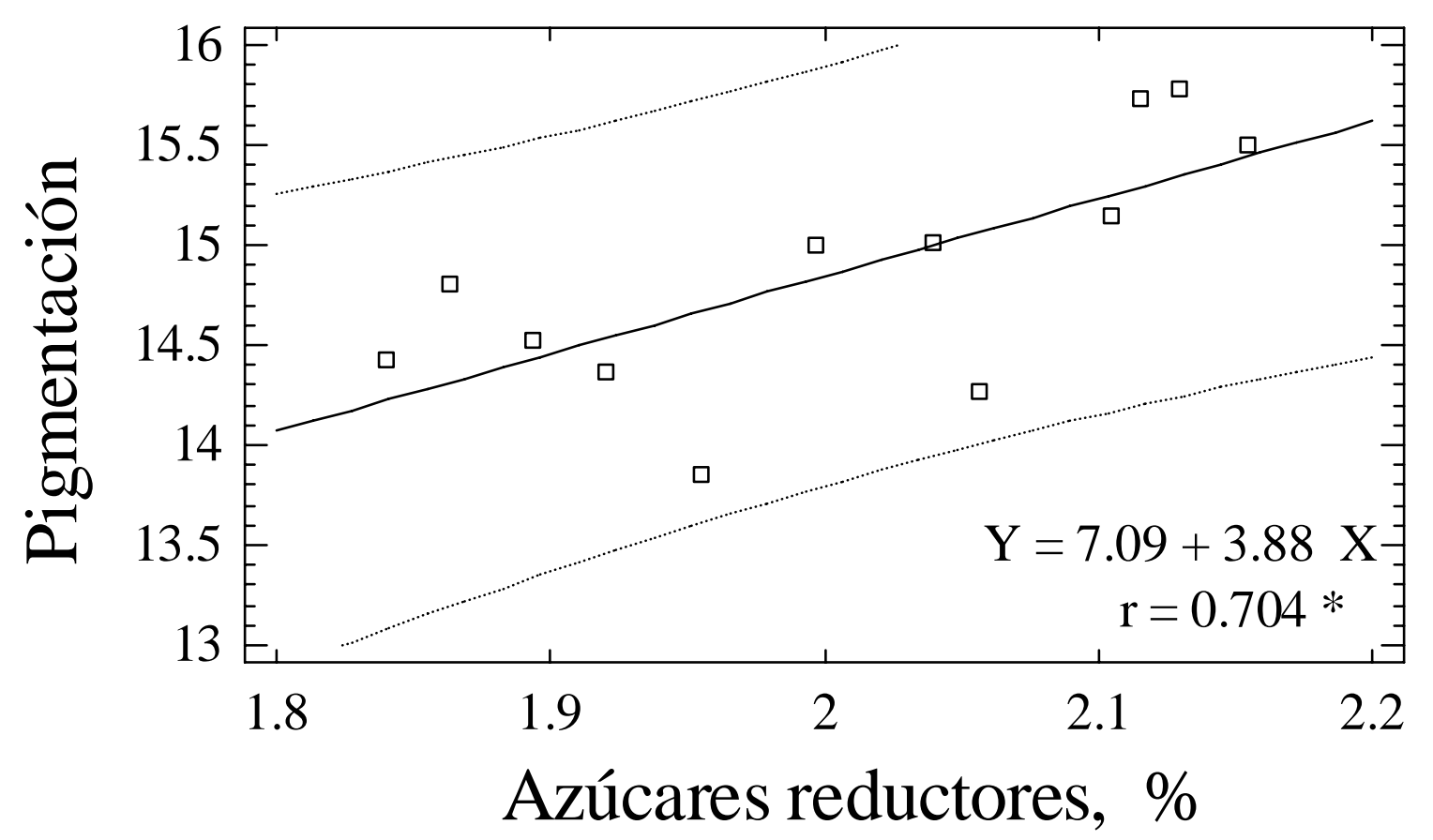




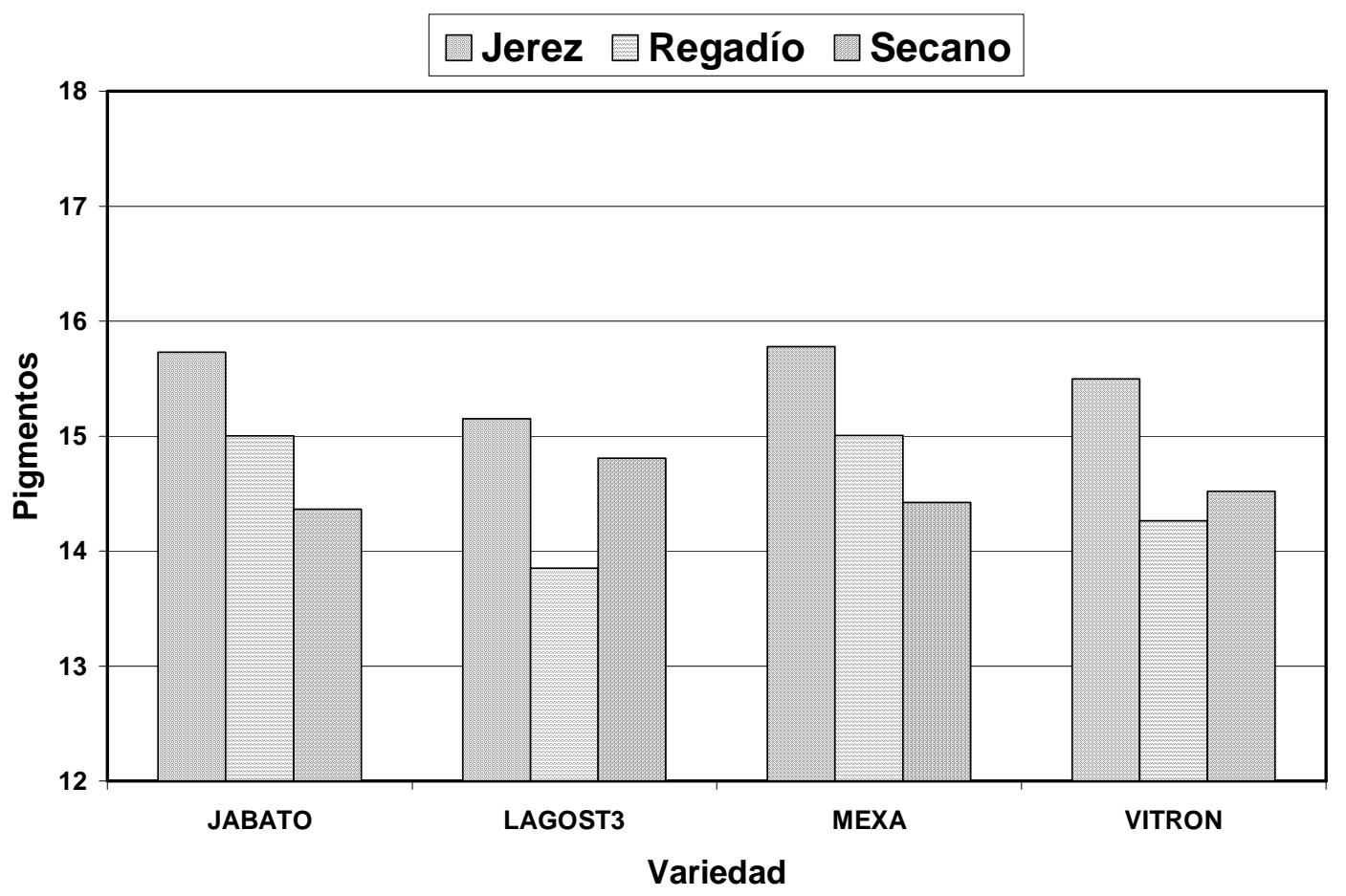

fig. 12.- valores medios de la pigmentación en el grano por ambiente y variedad.

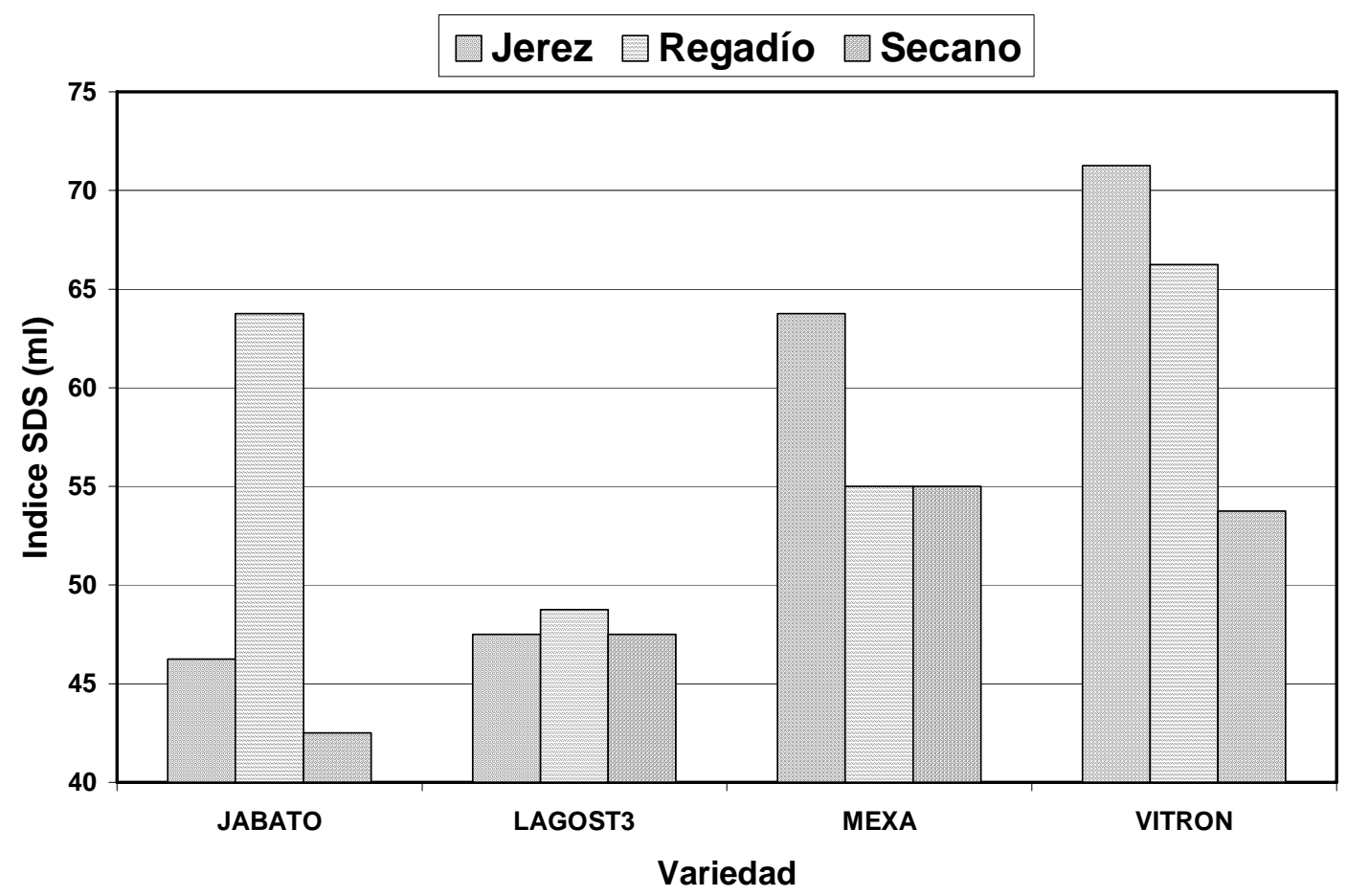

fig. 13.- valores medios del indice de sedimentación s.d.s. en el grano por variedad y ambiente. 
Entre los genotipos utilizados en este trabajo han aparecido diferencias significativas para el indice s.d.s, así como entre los ambientes estudiados (tabla 13a). de esta forma, el genotipo vitrón ha presentado el mayor valor s.d.s, con diferencias significativas frente a mexa, genotipo que, a su vez, ha diferido significativamente de lagost3 y jabato, los genotipos con menor indice s.d.s (tabla 2). entre los ambientes, jerez y el regadio han presentado mayor s.d.s que el secano (tabla 2).

En el conjunto de ensayos, el índice s.d.s ha presentado una elevada correlación negativa con el contenido de proteínas del grano (regresión 14), señalando que bajo nuestras condiciones experimentales un mayor contenido de proteínas determina una menor fuerza de la masa establecida mediante el indice s.d.s.

\subsection{Análisis por componentes principales}

Este análisis se ha realizado con objeto de obtener una visión simultánea de las relaciones entre las variables estudiadas y detectar aquellas combinaciones que expliquen más adecuadamente la variabilidad existente en los caracteres considerados.

Inicialmente el análisis se realizó con todas las variables estudiadas, explicando los cuatro primeros componentes principales el $81.9 \%$ de la variación total $(40.4,21.6,11.4 \mathrm{y}$ $8.5 \%$, para los ejes $1,2,3$ y 4 , respectivamente). sin embargo, el examen de la proyección de cada eigenvector sobre los correspondientes ejes, aconsejó eliminar del análisis las siguientes variables: peso medio por grano, peso específico y cenizas, dada su escasa representación sobre los dos ejes 1 y 2 , los más importantes para explicar la variación total.

En un segundo análisis sin estas variables, con sólo los tres primeros componentes principales se explica ahora el $81.5 \%$ de la variación total $(53,17.1$ y $11.4 \%$, respectivamente). de esta forma, la proyección de los datos sobre los planos determinados por los ejes 1 y 2 y 1 y 3 permite resumir la mayor parte de la información contenida en las variables analizadas. no obstante, y dado que en este estudio la mayor parte de la variabilidad es explicada por los ejes 1 y 2 (70.1\%), será su representación gráfica la que se discuta en detalle. 
REGRESIÓN 14.CONTENIDO EN PROTEÍNAS E INDICE DE SEDIMENT ACIÓN.

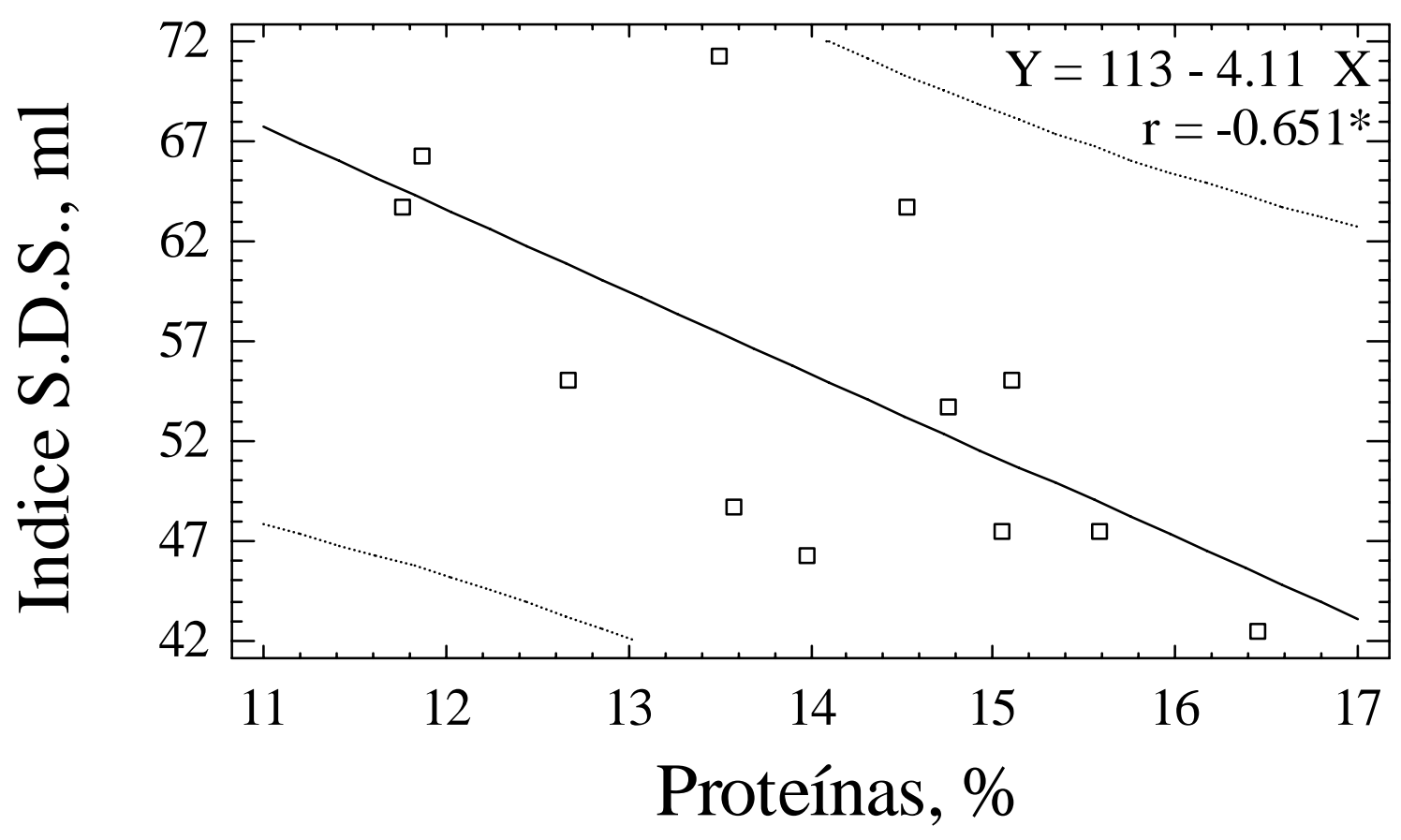

Fig. 14. - Representación de los eigenvectores obtenidos en el análisis por componentes principales.

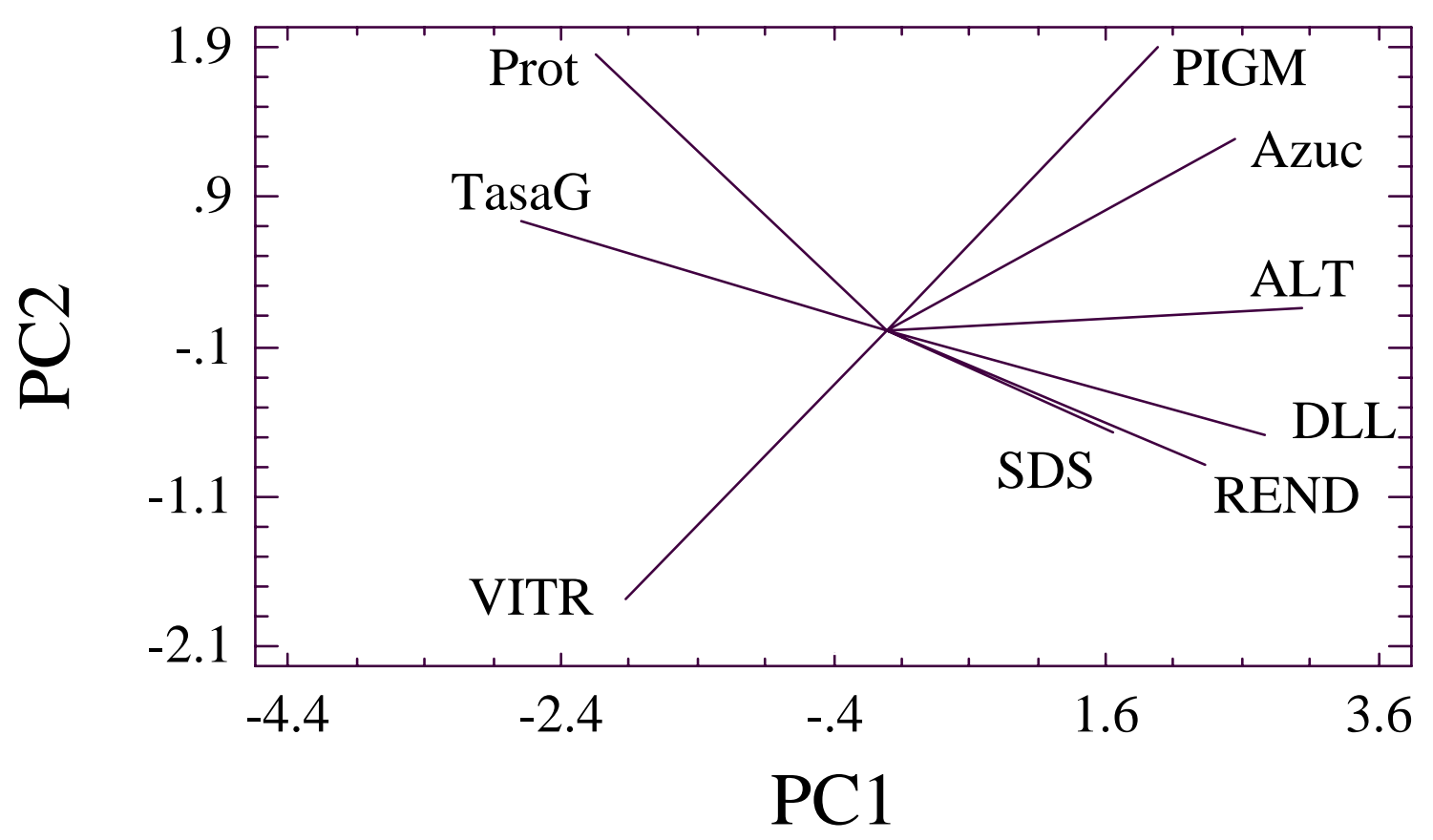


La fig. 14 recoge la representación de los eigenvectores para las variables utilizadas en el análisis. la longitud de la proyección de cada eigenvector sobre el eje de cada componente principal (pc1 y pc2) mide la carga (eigenvalor) de su influencia sobre ese eje, mientras el coseno del ángulo entre dos vectores es inversamente proporcional a su correlación estadística. el componente principal 1 estuvo relacionado directamente con la altura de la planta, el rendimiento, la duración del período de llenado del grano, y el índice s.d.s; y negativamente con la tasa de llenado de los granos. los incrementos en el componente principal 2 se asociaron con aumentos en el contenido en proteínas, en pigmentación del grano y en azúcares reductores, estas últimas características también con una fuerte proyección sobre el eje pc1. la vitrosidad del grano aparece negativamente relacionada con los dos ejes de los componentes principales. el análisis confirma las relaciones estadísticas directas encontradas entre altura de la planta y rendimiento, azúcares reductores y pigmentación, y tasa de llenado de los granos y proteína; y la relación inversa entre azúcares reductores y pigmentos con la vitrosidad. asimismo, el análisis advierte sobre la existencia de nuevas asociaciones directas entre rendimiento, indice s.d.s y duración del llenado del grano, que pudieran haber pasado inadvertidas en el análisis por correlación simple.

La fig. 15 representa la proyección de las medias de las 36 diferentes combinaciones entre variables (genotipo, ambiente y bloque), sobre el plano formado por los dos primeros ejes. se puede comprobar como el pca discrimina perfectamente entre los tres ambientes, suministrando tres nubes de puntos sin solapamiento. el análisis demuestra, asimismo, cómo jerez ha sido, entre los tres ambientes ensayados, el que ha presentado una mejor combinación de las variables estudiadas, ya que sus valores medios se proyectan más arriba en los dos ejes principales (pc1 y pc2). el ambiente de regadío se ha comportado de manera intermedia para el conjunto de variables, con una proyección de sus valores medios en la zona negativa del eje pc2. el secano, finalmente, tiende a situar sus valores medios en la zona negativa de ambos ejes, aunque con una fuerte tendencia a responder a incrementos en la componente principal 2, causada por su elevado contenido de proteínas y tasa de llenado de los granos, variables con una alta proyección sobre el eje pc2, como se ha discutido. 


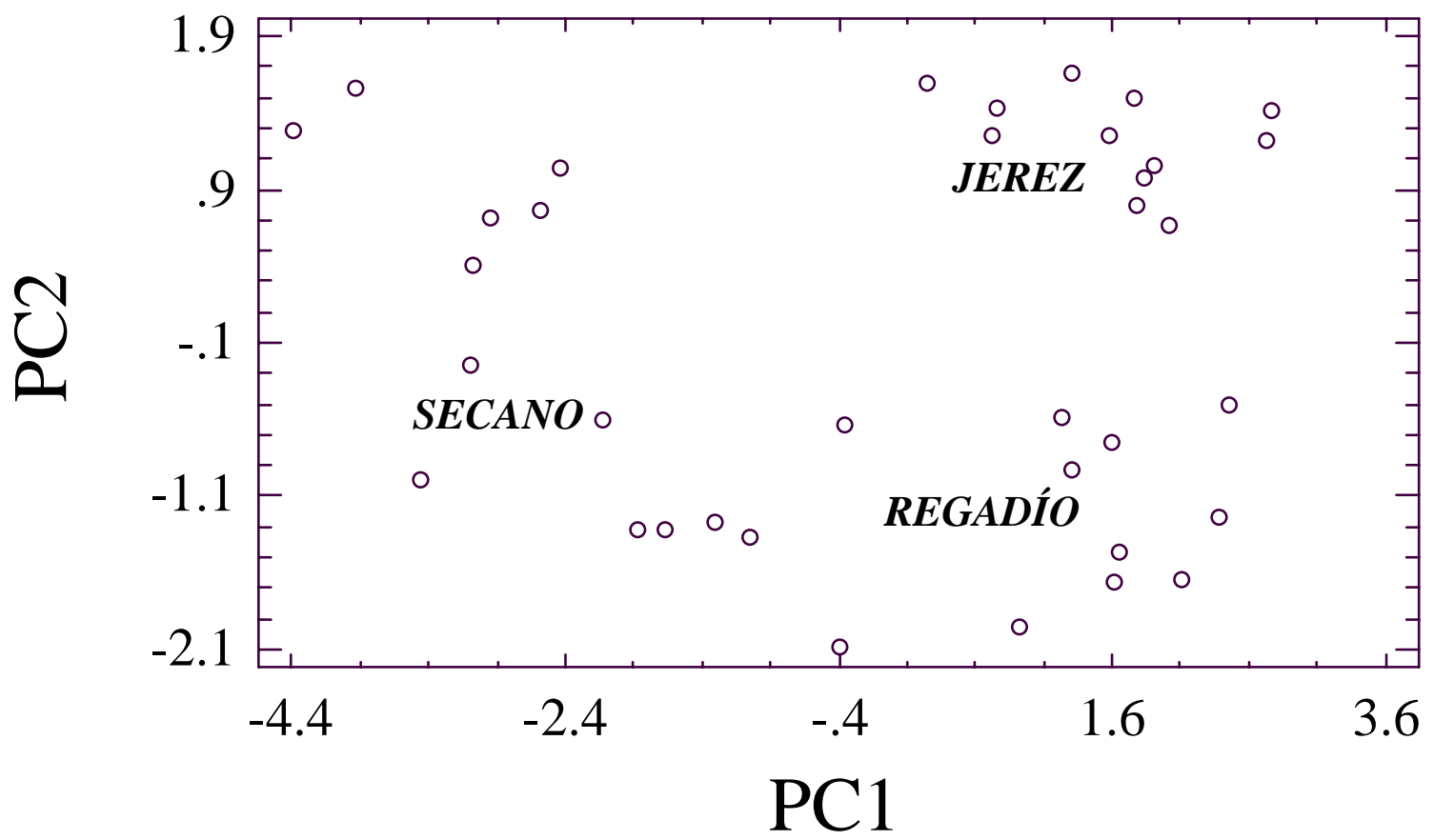

Fig. 15. - Representación de los eigenvalues obtenidos en el análisis por componentes principales. 


\section{Discusión.}

En el conjunto de ensayos, los genotipos más productivos han sido Jabato y Vitrón, con rendimientos medios superiores a $3450 \mathrm{Kg} / \mathrm{Ha}$. E1 genotipo menos productivo ha sido Mexa, que no ha llegado a alcanzar los $3000 \mathrm{Kg} \mathrm{Ha}-1$. Estas producciones están por encima de los rendimientos medios del año 1998 para la comunidad de Andalucía, que se situaron en $2600 \mathrm{Kg} \mathrm{Ha}-1$, y para la media nacional, que fue de $2170 \mathrm{Kg} \mathrm{Ha}-1$ (AETC, 1998). En España, Vitrón y Jabato son de las variedades de trigo duro más sembradas, representando el $10.65 \%$ y $8.62 \%$ del total nacional, respectivamente, mientras que Mexa supone un $3.77 \%$ (AETC, 1998). Entre ambientes, el regadio ha superado en un $22 \%$ la producción media de Jerez y en un $95 \%$ la del secano.

Resultados similares para la provincia de Granada son presentados por ElHani (1999), quien comparando 25 genotipos de trigo duro de diversa resistencia a la sequía durante dos campañas agrícolas, encuentra que fueron Jabato y Vitrón los de mayor rendimiento de grano, mientras que Mexa fue el de rendimiento más bajo. Igualmente, en sus ensayos, el rendimiento bajo condiciones de irrigación superó al obtenido bajo condiciones de secano.

Respecto del peso medio por grano, en el presente trabajo se ha encontrado variabilidad estadística entre genotipos y ambientes, siendo Lagost3 el genotipo de granos más pesados, con diferencias significativas frente a los demás, entre los cuales no han aparecido diferencias estadísticas. Para los ambientes, ha sido el regadio, por su mayor disponibilidad hídrica durante la maduración del cultivo, el que ha posibilitado la formación de granos de mayor tamaño, seguido de Jerez y, finalmente, del secano, cuyos granos han sido los de menor peso.

El crecimiento y llenado del grano del trigo puede dividirse en dos componentes: tasa de llenado y duración del mismo. En trigo duro hay variabilidad genética, tanto para la tasa como para la duración del llenado (Gebeyehou et al., 1982a). La tasa de llenado refleja la intensidad de las reacciones bioquímicas implicadas en la síntesis de almidón y proteínas, mientras que la duración refleja el programa de desarrollo del grano (Jenner et al., 1991).

Estos resultados concuerdan con lo encontrado en la presente Memoria, donde ha aparecido variabilidad estadística 
para la duración y la tasa de llenado, tanto entre genotipos como entre ambientes. De hecho, la variabilidad en la duración del llenado ha sido de casi 7 días entre los genotipos Jabato y Vitrón. Entre ambientes, esta variabilidad ha sido, incluso, mayor, presentando 10 días de diferencia entre el secano de Granada y el ambiente de regadio. Esto se ha debido a que las condiciones climáticas propias de la época de llenado en el área mediterránea (temperaturas a menudo por encima de $10 \mathrm{~s} 30^{\circ} \mathrm{C}$, alta intensidad luminosa, baja humedad relativa, poca disponibilidad de agua en el suelo, etc.), fuerzan a la planta a reducir drásticamente la duración del crecimiento de los granos (Turner y Nicolas, 1987). En trigo harinero se ha comprobado que por cada ${ }^{\circ} \mathrm{C}$ de aumento en la temperatura media diaria durante el llenado, este se reduce entre 2,8 y 3,1 días (Wiegand y Cuellar, 1981). De hecho, en trigo duro se ha encontrado una relación positiva entre la duración del llenado y el rendimiento de grano (Gebeyehou et al., 1982b), al igual que lo que ha ocurrido en nuestro estudio, donde la correlación entre duración del llenado $y$ rendimiento de grano ha sido positiva $y$ significativa $\left(\mathrm{r}=0.539^{* * *}, \mathrm{n}=48\right)$.

La tasa de llenado del grano aumenta con la temperatura. Sin embargo, este aumento en la velocidad no compensa la reducción en la duración del llenado (Wardlaw et al., 1989), por lo cual el tamaño del grano suele ser menor bajo condiciones secas y calurosas, en comparación con ambientes de regadío o zonas de clima templado. Ello ha ocurrido en el presente estudio, ya que aunque el secano ha presentado las mayores tasas de llenado del grano, el acortamiento del período de crecimiento ha determinado un menor peso medio por grano.

Además de disminuir el período de llenado del grano, la sequía y las altas temperaturas reducen el peso medio de los granos debido a acelerar la senescencia de las hojas y aumentar las pérdidas de carbohidratos por la respiración (Thorne, 1974; Wiegand y Cuéllar, 1981).

En ambientes como el Mediterráneo, durante el llenado del grano la fotosíntesis de la hoja no es la única fuente de asimilados, ya que la fotosíntesis de la espiga y la movilización de reservas del tallo constituyen también importantes fuentes de asimilados para el grano de los cereales (Thorne, 1974; Blum, 1988; García del Moral y Ramos, 1989). En condiciones de estrés hídrico terminal, la removilización de asimilados producidos antes de la polinización ejerce una notable contribución al rendimiento (del 70 al 95\%, dependiendo del grado de estrés 
hidrico) (Thorne, 1974; Evans et al., 1985; Blum, 1988). Las reservas de asimilados se localizan principalmente en las vainas foliares y en los tallos, lo que explica la correlación positiva entre la altura de la planta y el rendimiento, encontrada en el presente estudio y en otros realizados en la misma zona (Rojo y García del Moral, 1986; ElHany, 1999).

La calidad de la pasta obtenida del trigo duro depende de la cantidad de proteina presente en el endospermo. Aunque el contenido de proteína del grano de trigo duro puede llegar hasta el $20 \%$, en general se sitúa entre el 12 y el $14 \%$. Para obtener un producto de calidad aceptable es recomendable que el contenido de proteína sea moderadamente alto, esto es, igual o superior al $12 \%$. E1 contenido de proteína en el trigo duro está ligado al genotipo (posee una heredabilidad próxima a 0,60; Royo, comunicación personal,), pero está muy influido por el ambiente, en particular por la fertilización y condiciones ambientales durante la maduración de los granos (Nachit et al., 1995). Las variedades de trigo duro difieren en su habilidad para utilizar el nitrógeno, dependiendo tanto de la actividad nitrato-reductasa, como de la eficiencia en la translocación de los compuestos nitrogenados desde las partes vegetativas de la planta a los granos en crecimiento.

En este estudio, y para el conjunto de ensayos, el porcentaje de proteínas del grano ha mostrado la conocida relación inversa con el rendimiento. Aunque esta relación es un hecho bien establecido en los cereales, las causas fisiológicas que la determinan aún no están definitivamente aclaradas, dependiendo tanto de factores genéticos como ambientales (Nair y Chaterjee, 1990; Jenner et al., 1991). En efecto, la acumulación de proteínas en el grano de los cereales está controlada genéticamente, pero además se encuentra muy influenciada por otros factores, tales como tipo de suelo, prácticas de cultivo, condiciones climáticas (en especial temperatura y humedad), y dosis y época de aplicación de los fertilizantes nitrogenados. Ya que todas las proteínas de la planta se forman desde el $\mathrm{N}$ absorbido por las raíces, su disponibilidad en el suelo desempeña un papel dominante en la cantidad de proteínas que pueden ser almacenadas en el grano (Nair y Chatterjee, 1990). Temperatura y humedad son los factores climáticos que más influencian la acumulación de proteínas en los cereales, especialmente a través de modificaciones en la producción de grano (Nair y Chatterjee, 1990; García del Moral et al., 1995). 
En efecto, la acumulación de almidón y de proteínas en el grano de los cereales no son procesos sincrónicos, sino que, generalmente, la deposición de proteínas comienza antes, y finaliza más pronto, que la de almidón, estando ambos procesos controlados por factores distintos (Jenner et al., 1991). En general, las condiciones que promueven la senescencia de las hojas durante el llenado de los granos, tales como sequía o elevadas temperaturas, tienden a favorecer la acumulación de proteínas en detrimento del almidón, conduciendo a que el grano se enriquezca en proteínas.

Ello ha ocurrido en nuestro estudio, donde se comprueba que el porcentaje de proteínas del grano disminuyó de forma altamente significativa a medida que incrementó la humedad del suelo durante la maduración, condiciones que favorecieron la producción de grano. Ello indica que la humedad durante el crecimiento de los granos estimuló en mayor medida la producción de carbohidratos (al permitir una mayor duración e intensidad de la fotosíntesis), que la absorción y asimilación de $\mathrm{N}$ desde el suelo, que suele ser pequeña en este periodo, si no existen aportaciones tardias de este elemento. De esta forma, el aumento de almidón en el grano provoca una dilución de las sustancias nitrogenadas, disminuyendo el porcentaje de proteínas. Resultados similares se han encontrado en cebada (García del Moral et al., 1996) y triticale (García del Moral et al., 1995) en ambiente mediterráneo.

Las elevadas temperaturas durante la maduración, especialmente en el ambiente de secano de Granada, ejercieron un efecto contrario al de la humedad, disminuyendo de forma altamente significativa la producción de grano, pero incrementando su concentración de proteínas. Estos resultados parecen deberse a que la principal fuente de proteínas para el grano de los cereales con metabolismo fotosintético C3, la constituye la RuBisCO de las hojas (Nair y Chaterjee, 1990; Jenner et al., 1991), cuya hidrólisis se vería acelerada por el aumento de senescencia causado por la temperatura. Este fenómeno podría explicar la relación negativa encontrada entre la producción de grano y el porcentaje de proteínas en este y otros estudios, ya que un aumento de la senescencia foliar se traduciría en una disminución en la sintesis de carbohidratos, pero en un aumento de la proteína disponible para el grano, por hidrólisis de la RuBisCO. Por el contrario, un aumento de humedad durante la maduración, que retrasaría la senescencia de las hojas permitiendo una elevada duración del área foliar, favorecería la fotosintesis durante el llenado de los granos y el 
acúmulo de almidón. Ese retraso, sin embargo, provocaría que las proteínas foliares fuesen movilizadas en un momento en que la deposición de proteínas en el grano estuviese finalizando, lo cual podría limitar su acumulación.

Respecto a la cosecha de proteína, en este trabajo se ha puesto de manifiesto que, bajo clima mediterráneo, la producción de proteína por $\mathrm{Ha}$ depende en mayor medida del rendimiento de grano que de su contenido en proteínas, lo que está de acuerdo con resultados previos obtenidos en la zona para trigos duros, blandos y triticales (Rojo y García del Moral, 1986).

En este estudio se ha encontrado variabilidad genética y ambiental para el peso específico, la pigmentación del grano y el indice de sedimentación S.D.S. El contenido de azúcares reductores y la vitrosidad sólo han diferido significativamente entre ambientes, mientras que el contenido de cenizas sólo ha variado significativamente entre genotipos, pero no entre ambientes. Estos resultados coinciden, en general, con lo encontrado en ensayos multilocales en la cuenca mediterránea (Nachit et al., 1995), donde se han descrito valores altos para la heredabilidad del peso del grano, peso específico, contenido de pigmentos, cenizas, e índice de sedimentación; y valores mediobajos para el contenido de proteínas y vitrosidad (Nachit et al., 1995).

Los valores de peso específico obtenidos en este trabajo han diferido significativamente entre genotipos y ambientes, pero siempre por encima del mínimo exigido por la legislación española para la intervención (78 kg H1-1). Asimismo, el contenido de cenizas se ha mantenido por debajo del valor máximo aceptable para la industria semolera (2\%) y el porcentaje de granos no vítreos ha sido moderado (no llegando en ningún caso al $10 \%$ ), junto a valores aceptables de pigmentación e índice S.D.S., lo que permite concluir que tanto los genotipos como los ambientes han producido un grano de valor tecnológico adecuado.

No obstante y de acuerdo a los resultados del análisis por componentes principales, el ambiente que ha presentado un mejor equilibrio de los parámetros de rendimiento y de calidad estudiados, ha sido el de Jerez, seguido del regadío $y$, finalmente, del secano de Granada. 


\section{Conclusiones.}

De acuerdo a los objetivos y a los resultados presentados y discutidos, de este trabajo creemos que pueden extraerse las siguientes conclusiones:

Tanto el rendimiento por Ha como el peso medio del grano han resultado influidos significativamente por el genotipo y por el régimen hídrico, siendo superiores bajo condiciones de regadío que de secano.

La duración y la tasa de llenado de los granos han presentado variabilidad genotípica y ambiental, encontrándose inversamente relacionadas. De esta forma, para obtener un elevado peso medio por grano, los genotipos a cultivar en el área mediterránea deberían presentar una duración del período de llenado del grano superior a 30 días y una tasa de llenado de, al menos, $1.64 \mathrm{mg}$ por día.

En este estudio, el porcentaje de proteínas del grano ha mostrado la conocida relación inversa con el rendimiento de grano, debida a un efecto de dilución del nitrógeno a medida que aumenta la cantidad de almidón en el endospermo. Por ello, los secanos moderados como Jerez, resultan los más favorables, tanto para la producción de grano de trigo duro, como para su calidad tecnológica.

Respecto a la cosecha de proteína, en este trabajo se ha puesto de manifiesto que, bajo clima mediterráneo, la producción de proteína por Ha depende en mayor medida del rendimiento en grano, que de su contenido en proteínas.

En este estudio se ha encontrado variabilidad genética y ambiental para el peso específico, la pigmentación del grano y el índice de sedimentación S.D.S. El contenido de azúcares reductores y la vitrosidad sólo, han diferido significativamente entre ambientes, mientras que el contenido de cenizas sólo ha variado significativamente entre genotipos, pero no entre ambientes.

De acuerdo a los resultados del análisis por componentes principales, el ambiente que ha presentado un mejor equilibrio de los parámetros de rendimiento y de calidad, ha sido el de Jerez, seguido del regadío y, finalmente del secano de Granada. 


\section{7.- BIBLIOGRAFIA}

ACEVEDO, E.; CRAUFURD, P.Q.; AUSTIN, R.B. y PEREZ-MARCO, P. (1991): Traits associated with high yield in barley in lowrainfall environments. J. Agric. Sci., Camb., 116, 23-36.

AETC 1998. Encuesta de calidad de los trigos duros españoles. Cosecha 1998. Asociación Española de Técnicos Cerealistas Ministerio de Agricultura Pesca y Alimentación.

AUSTIN, R.B.; MORGAN, C.L.; FORD, M.A. y BLACKWELL, R.D. (1980). Contributions to grain yield from pre-anthesis assimilation in tall and dwarf barley phenotypes in two contrasting seasons. Ann. Bot., 45, 309-319.

BAKER C.K.; GALLAGHER, J.N. y MONTEITH, J.L. (1980): Daylength change and leaf appearance in winter wheat. Plant Cell Env., 3, 285-287.

BLUM, A. (1988). Plant breeding for stress environments. CRC Press, Boca Raton, Florida, USA.

BOOTH, M.R., EWART, J. A. D. (1970). Relationship between wheat proteins. J. Sci. Food Agric. 21, 187-192.

CAO, W. y MOSS, D.N. (1989): Temperature effect on leaf emergence and phyllochron in wheat and barley. Crop Sci., 29, 1018-1021.

CHEVAliER, P. , LINGLE S., E. (1983). Sugar metabolism in developing Kernels of wheat and barley. Crop Sci., 23, 272-277.

DALLOUL, A. (1980). Influence of the period of vernalization on 8 characteristics in winter $x$ spring crosses of wheat. Cereal Res. Comm., 8, 551-557.

DAVIDSON, D.J. y CHEVALIER, P.M. (1990): Preanthesis tiller mortality in spring wheat. Crop Sci., 30, 832-836.

DEL POZZO, A.H.; GARCIA-HUIDOBRO, J.; NOVOA, R. Y VILLASECA, S. (1987). Relationship of base temperature to development of spring wheat. Exp. Agric., 23: 21-30. 
DIKEMAN, e., pomeranz, i. y LAI, F.S. 1982. Mineral and protein content in hard red winter wheat. Cereal Chem., 59, 139.

ELHANI, s. (1999). Formación del rendimiento e identificación de parámetros fisiológicos de resistencia a la sequía en trigo duro (Triticum durum Desf.) bajo condiciones mediterráneas. Tesis doctoral, Universidad de Granada, 175 p.

ELLIS, R.H. y RUSSEL, G. (1984): Plant development and grain yield in spring and winter barley. J. Agric. Sci., Camb., 102, 85-95.

EVANS, L. T. y WARDLAW, I.F. (1976). Aspects of the comparative physiology of grain yield in cereals. Adv. Agron., 28, 301-359.

EVANS, L.T., WARDLAW, I.F. y FISCHER, R.A. (1983). Trigo. In: Fisiología de los cultivos, L.T. Evans (ed.), pp. 113-164, Hemisferio Sur, Buenos Aires.

finney, k.f., yamazaki, w.t., youngs, v.1. y rubenthaler, g.1. (1987). Quality of hard, soft, and durum wheats. In: Wheat and wheat improvement, E.G. Heyne (ed.), pp. 677-748.American Society of Agronomy, Madison.

FISCHER, R.A. Y WOOD, J.T. (1979). Drought resistance in spring wheat cultivars. III. Yield associations with morphophysiological traits. Aust. J. Agric. Res., 30, 1000-1020.

FLOOD, R.G. y HALLORAN, G.M. (1984). Temperature as a component of the expression of developmental responses in wheat. Euphytica, 33, 91-98.

FRANK, A.B. y BAUER, A. (1995). Phyllochron differences in wheat, barley, and forage grasses. Crop Sci., 35, 19-23.

GARCIA DEL MORAL, L.F. y RAMOS, J.M. (1989). Fisiología de la producción de grano. In La cebada. J.L. Molina-Cano (ed), pp. 137-178. Mundi-Prensa-MAPA., Madrid.

garcia del moral, m.b. y garcia del moral, 1.f. (1995). Tiller production and survival in relation to grain yield in winter and spring barley. Field Crops Res., 44, 85-93. 
GARCIA DEL MORAL, L.F.; RAMOS, J.M. y RECALDE, L. (1984). Tillering dynamics of winter barley as influenced by cultivar and nitrogen fertilizer: A field study. Crop. Sci., 24, 179-181.

GARCIA DEL MORAL, L.F.; RAMOS, J.M.; GARCIA DEL MORAL, M.B. y JIMENEZ-TEJADA, P. (1991): Ontogenetic approach to grain production in spring barley based on path-coefficient analysis. Crop Sci., 31, 1179-1185.

Garcia del Moral, L.F; Boujenna, A.; Yáñez, J.A. y Ramos, J.M. (1995) Forage production, grain yield, and protein content in dual-purpose triticale grown for both grain and forage. Agron J 87: 902-908.

García del Moral, L.F., García del Moral, M.B., Boujenna, A. y Ramos, J.M. (1996). Acumulación de proteínas en el grano de cebada en ambiente mediterráneo. In: : Nutrición Mineral de las Plantas en la Agricultura Sostenible, R. Sarmiento, E. O. Leidi, y A. Troncoso Eds.)., pp. 275-279, Junta de Andalucía, Sevilla,

GEBEYEHOU, G.; KNOTT, D.R. y BAKER, R.J. (1982a). Rate and duration of grain filling in durum wheat cultivars. Crop Sci., 22: 337-340.

GEBEYEHOU, G.; KNOTT, D.R. y BAKER, R.J. (1982b). Relationships among durations of vegetative and grain filling phases, yield components and grain yield in durum wheat cultivars. Crop Sci., 22: 287-290.

HAY, R.K.M. y KIRBY, E.J.M. (1991). Convergence and synchrony - a review of the coordination of development in wheat. Aust. J. Agric. Res., 42, 661-700.

Hay R.K.M. and Ellis R.P 1998. The control of flowering in wheat and barley: What recent advances in molecular genetics can reveal. Ann. Bot. 82, 541-554.

HUCL, P. y BAKER, R.J. (1989). Tillering patterns of spring wheat genotypes grown in a semiarid environment. Can. J. Plant Sci., 69, $71-79$.

JENNER, C.F.; UGALDE, T.D. y ASPINALL, D. (1991). The physiology of starch and protein deposition in the endosperm of wheat. Aust. J. of Plant Physiol., 18: 211-226. 
JOHNSON, D.E. (2000). Métodos multivariados aplicados al análisis de datos. Thomson Editores, México, 566 p.

KAMELI, A. y LÖSEL, D.M. (1993). Carbohydrates and water status in wheat plants under water stress. New Phytol., 125, 609-614.

KIMBER, G. y SEARS, E.R. (1987). Evolution in the genus Triticum and the origin of cultivated wheat. In: Wheat and wheat improvement. E.G. Heyne (ed.), American Society of Agronomy, No. 13, pp. 154-164, Madison, Wisconsin.

KIRBY, E.J.M. (1995). Factors affecting rate of leaf emergence in barley and wheat. Crop Sci., 35, 11-19.

KIRBY, E.J.M. y APPLEYARD, M. (1980). Effects of photoperiod on the relation between development and yield per plant of a range of spring barley varieties. Z. Pflanzenzüchtg., 85, 226-239.

KIRBY, E.J.M. y APPLEYARD, M. (1984). Cereal plant development and its relation to crop management. In Cereal Production. E.J. Gallagher (ed.), pp. 161-173. Butterworths, London.

KIRBY, E.J.M. y APPLEYARD, M. (1986). Cereal Development Guide. N.A.C., Stoneleigh, 95 p.

KIRBY, E.J.M.; APPLEYARD, M. y FELLOWES, G. (1982): Effect of sowing date on the temperature response of leaf emergence and leaf size in barley. Plant Cell Env., 5, 477-484.

KIRBY, E.J.M.; APPLEYARD, M. y FELLOWES, G. (1985): Effect of sowing date and variety on main shoot leaf emergence and number of leaves of barley and wheat. Agronomie, 5, 117-126.

KIRBY, E.J.M.; PORTER, J.R.; DAY, W.; ADAM, J.S.; APPLEYARD, M.; AYLING, S.; BAKER, C.K.; BELFORD, R.K.; BISCOE, P.V.; CHAPMAN, A.; FULLER, M.P.; HAMPSON, J.; HAY, R.K.M.; MATTHEWS, S.; THOMPSON, N.J.; WEIR, A.H.; WILLINGTON, V.B.A. y WOOD, D.W. (1987). An analysis of primordium initiation in Avalon winter wheat crops with different sowing dates in England and Scotland. J. Agric. Sci., Camb., 109, $123-134$. 
KIRBY, E.J.M.; SPINK, J.H.; FROST, D.L.; SYLVESTER-BRADLEY, R.; SCOTT, R.K.; FOULKES, M.J.; CLARE, R.W.; EVANS, E.J. (1999). A study of wheat development in the field: analysis by phases. European J. Agron., 11, 63-82.

KRAMER, T. (1979). Environmental and genetics variation for protein content in winter wheat (Triticum aestivum L.). Euphytica, 28, 209-218.

KRENZER, E.G. y NIPP, T.L. (1991). Mainstem leaf development and tiller formation in wheat cultivars. Agron. J., 83, 667-670.

LAUER, J.G. y SIMMONS, S.R. (1989): Canopy light and tiller mortality in spring barley. Crop Sci., 29, 420-424.

LERSTEN, N.R. (1987). Morphology and anatomy of the wheat plant. In: Wheat and wheat improvement. E.G. Heyne (ed.), American Society of Agronomy, No. 13, pp. 33-71, Madison, Wisconsin.

LOPEZ BELlido, L. (1991). Cultivos herbáceos. Vol. I. Cereales. Mundi-Prensa, $539 \mathrm{p}$.

McMASTER,G.S. (1998). Phenology, development, and growth of the wheat (Triticum aestivum L.) shoot apex: a review. Adv. Agron. 59, 63-118.

NACHIT, M.M.; BAUM, M.; IMPIGLIA, A.; KETATA, H. 1995. Studies on some grain quality traits in durum wheat grown in Mediterranean environments. En: di Fonzo, N.; Kaan, F. ; Nachit, M. (Eds.): Durum wheat quality in the Mediterranean Region. Options Méditerranéennes. CIHEAM, 22: 181-188.

NAIR, T.V.R. y CHATTERJEE, S.R (1990). Nitrogen metabolism in cereals: Case studies in wheat, rice, maize and barley. In: YP Abrol, ed, Nitrogen in higher plants, Research Studies Press Ltd., Somerset, England, pp. 367-426.

PACUCCI, G., BLANCO, A. (1973). Agronomic evaluation and technological properties of new durum wheat lines and varieties in southern Italy. Proc. Symp. Genet. and Breeding of Durum Wheat, Bari, Italy (G.T. Scarascia-Mugnozza, de.): 447-469.

PORCEDDU, e. (1995). Durum wheat quality in the Mediterranean countries. PEn: di Fonzo, N.; Kaan, F. ; Nachit, M. (Eds.): Durum wheat quality in the Mediterranean Region. Options Méditerranéennes. CIHEAM, 22: 11-21. 
RAWSON, H.M. y RICHARDS, R.A. (1993). Effects of high temperature and photoperiod on floral development in wheat isolines differing in vernalisation and photoperiod genes. Field Crops Res., 32, 181-192.

REILLY, M.L. (1990). Nitrate assimilation and grain yield. In Nitrogen in higher plants. Y.P. Abrol (ed.), pp. 335-366. Wiley \& Sons, Gran Bretaña.

ROJO, G. y GARCIA DEL MORAL, L.F. (1986). Fisiologia de la producción de grano y de proteinas en los cultivos de trigo blando (Triticum aestivum L.), trigo duro (T. turgidum L) y triticale (X Triticosecale Wittmack). An. Edaf. Agrobiol. XLV, $1597-1614$.

ROMAGOSA, I. y ARAUS, J.L. (1991). La mejora genética vegetal para zonas con déficits hídricos. Rev. Real Acad. Ciencias Exactas, Físicas y Naturales, 85, 349-366.

SHARIF, R. y DALE, J.E. (1980): Growth-regulating substances and the growth of tiller buds in barley: effects of IAA and GA3. J. exp. Bot., 31, 1191-1197.

SIMMONS, S.R. (1987). Growth, development and physiology. In: Wheat and wheat improvement. E.G. Heyne (ed.), American Society of Agronomy, No. 13, pp. 77-105, Madison, Wisconsin.

SINGH,N., SINGH,H., SINGH BAKSHI,M. (1998). Determining the distribution of ash in wheat using debranning and conductivity. Food Chemistry, 62, 169-172.

SLAFER, G.A. y SAVIN, R. (1991). Developmental base temperature in different phenological phases of wheat (Triticum aestivum). J. Exp. Bot., 42, 1077-1082.

SLAFER, G.A. y RAWSON, H.M. (1994a). Does temperature affect final number of primordia in wheat. Field Crops Res., 39, 111 117 .

SLAFER, G.A. y RAWSON, H.M. (1994b). Sensitivity of wheat phasic development to major environmental factors: A reexamination of some assumptions made by physiologists and modellers. Aust. J. Plant Physiol., 21, 393-426. 
SLAFER, G.A. y RAWSON, H.M. (1995a). Photoperiod X temperature interactions in contrasting wheat genotypes - Time to heading and final leaf number. Field Crops Res., 44, 73-83.

SLAFER, G.A. y RAWSON, H.M. (1995b). Base and optimum temperatures vary with genotype and stage of development in wheat. Plant Cell Environ., 18, 671-679.

STEEL, R.G.D. y TORRIE, J.H. (1985). Bioestadística: Principios y procedimientos. McGraw-Hill Latinoamericana, Bogotá.

STONE, P.J. y NICOLAS, M.E. (1995a). Effect of timing of heatstress during grain filling on 2 wheat-varieties differing in heat tolerance. 1. Grain-growth. Aust. J. Plant Physiol., 22, 927-934.

STONE, P.J. y NICOLAS, M.E. (1995b). Comparison of sudden heat-stress with gradual exposure to high-temperature during grain filling in 2 wheat-varieties differing in heat tolerance. 1. Grain-growth. Aust. J. Plant Physiol., 22, 935-944.

THORNE, G.N. (1974): Physiology of grain yield of wheat and barley. Rothamsted Exp. Stn. Report for 1973, part 2, 5-25.

THORNE, G.N. (1981). Growth and development of cereals and the environment. In Opportunities for Manipulation of Cereal Productivity. A.F. Hawkins and B. Jeffcoat (eds.), pp. 204-209. British Plant Growth Regulator Group, Monograph 7.

TURNER, N.C. y NICOLAS, M.E. (1987). Drought resistance of wheat for light-textured soils in a Mediterranean climate. En: Srivastava, J.P.; Porceddu, E.; Acevedo, E.; Varma, S. (ed.) Drought Tolerance in Winter Cereals. John Wiley, New York, NY. 203-216.

VADILLO, J. (1989. La calidad en los trigos. Ministerio de Agricultura, Pesca y Alimentación, Hoja INIA, Núm 2/89 HD, Madrid, 24 p.

WARDLAW, I.F.; DAWSON, I.A. y MUNIBI, P. (1989). The tolerance of wheat to high temperatures during reproductive growth. II. Grain development. Aust. J. Agric. Res., 40: 15-24. WHEELER, T.R.; HONG, T.D.; ELLIS, R.H.; BATTS, G.R.; MORISON, J.L. y HADLEY, P. (1996). The duration and rate of grain-growth, and harvest index of wheat (Triticum aestivum L.) in response to temperature and CO2. J. Exp. Bot., 47, 623-630. 
WIEGAND, C.L. y CUELLAR, J.A. (1981). Duration of grain filling and kernel weight of wheat as affected by temperature. Crop Sci., 21, 95-101.

WILlEY, R.W, HOLlidAY, R. (1971). Plant population, shading and thinning studies in wheat. J. Agric. Sci., Cambridge, 77, 453-461.

YAÑEZ, J.A. (1997). Contribución al estudio del desarrollo apical, llenado del grano y productividad en triticale. Tesis Doctorales. Universidad de Granada. $133 \mathrm{p}$.

ZADOKS, J.C.; CHANG, T.T. y KONZAK, C.F. (1974). A decimal code for the growth stages of cereals. Weed Res., 14, 415-421. 


\section{Apéndice de Tablas}

Apéndice de Tablas

Tabla 1A.- Análisis de la varianza para el rendimiento por $\mathrm{Ha}$.

\begin{tabular}{llrrrr}
\hline Source & Sum of Squares & Df & Mean Square & F-Ratio & P-Value \\
Genotipo & $8.37464 \mathrm{E} 6$ & 3 & $2.79155 \mathrm{E} 6$ & 17.77 & 0.0000 \\
AMBIENTE & $3.72665 \mathrm{E} 7$ & 2 & $1.86332 \mathrm{E} 7$ & 118.62 & 0.0000 \\
Bloq (AMBIENTE) & $6.49722 \mathrm{E} 6$ & 9 & 721913.0 & 4.60 & 0.0010 \\
Genotipo*AMBIENTE & $2.09677 \mathrm{E} 6$ & 6 & 349461.0 & 2.22 & 0.0714 \\
Residual & $4.24114 \mathrm{E} 6$ & 27 & 157079.0 & & \\
- & $5.84763 \mathrm{E} 7$ & 47 & & & \\
Total (corrected) & &
\end{tabular}

All F-ratios are based on the residual mean square error.

Tabla 2A.- Análisis de la varianza para el peso medio por grano.

\begin{tabular}{|c|c|c|c|c|c|}
\hline Source & Sum of Squares & Df & Mean Square & F-Ratio & P-Value \\
\hline Genotipo & 165.288 & 3 & 55.0959 & 25.45 & 0.0000 \\
\hline AMBIENTE & 236.263 & 2 & 118.132 & 54.57 & 0.0000 \\
\hline Bloq (AMBIENTE) & 31.7522 & 9 & 3.52802 & 1.63 & 0.1586 \\
\hline Genotipo*AMBIENTE & 128.138 & 6 & 21.3563 & 9.86 & 0.0000 \\
\hline Residual & 56.2876 & 26 & 2.16491 & & \\
\hline
\end{tabular}

Tabla 3A.- Análisis de la varianza para la duración del crecimiento del grano.

\begin{tabular}{lrrrrr} 
& Sum of Squares & Df & Mean Square & F-Ratio & P-Value \\
Source & 295.748 & 3 & 98.5827 & 58.30 & 0.0000 \\
\hline Genotipo & 931.206 & 2 & 465.603 & 275.36 & 0.0000 \\
AMBIENTE & 30.3405 & 9 & 3.37117 & 1.99 & 0.0802 \\
Bloq (AMBIENTE) & 154.362 & 6 & 25.7269 & 15.21 & 0.0000 \\
Genotipo*AMBIENTE & 45.6547 & 27 & 1.69091 & & \\
Residual & 1457.31 & 47 \\
--- & & & \\
Total (corrected) & All F-ratios are based on the residual mean square error.
\end{tabular}

Tabla 4A.- Análisis de la varianza para la tasa de llenado del grano.

\begin{tabular}{lrrrrr}
\hline Source & Sum of Squares & Df & Mean Square & F-Ratio & P-Value \\
Genotipo & 0.934636 & 3 & 0.311545 & 35.45 & 0.0000 \\
AMBIENTE & 1.70419 & 2 & 0.852094 & 96.94 & 0.0000 \\
Bloq (AMBIENTE) & 0.163594 & 9 & 0.0181771 & 2.07 & 0.0699 \\
Genotipo*AMBIENTE & 0.867737 & 6 & 0.144623 & 16.45 & 0.0000 \\
Residual & 0.237316 & 27 & 0.00878948 & & \\
- & & &
\end{tabular}

Total (corrected)

3.90747

47

All F-ratios are based on the residual mean square error. 
Tabla 5A.- Análisis de la varianza para la altura de la planta.

\begin{tabular}{|c|c|c|c|c|c|}
\hline Source & Sum of Squares & Df & Mean Square & F-Ratio & P-Value \\
\hline Genotipo & 289.378 & 3 & 96.4594 & 6.61 & 0.0017 \\
\hline AMBIENTE & 8833.44 & 2 & 4416.72 & 302.64 & 0.0000 \\
\hline Bloq (AMBIENTE) & 317.711 & 9 & 35.3012 & 2.42 & 0.0367 \\
\hline Genotipo*AMBIENTE & 71.3768 & 6 & 11.8961 & 0.82 & 0.5677 \\
\hline Residual & 394.035 & 27 & 14.5939 & & \\
\hline
\end{tabular}

Tabla 6A.- Análisis de la varianza para el contenido de proteínas del grano.

\begin{tabular}{|c|c|c|c|c|c|}
\hline Source & Sum of Squares & Df & Mean Square & F-Ratio & P-Value \\
\hline \multicolumn{6}{|c|}{ 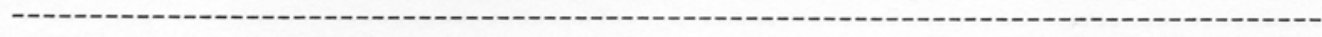 } \\
\hline Genotipo & 11.1793 & 3 & 3.72644 & 11.08 & 0.0001 \\
\hline AMBIENTE & 72.807 & 2 & 36.4035 & 108.28 & 0.0000 \\
\hline Bloq (AMBIENTE) & 5.09979 & 9 & 0.566643 & 1.69 & 0.1415 \\
\hline Genotipo*AMBIENTE & 9.33314 & 6 & 1.55552 & 4.63 & 0.0024 \\
\hline Residual & 9.07772 & 27 & 0.336212 & & \\
\hline Total (corrected) & 107.497 & 47 & & & \\
\hline
\end{tabular}

Tabla 7A.- Análisis de la varianza para la cosecha de proteínas.

\begin{tabular}{|c|c|c|c|c|c|}
\hline Source & Sum of Squares & Df & Mean Square & F-Ratio & P-Value \\
\hline Genotipo & 122485.0 & 3 & 40828.2 & 10.56 & 0.0001 \\
\hline AMBIENTE & 347259.0 & 2 & 173630.0 & 44.92 & 0.0000 \\
\hline Bloq (AMBIENTE) & 128770.0 & 9 & 14307.8 & 3.70 & 0.0039 \\
\hline Genotipo*AMBIENTE & 11767.2 & 6 & 1961.2 & 0.51 & 0.7973 \\
\hline Residual & 104374.0 & 27 & 3865.72 & & \\
\hline
\end{tabular}

Total (corrected)

714655.0

47

All F-ratios are based on the residual mean square error.

Tabla 8A.- Análisis de la varianza para el peso específico del grano.

\begin{tabular}{|c|c|c|c|c|c|}
\hline Source & Sum of Squares & Df & Mean Square & F-Ratio & P-Value \\
\hline Genotipo & 60.3372 & 3 & 20.1124 & 25.76 & 0.0000 \\
\hline AMBIENTE & 75.5521 & 2 & 37.7761 & 48.38 & 0.0000 \\
\hline Bloq (AMBIENTE) & 11.1799 & 9 & 1.24221 & 1.59 & 0.1681 \\
\hline Genotipo*AMBIENTE & 6.56409 & 6 & 1.09401 & 1.40 & 0.2503 \\
\hline Residual & 21.0815 & 27 & 0.780795 & & \\
\hline
\end{tabular}

Total (corrected)

174.715

47

All F-ratios are based on the residual mean square error. 
Tabla 9A.- Análisis de la varianza para el contenido de azúcares reductores del grano.

\begin{tabular}{|c|c|c|c|c|c|}
\hline Source & Sum of Squares & Df & Mean Square & F-Ratio & P-Value \\
\hline Genotipo & 0.0167901 & 3 & 0.00559669 & 2.04 & 0.1450 \\
\hline AMBIENTE & 0.367017 & 2 & 0.183508 & 66.73 & 0.0000 \\
\hline Blog (AMBIENTE) & 0.0361853 & 6 & 0.00603089 & 2.19 & 0.0919 \\
\hline Genotipo*AMBIENTE & 0.0171835 & 6 & 0.00286392 & 1.04 & 0.4316 \\
\hline Residual & 0.0494987 & 18 & 0.00274993 & & \\
\hline
\end{tabular}

Tabla 10A.- Análisis de la varianza para el contenido de cenizas del grano.

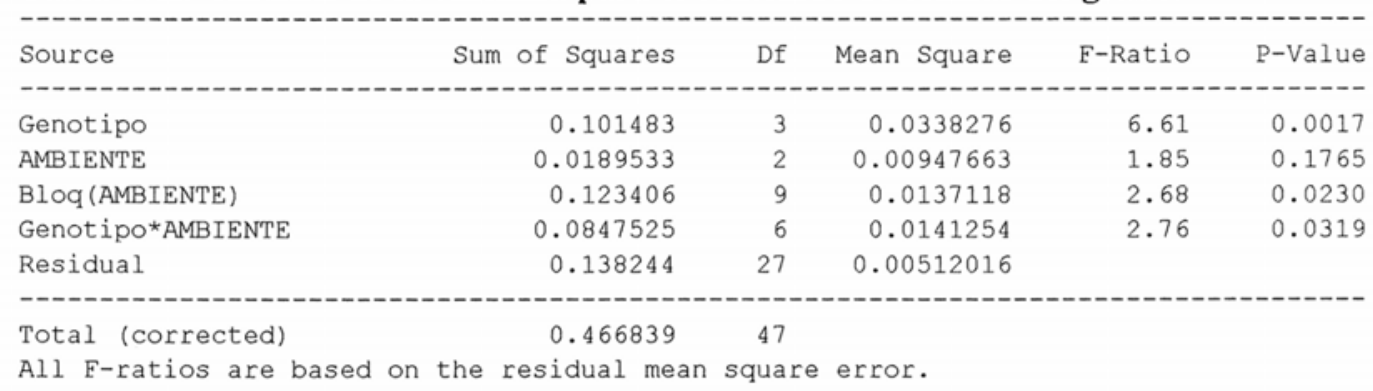

Tabla 11A.- Análisis de la varianza para el porcentaje de vitrosidad del grano.

\begin{tabular}{|c|c|c|c|c|c|}
\hline Source & Sum of Squares & Df & Mean Square & F-Ratio & P-Value \\
\hline Genotipo & 21.4552 & 3 & 7.15173 & 2.37 & 0.0925 \\
\hline AMBIENTE & 208.075 & 2 & 104.037 & 34.51 & 0.0000 \\
\hline Bloq (AMBIENTE) & 25.5292 & 9 & 2.83658 & 0.94 & 0.5072 \\
\hline Genotipo*AMBIENTE & 81.0396 & 6 & 13.5066 & 4.48 & 0.0029 \\
\hline Residual & 81.4033 & 27 & 3.01494 & & \\
\hline
\end{tabular}

Total (corrected)

$417.502 \quad 47$

All F-ratios are based on the residual mean square error.

Tabla 12A.- Análisis de la varianza para la pigmentación del grano.

$\begin{array}{lrrrrr}\text { Source } & \text { Sum of Squares } & \text { Df } & \text { Mean Square } & \text { F-Ratio } & \text { P-Value } \\ \text { Genotipo } & 1.78442 & 3 & 0.594807 & 14.75 & 0.0000 \\ \text { AMBIENTE } & 10.8659 & 2 & 5.43295 & 134.68 & 0.0000 \\ \text { Bloq (AMBIENTE) } & 0.237362 & 9 & 0.0263736 & 0.65 & 0.7418 \\ \text { Genotipo*AMBIENTE } & 3.5806 & 6 & 0.596766 & 14.79 & 0.0000 \\ \text { Residual } & 1.08917 & 27 & 0.0403395 & \\ \text {-- } & 17.5575 & 47 \\ \text { Total (corrected) } & \\ \text { All F-ratios are based on the residual mean square error. }\end{array}$


Tabla 13A.- Análisis de la varianza para el índice S.D.S.

\begin{tabular}{|c|c|c|c|c|c|}
\hline Source & Sum of Squares & Df & Mean Square & E-Ratio & P-Value \\
\hline (1) & 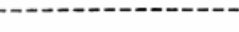 & 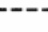 & 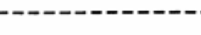 & & \\
\hline Genotipo & 1830.73 & 3 & 610.243 & 27.25 & 0.0000 \\
\hline AMBIENTE & 716.667 & 2 & 358.333 & 16.00 & 0.0000 \\
\hline Bloq (ANBIENTE) & 301.563 & 9 & 33.5069 & 1.50 & 0.1996 \\
\hline Genotipo*AMBIENTE & 1170.83 & 6 & 195.139 & 8.71 & 0.0000 \\
\hline Residual & 604.688 & 27 & 22.3958 & & \\
\hline
\end{tabular}

Total (corrected)

4624.48

47

All F-ratios are based on the residual mean square error. 